\title{
REGULATION OF TAIL MUSCLE ENERGETICS DURING ANOXIA IN THE FRESHWATER CRAYFISH, ORCONECTES VIRILIS
}

\author{
By \\ Neal Dawson \\ B.Sc. (Hons.), 2006
}

A Thesis Submitted to the Faculty of Graduate Studies and Research in partial fulfillment of the requirements for the degree of

\author{
Master of Science \\ Department of Biology
}

Carleton University

Ottawa, Ontario, Canada

(C) copyright 2009

The undersigned hereby recommend to the Faculty of Graduate Studies and Research acceptance of this thesis 



\begin{abstract}
Metabolic rate depression is vital to the survival of many organisms in the face of low oxygen levels. This is achieved by a coordinated suppression of both ATPconsuming and ATP-producing metabolic pathways. The role of reversible protein phosphorylation in metabolic rate depression during anoxia was explored in the tail muscle of the anoxia-tolerant freshwater crayfish, Orconectes virilis. This study investigated glutamate dehydrogenase (GDH), the enzymatic bridge between amino acid and carbohydrate metabolism, arginine kinase (AK), an important enzyme involved in regulation of phosphagen reserves, and hexokinase (HK), the enzyme at the forefront of carbohydrate metabolism. The data obtained showed that GDH and AK are regulated by reversible phosphorylation during anoxia, resulting in less phosphorylated, less active forms of these enzymes. Experiments were performed under normoxic and anoxic conditions, and protein expression levels, susceptibility to urea denaturation, structural stability, response to specific protein kinase and phosphatase incubations as well as elution profiles from an ion-exchange column were explored. The data from GDH suggests that amino acid metabolism is left largely separate from carbohydrate metabolism by the reduction of this vital bridge point. AK results suggest that precious ATP is not involved in the regeneration of phosphagen reserves during anoxia. HK was also explored using similar experiments, and it seems that HK protein levels increase during anoxia, and reversible phosphorylation seems to increase protein stability and affect cellular localization. Overall, these studies suggest that reversible phosphorylation plays a key role in the regulation of muscle energetics in the freshwater crayfish, $O$. virilis.
\end{abstract}




\section{ACKNOWLEDGEMENTS}

There are so many people that I owe so much too, that I cannot possibly hope to thank them all, and I apologize in advance for those I'll surely miss. I would like to thank, first and foremost, my family. Mom, Dad, you have shown infinite patience, love and otherworldly guidance in my often eccentric choices in life. I cannot thank the two of you enough. Jen and Deb, my two sisters, for being two of my best friends, and putting up with me for so long (I'm not sure how you did...). I could not have gotten this far in both my academics or life without the help of you guys, thanks!

I must also thank Dr. Ken Storey and Jan Storey for taking a chance on a confused basketball player. I have learnt (and am continuing to learn) so much from the two of you, not simply about science, but about life, and the harsh decisions that one must make. I thank you both for forcing me to think critically about my work and my personal life. I would also like to thank Jan for all of her help with editing, suggestions, and many other forms of help with my work. I must also thank my peer-mentors; Ryan, Judeh, and last but certainly not least, Chris D. I could not have survived this long without your guidance.

I would also like to thank my friends outside the lab. For their encouraging words, constructive criticism, and reminding me to stay grounded with "real life ", as it is all too easy to get wrapped up in the scientific state of mind.

Finally I would like to thank the many friends I have made in the Storey lab. Special thanks to Ben, Oscar, and Jacques. But I can't forget Mike, Shannon, Kyle, Craig, Marcus, and all the Storey lab members. Thank you. 


\section{TABLE OF CONTENTS}

Title Page

Acceptance Sheet

Abstract

Acknowledgements

Table of Contents

List of Abbreviations

List of Tables viii

List of Figures ix

Chapter 1: General Introduction 1

Chapter 2: Regulation of tail muscle glutamate dehydrogenase in the anoxia12 tolerant freshwater crayfish, Orconectes virilis freshwater crayfish, Orconectes virilis

Chapter 4: Regulation of tail muscle hexokinase in the anoxia-tolerant freshwater crayfish, Orconectes virilis

Chapter 5: General Discussion

References 


\section{LIST OF ABBREVIATIONS}

AMP, ADP, ATP - adenosine mono-, di-, or triphosphate

AMPK - AMP activated protein kinase

$\boldsymbol{\beta}-\mathbf{G P}$ - $\beta$-glycerol phosphate

Bis-Tris propane - 1,3-bis(tris(hydroxymethyl)methylamino)propane

CaM - calmodulin

CaMK - calmodulin- and $\mathrm{Ca}^{2+}$ - dependent protein kinase

cAMP - 3', 5'-cyclic adenosine monophosphate

cGMP - 3', 5' -cyclic guanosine monophosphate

DEAE - diethylaminoethyl

$\mathbf{E}_{\mathbf{a}}$ - Activation energy

EDTA - ethylenediamine tetraacetate

EGTA - ethyleneglycol bis tetraacetate

G6P - glucose-6-phosphate

G6PDH - glucose-6-phosphate dehydrogenase

HK - hexokinase

$\mathbf{I}_{\mathbf{5 0}}$ - inhibitor concentration reducing enzyme velocity by $50 \%$

kDa - kiloDalton

$\mathbf{K}_{\mathbf{m}}$ - substrate concentration producing half maximal enzyme activity

MAPK - mitogen-activated protein kinase

MES - 2-(N-morpholino)ethanesulfonic acid

NADP ${ }^{+}, \mathbf{N A D P H}$ - oxidized and reduced nicotinamide adenine dinucleotide phosphate

NaF - sodium fluoride 
$\mathrm{Na}_{3} \mathrm{VO}_{4}$ - sodium orthovanadate

PEP - phosphoenolpyruvate

PKA - cAMP-dependent protein kinase

PKB - protein kinase B

PKC - $\mathrm{Ca}^{2+}$ - and phospholipid-dependent protein kinase

PK - pyruvate kinase

PKG - protein kinase $\mathrm{G}$

PMA - phorbol myristate acetate

PMSF - phenylmethylsulfonyl fluoride

PP1 - protein phosphatase type-1

PP2A, PP2B, PP2C - protein phosphatase type-2A, -2B and -2C

Tris - Tris[hydroxymethyl]aminomethane

$\mathbf{V}_{\max }-$ maximal enzyme velocity 


\section{LIST OF TABLES}

TABLE

PAGE

2.1 Comparison of kinetic parameters of partially purified GDH from 28 tail muscle of anoxic and control crayfish.

3.1 Purification of AK from tail muscle of control crayfish.

3.2 Comparison of kinetic parameters of purified AK from tail muscle 55 of anoxic and control crayfish.

4.1 Purification of HK from tail muscle of control crayfish.

81

4.2 Comparison of kinetic parameters of crude HK from tail muscle of 82 control and anoxic crayfish assayed at $23^{\circ} \mathrm{C}$. 


\section{LIST OF FIGURES}

FIGURE

PAGE

2.1 GTP-agarose elution profiles for tail muscle GDH from control at $\mathrm{pH} 8$.

2.2 A flow chart showing the overview of the incubation protocol.

2.3 Western blotting analysis of the amount of GDH protein in the tail muscle of $O$. virilis showing no significant difference between control and anoxic conditions.

2.4 A comparison of the relative phosphorylation level of control and anoxic GDH from the tail muscle of $O$. virilis using Pro-Q diamond phospho-staining.

2.5 Effects of in vitro incubations to stimulate the activities of endogenous protein kinases or phosphatases on fold activation by $\mathrm{ADP}$ of GDH in $O$. virilis tail muscle extracts.

2.6 Stability of GDH from crude extracts of tail muscle.

3.1 SDS-PAGE with Coomassie blue staining of samples taken at 56 every step in the purification of AK from the tail muscle of control O.virilis.

3.2 Western blotting analysis of the amount of AK protein in the tail muscle of $O$. virilis showing no significant difference between control and anoxic conditions.

3.3 $\mathrm{DEAE}^{+}$Sephadex elution profiles for $\mathrm{AK}$ activity from tail muscle tissue from normoxic and anoxic crayfish.

3.4 A comparison of the relative phosphorylation level of control and anoxic AK from the tail muscle of $O$. virilis using Pro-Q diamond phospho-staining.

3.5 Effects of in vitro incubations to stimulate the activities of endogenous protein kinases or phosphatases on the $\mathrm{K}_{\mathrm{m}}$ of Larginine for $\mathrm{AK}$ in $O$. virilis tail muscle extracts.

3.6 (A) Stability of AK from crude extracts of tail muscle. (B) Effect of $24 \mathrm{~h}$ incubation with different concentrations of urea on the recoverable activity of crude $\mathrm{AK}$. 
4.1 SDS-PAGE with Coomassie blue staining of samples taken at every step in the purification of HK from the tail muscle of control $O$. virilis.

4.2 Distribution of HK between cytoplasmic and bound states in tail muscle extracts of control and anoxic crayfish. Total HK is cytoplasmic HK + bound HK.

4.3 Western blotting analysis of the amount of HK protein in the tail muscle of $O$. virilis showing upregulation of protein amount from control to anoxic conditions.

4.4 $\mathrm{DEAE}^{+}$Sephadex elution profiles for HK activity from tail muscle from normoxic and anoxic crayfish.

4.5 A comparison of the relative phosphorylation state of control and anoxic HK from the tail muscle of $O$. virilis using Pro-Q diamond phospho-staining.

4.6 Effects of in vitro incubations that stimulated the activities of endogenous protein kinases or protein phosphatases on the $\mathrm{K}_{\mathrm{m}}$ of glucose of $\mathrm{HK}$ from $O$. virilis tail muscle extracts.

4.7 Stability of HK from crude extracts of tail muscle. 


\section{CHAPTER 1}

General Introduction 


\section{Introduction}

Faced with environmental stressors that may arise due to seasonal changes or alterations in habitat (such as high or low tide, ice formation, etc.), many species cope by altering their metabolism and metabolic pathways. Many invertebrates have to endure multiple stressors that may arise due to seasonal and/or environmental changes in their habitat, such as exposure to low oxygen or hypoxia, complete oxygen deprivation or anoxia, exposure to extremely dry conditions, changes in the levels of salinity in the environment, or large variations in temperature (which at low temperatures can cause freezing of bodily fluids and at high temperatures can cause heat stress or contribute to severe desiccation).

Hypoxia and anoxia are amongst the more difficult stressors to endure since oxygen plays a key role in the production of ATP by acting as the terminal electron acceptor of the electron transport chain. Oxygen is also a substrate for many other cellular reactions which are affected greatly in periods of low oxygen stress.

Many invertebrates are capable facultative anaerobes, and may live without oxygen conditions for weeks at a time. Most crustaceans have a relatively low capacity to endure hypoxia/anoxia but some have a well-developed tolerance such as barnacles that live in the marine intertidal zone. Tolerance to low oxygen is also well-developed in freshwater crayfish that experience seasonal exposures to hypoxic or anoxic water.

Orconectes virilis is a freshwater crayfish that is widely distributed across North America and abundant in our lakes and streams in eastern Ontario. Crayfish are able to live in areas with high pollution and/or low oxygen content. They can survive long periods of low oxygen exposure with a switch to anaerobic metabolism (Cowan and 
Storey, 2001). A key adaptive response to hypoxia or anoxia is metabolic rate depression which involves the coordinated suppression of all cellular processes so that long term viability is achieved but with a very much lower rate of ATP turnover (Storey and Storey, 2007). Crayfish have a varied diet that includes living or dead animal or plant foods and have even been reported to eat other crayfish including their young (Figler et al., 1995; Brewis and Bowler, 2006; Celada et al., 2007).

The crayfish's body is divided into two large sections; the cephalothorax, and the abdomen. Projecting ventrally from the cephalothorax, there are five pairs of distinct chelate walking legs, two antennae, and four antennules. The abdomen contains the reproductive organs as well as the swimmerets on its ventral surface, as well as the anus and telson of the crayfish. The internal anatomy of a crayfish is most appropriately described starting with the description of how the animal procures its food, and a brief description of the journey of the food through the animal. The crayfish has two large pincers (first set of walking legs) or chelipeds which it uses for walking and manipulating food or prey. The food is then broken into pieces and transferred to the anterior ambulatory limbs or the maxillipeds, then broken down further and passed to the mouth. The food then passes into the cardiac stomach that is located just behind the eyes, brain and antennal gland of the crayfish; note that the antennal gland is used to excrete ammonia that accumulates as a waste product. After a brief stop in the cardiac stomach, the food is relocated to the pyloric stomach before reaching the intestine. The intestine is surrounded by the heart and reproductive organs (on top), the ventral thoracic cavity and gills (sides), and the digestive gland (below). The posterior section of the intestine is surrounded by the tail muscles of the crayfish. The non-digested portions of the initial 
meal are then ejected from the intestine via the anus.

Orconectes virilis face oxygen limitation or deprivation during both the summer and winter months. In the summer, crayfish often find themselves trapped in low flow, high temperature water which can result in a hypoxic environment. In the winter, the water that crayfish inhabit often freezes on the surface and over time the respiration of animals, plants and microbes depletes the oxygen leading to hypoxia or anoxia.

Therefore, to survive, crayfish must switch to anaerobic metabolism to generate ATP from glycolysis, coupled with strong metabolic rate depression to reduce the rates of ATP-consuming processes or pathways during these periods of limited oxygen (Storey and Storey, 2004). Metabolic rate depression also includes physical changes such as reduced movement, breathing, heart rate and digestion to lower their metabolic needs, while biochemically, anoxic tolerant organisms often employ the inhibition of protein synthesis, reduction of ion channel activity and regulation of energy supply pathways (such as carbohydrate catabolism) to survive long periods of stress (Storey and Storey, 2004). Metabolic rate depression has been characterized, and hypometabolic organisms often drop their metabolic rate to less than $30 \%$ of their normal levels, and in some extreme cases, less than $10 \%$ of normal levels (Storey, 2002). Since ion pump activity can consume up to $30 \%$ of cellular ATP expenditures, at metabolic rates of less than $30 \%$ or less than $10 \%$, serious regulation of these energetically costly process must be achieved (Storey, 2002).

\section{Regulation of carbohydrate metabolism}

During periods of normal oxygen consumption (normoxia), organisms use 
carbohydrates, fatty acids, triglycerides or amino acids as sources of fuel for aerobic metabolism. During anoxia, a switch to carbohydrates as the primary fuel source arises since oxidation of hexose phosphates (derived from glucose or glycogen) to glycolytic end products (primarily lactate) produces ATP by substrate level phosphorylation in the absence of oxygen (Storey and Storey, 2004).

Aerobic metabolism typically produces 36 molecules of ATP/glucose molecule, which provides the cell with ample energy to drive biochemical reactions, and sustain life. Under anoxic conditions however, a switch to anaerobic metabolism results in only 2 mol ATP/glucose molecule, and the accumulation of potentially harmful end products from fermentation. Facultative anaerobes must therefore adapt to maximize the length of time they can sustain life without oxygen. Some survival strategies are; the storage of large quantities of fermentable fuel sources, coupling of glycolysis to alternate pathways to achieve further substrate-level phosphorylations and a greater ATP yield per molecule of glucose, producing alternative end products to lactate, and strongly suppressing metabolic rate (Storey and Storey 1990; Churchill and Storey 1996; Storey and Storey 2004).

Crayfish do not accumulate alternative glycolytic end products to lactate but they are able to buffer proton accumulation associated with lactate production by the release of carbonate ions from their carapace (Jackson et al. 2001). Therefore, crayfish can tolerate a large buildup of lactate from fermentative metabolism, and studies have show that they also have the ability to depress their metabolic rate via modifications to ATP consuming pathways during periods of prolonged anoxia (Cowan and Storey, 2001). Crayfish, therefore, are able to survive long periods of hypoxia or anoxia through a 
switch to fermentative metabolism, the buffering of protons (lactate) produced by fermentation, and by critically suppressing their energy consumption until oxygen is restored.

\section{Regulation of adenylate energy charge and adenylate pools}

ATP is often described as the energy currency of the cell. Through the hydrolysis of ATP, endergonic biochemical reactions are facilitated which make survival possible. The hydrolysis of ATP produces ADP, and without replenishing ATP levels, ADP accumulates. Many ways of replenishing ATP are known. Adenylate kinase allows for some of this ADP to be recycled into ATP via the reaction;

$$
2 \mathrm{ADP} \rightarrow \mathrm{ATP}+\mathrm{AMP}
$$

This is not a permanent solution since AMP then accumulates and eventually both ATP and ADP would be exhausted. Furthermore, accumulation of AMP leads to the activation of several catabolic pathways (Brenman and Temple, 2007; Röckl et al., 2008), and many derivatives of AMP such as adenosine, inosine, and IMP also hold similar signalling functions. Therefore, when the levels of ATP begin to fall, several signalling events take place to quickly replenish levels to normal quantities, or else damage and eventual death of the organism will take place.

Hydrolysis results in the highest possible release of energy from ATP (Gajewki et al., 1986). Therefore, it is necessary to keep ATP levels much higher than ADP and AMP levels. This delicate balance of adenylates is a good gauge of the energy state of the cell. The ratio of ATP to ADP and AMP levels is referred to as the adenylate energy charge (AEC) of the cell (Pradet and Raymond, 1983). The equation for the AEC of a system is 
as follows;

$$
\mathrm{AEC}=\frac{[\mathrm{ATP}]+1 / 2[\mathrm{ADP}]}{[\mathrm{ATP}]+[\mathrm{ADP}]+[\mathrm{AMP}]}
$$

The cell is then in a constant battle to maintain ATP levels, and by association the AEC of the cell. In order to keep ATP levels high, catabolic pathways involving carbohydrates, fatty acids, triglycerides are broken down and their products are thrust into glycolysis, oxidation pathways and ultimately the TCA cycle and oxidative phosphorylation and production of ATP. There are additional methods that are important for keeping ATP levels high, particularly when ATP is being hydrolyzed at very high rates, as is often the case during burst muscle work. This involves the mobilization of stored phosphagens such as phosphocreatine, phosphoarginine or others that can be mobilized to quickly replenish ATP in reactions of a general formula: $\mathrm{P}-\mathrm{X}+\mathrm{ADP} \rightarrow \mathrm{X}+$ ATP (where X is creatine, arginine, etc.) (Newsholme et al., 1978; McLeish and Kenyon, 2005).

ATP levels in crayfish have been shown to vary greatly in response to anoxia. Crayfish have been reported to maintain high cellular energy levels even in the face of prolonged exposure to anoxia (Gäde, 1984). However, studies on other crayfish species have found a significant decrease in ATP with large increases in AMP levels, suggesting recycling of ADP via adenylate kinase; the same study also suggested that there may be a reduction in adenylate levels during prolonged exposure to anoxia suggesting that AMP deaminase may be at work (Fujimori and Abe, 2002). The study by Gäde (1984) also showed decreased levels of phosphoarginine during exposure to anoxia indicating that the phosphagen is being used to replenish ATP levels under anoxia, not just during muscle work. These findings, when taken together, suggest that crayfish maintain fine control 
over their adenylate pools, even in the face of prolonged exposure to anoxic events through manipulation and regulation of their ATP producing pathways.

\section{Reversible Phosphorylation of Proteins}

Metabolism can be controlled at many levels. Organisms often employ the use of transcriptional or translational regulation to make major changes to their metabolic pathways, however, these process are energetically costly and require more time to achieve. Post-translational modifications are an energetically cheap and efficient method of regulating essential pathways. Reversible phosphorylation by protein kinases or protein phosphatases in response to stress signals can rapidly activate or deactivate proteins (Storey, 1996).

Reversible protein phosphorylation in the freshwater crayfish has been observed in previous studies; for example, two main glycolytic enzymes, pyruvate kinase and phosphofructokinase, are controlled by reversible phosphorylation (Cowan and Storey, 2001). Furthermore, significant changes in the activities of protein kinase A (PKA) and protein phosphatases (PP1, PP2A, PP2C) occurred under anoxia (Cowan and Storey, 2001). The activities of PP1, PP2A and PP2C all decreased significantly during the first 2 hours of anoxia exposure in $O$. virilis, whereas the activity of PKA increased significantly as early as the first hour of exposure to anoxia. This suggests that PKA may be one of the main regulatory kinases involved in enzyme phosphorylation and regulation upon early entry into anoxia, whereas protein phosphatases may play a regulatory role later in the anoxic response of $O$. virilis.

\section{Objectives and Hypotheses}


The freshwater crayfish can survive prolonged exposures to hypoxia and anoxia in its natural environment. A coordinated suppression of regulatory mechanisms are required to respond to the demands placed on the organism during this period of stress as well as regulation of key enzymes that must be controlled to either enhance anaerobic ATP production or suppress ATP use for nonessential functions to achieve strong metabolic rate depression. I have made the following hypotheses about the regulation of selected key enzymes that are involved in energy metabolism in the tail muscle of the freshwater crayfish, $O$. virilis:

i) TCA cycle intermediates are often funnelled out of the TCA cycle and used to synthesize a variety of biological molecules including the amino acids needed for protein synthesis. During anoxia, however, energy-expensive protein synthesis is largely arrested as one part of anoxia-responsive metabolic rate depression. Hypothesis: Glutamate dehydrogenase, the enzymatic bridge between carbohydrate and amino acid metabolism will be regulated to strongly suppress amino acid biosynthesis under anoxic conditions.

ii) Anoxia survival requires a dependence on carbohydrate fuels to produce ATP via fermentative glycolysis. Strict control of the use of carbohydrate substrates (glucose, glycogen) will therefore be required. Hypothesis: Hexokinase, the enzyme responsible for gating glucose entry into the glycolytic pathway will be differentially regulated in aerobic versus anoxic states to manage the utilization of glucose. 
iii) To sustain viability during long term exposure to anoxia, ATP levels and the AEC must be maintained. As a method of replenishing ATP levels during anaerobic metabolism, alternative energy reserves must be tapped. Hypothesis: Arginine kinase, the enzyme responsible for the reversible production versus catabolism of high energy phosphagen reserves will be regulated to favour the production of ATP under anoxia by favouring the catabolism of phosphoarginine.

iv) In order to achieve the regulations described above, modifications to key enzymes must be made to modify their properties and/or activities. Through this modification, major energy using/generating pathways can be controlled to ensure optimal usage of cellar resources in the anoxic state. Hypothesis: Reversible protein phosphorylation, by protein kinases and/or protein phosphatases, plays a vital role in enzyme regulation during anoxia.

Key enzymes involved in the maintenance of energy supplies, glucose metabolism and amino acid metabolism are explored throughout this thesis.

\section{Glutamate Dehydrogenase (GDH)}

GDH is often described as an enzymatic bridge between anabolic and catabolic pathways of amino acid metabolism. GDH is vital for nitrogen incorporation from ammonia in animals and is also a key enzyme that supports amino acid catabolism as a 
fuel by feeding $\alpha$-ketoglutarate into the citric acid cycle. GDH catalyzes the following reaction;

$$
\text { L-glutamate }+\mathrm{NAD}(\mathrm{P})^{+}+\mathrm{H}_{2} \mathrm{O} \leftrightarrow \alpha \text {-ketoglutarate }+\mathrm{NH}_{4}{ }^{+}+\mathrm{NAD}(\mathrm{P}) \mathrm{H}+\mathrm{H}^{+}
$$

Chapter 2 explores the kinetic and regulatory properties of crayfish tail muscle GDH.

\section{Arginine Kinase (AK)}

$\mathrm{AK}$ is the invertebrate analogue of creatine kinase found in vertebrate species. AK occurs in tissues where high energy demands are present such as muscle and regulates the synthesis, shuttling, and breakdown of the phosphagen, arginine phosphate, in response to metabolic demands. AK catalyzes the following reaction;

$$
\mathrm{ATP}+\mathrm{L} \text {-arginine } \leftrightarrow \mathrm{ADP}+\text { phospho-L-arginine }
$$

Chapter 3 explores the kinetic and regulatory properties of anoxic tail muscle AK.

\section{Hexokinase (HK)}

HK is a very important enzyme to study in terms of energy regulation as it catalyzes the formation of glucose-6-phosphate which can enter many pathways, including glycolysis for the production of ATP, glycogen synthesis for fuel storage, and the pentose phosphate pathway for the production of NADPH and sugar phosphates. HK catalyzes the following reaction;

$$
\text { ATP }+ \text { glucose } \rightarrow \text { ADP }+ \text { glucose-6-phosphate }
$$

Chapter 4 explores the kinetic and regulatory properties of anoxic tail muscle HK. 


\section{CHAPTER 2}

\section{Regulation of tail muscle glutamate dehydrogenase in the anoxia-tolerant freshwater crayfish, Orconectes virilis}




\subsection{Introduction}

Glutamate dehydrogenase (GDH) (E.C.1.4.1.3) is a crucial enzyme linking amino acid and carbohydrate metabolism. GDH is present in the mitochondrial matrix of eukaryotic cells and catalyses the following reaction;

L-glutamate $+\mathrm{NAD}(\mathrm{P})^{+}+\mathrm{H}_{2} \mathrm{O} \leftrightarrow \alpha$-ketoglutarate $+\mathrm{NH}_{4}{ }^{+}+\mathrm{NAD}(\mathrm{P}) \mathrm{H}+\mathrm{H}^{+}$

GDH exists as a homohexamer with a molecular mass that has been shown to vary greatly, anywhere from 250-400 kDa in mammals (Eisenberg and Reisler, 1970). GDH is composed of 4 identical subunits, each subunit of GDH is catalytically inactive in its monomeric state (Schmidt and Schmidt, 1988). Each monomer contains two domains which form an active site at the cleft of the two domains (Nakasako, 2001). The GDH monomer also contains allosteric binding sites for ADP/GDP, and GTP/ATP on each domain. Traditionally, GDH has been thought to be catalytically activated by ADP/GDP and inhibited by their high energy counterparts, ATP/GTP (Schmidt and Schmidt, 1988). GTP is the most potent inhibitor, more than 100 times more effective than ATP (Frieden, 1965). The balance of allosteric activation and inhibition of GDH by these common metabolites has been proposed to be one of the main regulatory mechanisms of the activity of GDH (Smith and Stanley, 2008).

GDH catalyzes a reversible reaction; in one direction it is a key player in amino acid biosynthesis from carbohydrate, in the other direction it catalyzes the oxidative deamination of L-glutamate to form $\alpha$-ketoglutarate that can be used as a fuel for the Krebs cycle to drive the electron transport chain and ATP production by oxidative phosphorylation. The ammonia produced by the oxidative deamination of L-glutamate is 
typically excreted, either directly by aquatic organisms or incorporated into urea or uric acid by terrestrial animals. For example, in crayfish, ammonia is excreted across the gills and through the antennal glands (Wheatly and Toop, 1989).

NAD-dependant GDH has been shown to exist in two distinct phosphorylated and dephosphorylated forms in yeast (Hemmings, 1980), and is also phosphorylated in a diverse range of other organisms from microbes (Lin and Reeves, 1994; Hemmings, 1980) to plants (Miflin and Habash, 2002). However, very little is known about phosphorylation of GDH in crayfish. There is evidence to support reversible phosphorylation as a potential control mechanism of metabolic enzymes in O. virilis since regulation of protein kinases and phosphatases (PKA, PP1, PP2A, PP2C) have been demonstrated to change kinetic parameters of selected enzymes during anoxia as compared to the control state (Cowan and Storey, 2001). This chapter investigates the regulation of GDH in the tail muscle of $O$. virilis and the responses of the enzyme to whole animal anoxia exposure. I hypothesized that GDH is differentially regulated during anoxia, and that reversible phosphorylation is the mechanism responsible.

\subsection{Materials and Methods}

\subsubsection{Animals}

Freshwater crayfish, Orconectes virilis, were obtained from local area bait shops in Ottawa, Ontario. All crayfish are placed in freshwater tubs (filled with $10 \mathrm{~L}$ of water), in incubators acclimated to $15^{\circ} \mathrm{C}$, for 7 days. Crayfish were then separated into two groups, still at $15^{\circ} \mathrm{C}$, with either ample oxygen content in plastic tubs aerated using 
bubblers (normoxic conditions), or plastic tubs fitted with lids two holes (one to allow entry for the nitrogen gas line, and the other to allow for gas ventilation) (anoxic conditions). For the anoxia exposure, the water was initially bubbled with nitrogen gas (containing $<0.2 \% \mathrm{O}_{2}$ ) for 45 minutes before adding the animals and then nitrogen bubbling was continued throughout a $20 \mathrm{~h}$ anoxia exposure. Oxygen levels in the water fell to essentially zero in 15-20 minutes. Actual blood concentration of oxygen in crayfish was not measured, but by measuring the oxygen content in the water, a transition between normoxic, hypoxic and anoxic conditions is achieved. This model may well mimic the in vivo conditions met by the crayfish, as the crayfish are exposed to hypoxic and anoxic waters during different seasons. Ultimately, we've measured the anoxic transition of the crayfish. For sampling, animals were killed by severing the head and then tail muscle was quickly harvested, immediately frozen in liquid nitrogen, and stored at $-70^{\circ} \mathrm{C}$.

\subsubsection{Preparation of Tissue Extracts}

Samples of tail muscle tissue were homogenized 1:5 w:v in $50 \mathrm{mM}$ Tris buffer, at $\mathrm{pH}$ 8.0. Activity was measured at a range of $\mathrm{pH}$ levels, indicating a maximum at $\mathrm{pH} 8.0$, therefore, this value was used in subsequent assay conditions. In most cases, the buffer also included inhibitors of protein phosphatases ( $25 \mathrm{mM} \beta$-glycerophosphate) and protein kinases (2.5 mM EGTA, 2.5 mM EDTA) along with a few crystals of phenylmethylsulfonyl fluoride (PMSF, $\sim 1 \mathrm{mM}$ ), a protease inhibitor. The stability of extracts were measured by assessing their activity levels over time. No proteolysis or protein unfolding was evident during the times used for the experiments performed 
hereafter. Therefore, no other protease inhibitors were used. In hepatopancreas tissues, however, activity was noticeably lost after 6 hours, therefore muscle tissue was chosen as protein stability was required for subsequent experiments. Initial optimization tests demonstrated that $\beta$-glycerophosphate, an alternate inhibitor of protein phosphatases, yielded higher GDH activity than $\mathrm{NaF}$ so $\beta$-glycerophosphate was used. The aforementioned buffer will be referred to as homogenization buffer A. Tail muscle homogenates were centrifuged at $13500 \mathrm{xg}$ at $4^{\circ} \mathrm{C}$ and the supernatant was decanted; both the supernatant and the pellet were held on ice until use.

\subsubsection{Purification of GDH}

A GTP-agarose column $(2.8 \times 1.2 \mathrm{~cm} \mathrm{~h} \mathrm{x} \mathrm{d})$ was equilibrated in homogenization buffer $\mathrm{A}$ and a $500 \mu \mathrm{L}$ aliquot of tail muscle supernatant prepared as described previously was applied to the column. The column was initially washed with $10 \mathrm{~mL}$ of buffer A to remove any unbound enzyme or endogenous materials. Tail muscle GDH was then eluted with a $15 \mathrm{~mL}$ 0-1 $\mathrm{M}$ linear $\mathrm{KCl}$ gradient in homogenization buffer $\mathrm{A}$. Fractions were collected in $\sim 0.5 \mathrm{~mL}$ aliquots, and assayed under optimal conditions for tail muscle GDH; the peak 3 fractions were pooled and held on ice until use (Figure 2.1).

\subsubsection{GDH Assay}

Optimal assay conditions for the L-glutamate-utilizing direction of crayfish muscle GDH were determined to be $50 \mathrm{mM}$ Tris buffer, $\mathrm{pH} 8.0$ with $62.5 \mathrm{mM} \mathrm{L}$ - 
glutamate, $1.5 \mathrm{mM} \mathrm{NAD}^{+}$, and $1.5 \mathrm{mM} \mathrm{Mg} \bullet \mathrm{ADP}$ in a total volume of $200 \mu \mathrm{L}$ with $40 \mu \mathrm{L}$ $(\sim 5$ units) of semi-purified enzyme extract per assay. The optimal assay conditions for the reverse reaction were $50 \mathrm{mM}$ Tris buffer, $\mathrm{pH} 7.0$ with $1 \mathrm{mM} \alpha$-ketoglutarate, $100 \mathrm{mM}$ $\mathrm{NH}_{4} \mathrm{Cl}, 0.15 \mathrm{mM} \mathrm{NADH}$, and $1.0 \mathrm{mM} \mathrm{Mg} \bullet \mathrm{ADP}$ in a total volume of $200 \mu \mathrm{L}$ with $5 \mu \mathrm{L}$ $\left(\sim 0.5\right.$ units) of purified enzyme extract per assay. Standard assays were run at $23^{\circ} \mathrm{C}$. Enzyme activity was assayed with a Thermo Labsystems Multiskan spectrophotometer at $340 \mathrm{~nm}$. Data were analyzed and kinetic parameters were calculated using Kinetics v.3.5.1 program (Brooks, 1994). One unit is defined as the amount of enzyme that consumed $1 \mu \mathrm{mol}$ NAD(H) per minute. Significance was determined using a students ttest $(\mathrm{p}<0.05)$. Data was represented using Microsoft EXCEL graphing and spreadsheet program. If changes in $\mathrm{K}_{\mathrm{m}}$ were more than 1 fold, then fold increase was used to represent the changes discovered, whereas, if the changes in $\mathrm{K}_{\mathrm{m}}$ were less than 1 fold, \% change was used to represent the kinetic differences.

Protein concentrations of tail muscle extracts were determined using the Coomassie blue dye-binding method using BioRad prepared reagent. Bovine serum albumin was used as a standard.

\subsubsection{In vitro Incubation to Stimulate Protein Kinases and Phosphatases}

Samples of muscle extracts, prepared as previously described, were filtered through a Sephadex G50 spun column equilibrated in buffer A to remove small molecular weight ions and metabolites. Aliquots of the filtered supernatants were incubated for 12 hours at $\sim 4^{\circ} \mathrm{C}$ with specific inhibitors and/or stimulators of endogenous protein kinases 
and phosphatases, as well as a commercial phosphatase as described in Macdonald and Storey (1999). Each aliquot was mixed 1:2 v:v with the appropriate solutions to stimulate each specific kinase or phosphatase. Figure 2.2 shows a simple flow chart of the experimental procedure. Each solution was prepared in a incubation buffer (50 mM Tris, 10\% v:v glycerol, $30 \mathrm{mM} \beta$-mercaptoethanol, $\mathrm{pH} 8.0$ ) with the following additions:

(I) STOP conditions: $2.5 \mathrm{mM}$ EGTA, $2.5 \mathrm{mM}$ EDTA and $30 \mathrm{mM} \beta$ glycerophosphate.

(II) Stimulation of endogenous kinases: $5 \mathrm{mM} \mathrm{Mg-ATP,} 30 \mathrm{mM} \beta$ glycerophosphate and one of the following;

1) $1 \mathrm{mM}$ cAMP, to stimulate protein kinase $\mathrm{A}(\mathrm{PKA})$

2) $1 \mathrm{mM}$ cGMP, to stimulate protein kinase $\mathrm{G}(\mathrm{PKG})$

3) $1.3 \mathrm{mM} \mathrm{CaCl}$ and $7 \mu \mathrm{g} / \mathrm{mL}$ phorbol myristate acetate (PMA), to stimulate protein kinase $\mathrm{C}(\mathrm{PKC})$

4) $1 \mathrm{mM}$ AMP, to stimulate AMP-dependent protein kinase (AMPK)

5) $1 \mathrm{U}$ of calf intestine calmodulin and $1.3 \mathrm{mM} \mathrm{CaCl}_{2}$, to stimulate calciumcalmodulin protein kinase (CaMK)

(III) Stimulation of endogenous phosphatases:

1) $2 \mathrm{mM}$ EDTA, $2 \mathrm{mM}$ EGTA, and $5 \mathrm{mM}$ sodium orthovanadate $\left(\mathrm{Na}_{3} \mathrm{VO}_{4}\right)$, for protein phosphatase 1 and $2 \mathrm{~A}(\mathrm{PP} 1+\mathrm{PP} 2 \mathrm{~A})$

2) $1 \mu \mathrm{M}$ okadaic acid, $2 \mathrm{mM}$ EDTA, $5 \mathrm{mM} \mathrm{CaC}_{12}$, and $5 \mathrm{mM} \mathrm{Na}_{3} \mathrm{VO}_{4}$, for protein phosphatase 2B (PP2B)

3) $1 \mu \mathrm{M}$ okadaic acid, $2 \mathrm{mM}$ EGTA, $5 \mathrm{mM} \mathrm{MgCl}_{2}$, and $5 \mathrm{mM} \mathrm{Na}_{3} \mathrm{VO}_{4}$, for protein phosphatase $2 \mathrm{C}(\mathrm{PP} 2 \mathrm{C})$ 
4) $10 \mathrm{mM} \mathrm{MgCl}_{2}, 5 \mathrm{mM}$ EDTA and $1 \mathrm{U}$ of calf intestine alkaline phosphatase (Alk PPase)

After incubation, low molecular weight metabolites and ions were removed from the extracts by centrifugation for $2 \mathrm{~min}$ at $2000 \mathrm{rpm}$ through small spun columns of Sephadex G50 equilibrated in buffer A.

\subsubsection{Western blotting analysis of GDH}

For protein analysis, tail muscle samples were gently homogenized $(1: 3 \mathrm{w} / \mathrm{v})$ with a ground glass homogenizer in homogenization buffer $(25 \mathrm{mM}$ Tris, $\mathrm{pH}$ 7.6, $25 \mathrm{mM}$ $\mathrm{NaCl}, 100 \mathrm{mM}$ sucrose, $1 \% \mathrm{w} / \mathrm{v} \mathrm{SDS}$ ), centrifuged $13500 \mathrm{xg}$ at $4{ }^{\circ} \mathrm{C}$ and soluble protein concentration was measured by the Coomassie blue dye binding method. Tail muscle samples were then mixed 1:1 v:v with SDS loading buffer $(100 \mathrm{mM}$ Tris buffer, $\mathrm{pH}$ 6.8, $4 \% \mathrm{w} / \mathrm{v}$ SDS, $20 \% \mathrm{v} / \mathrm{v}$ glycerol, $0.2 \% \mathrm{w} / \mathrm{v}$ bromophenol blue, $10 \% \mathrm{v} / \mathrm{v} 2-$ mercapotethanol) and subsequently boiled for 5 minutes and stored at $-20^{\circ} \mathrm{C}$ until used. Each lane of $10 \%$ SDS-PAGE gels was loaded with $20 \mu \mathrm{g}$ of protein and electrophoresis was carried out at $180 \mathrm{~V}$ for $45 \mathrm{~min}$. Proteins were transferred to polyvinylidene difluoride membranes at $70 \mathrm{~V}$ overnight. Membranes were then blocked with $5 \%$ non-fat dried milk in Tris-buffered saline containing the detergent Triton-X (TBST) for 1 hour and washed three times with TBST. Incubation with primary antibody for GDH (antiglutamate dehydrogenase, anti-rabbit) (Applied Biological Materials Inc, Richmond, BC, Canada) in $10 \mathrm{ml}$ of TBST overnight at $4^{\circ} \mathrm{C}$. After washing with TBST, membranes were 
incubated with secondary antibody anti-rabbit IgG secondary antibody (1:10000 dilution) (Santa Cruz Biotechnology, Santa Cruz, CA, USA) for $1 \mathrm{~h}$ and then washed.

Immunoreactive bands were visualized with the enhanced chemiluminescence and visualized on the ChemiGenius Bioimaging System (Syngene, Frederick, MD). Band intensities were quantified using GeneTools software. Coomassie blue staining was used to standardize the amount of protein in each respective band. The experimental visualization methods and quantification methods used by GeneSnap and GeneTools software respectively can be found on the websites; http://www.syngene.com/html/genesnap.html and http://www.syngene.com/html/genetools.html. To ensure that simple manipulations of the techniques used by the software did not influence results, boxes of various sizes and shapes were used to quantify the bands of interest, all of which demonstrated similar comparative results.

\subsubsection{ProQ Diamond Phosphoprotein Staining}

Enzyme extracts from both normoxic and anoxic crayfish tail muscle were partially purified as described above using affinity chromatography. However, $2 \mathrm{~mL}$ of enzyme extract was added in this case to completely saturate the column and maximize the protein yield. The top three fractions were pooled, and protein levels in the pooled fractions were quantified using the Coomassie blue dye-binding method. Aliquots of the pooled fractions were then mixed 1:1 v:v with SDS loading buffer (100 mM Tris buffer, 
$\mathrm{pH} 6.8,4 \% \mathrm{w} / \mathrm{v}$ SDS, $20 \% \mathrm{v} / \mathrm{v}$ glycerol, $0.2 \% \mathrm{w} / \mathrm{v}$ bromophenol blue, $10 \% \mathrm{v} / \mathrm{v} 2$ mercapotethanol) and subsequently boiled for 5 minutes and stored at $-20^{\circ} \mathrm{C}$ until used.

Appropriate volumes of each sample was used to load $0.5 \mu \mathrm{g}$ protein per well on a $10 \%$ SDS-PAGE gel. The gel was run at $180 \mathrm{~V}$ for 45 minutes in running buffer $(0.5 \mathrm{M}$ Tris, $5 \mathrm{M}$ glycine, $0.5 \% \mathrm{w} / \mathrm{v}$ SDS). The gel was removed and washed in fixing solution $(50 \% \mathrm{v} / \mathrm{v}$ methanol, $10 \% \mathrm{v} / \mathrm{v}$ acetic acid) twice for 10 minutes, then left in fixing solution overnight at $\sim 4^{\circ} \mathrm{C}$ followed by 3 washes with $\mathrm{ddH}_{2} \mathrm{O}$ for 10 minutes. The gel was then stained with ProQ Diamond Phosphoprotein stain (Invitrogen, Eugene, OR) for 90 minutes and washed. The gel was covered during staining (and for the remainder of the protocol) with aluminum foil to prevent the photosensitive stain from interacting with light.

Upon completion of the staining, bands on the gel were visualized using the ChemiGenius Bioimaging System (Syngene, Frederick, MD) to assess the relative intensities of the fluorescent bands. The fluorescence of the bands was quantified using the accompanying GeneTools software. Due to background on the gels which caused distortion or interference in quantifying bands, the gel was washed in ProQ Diamond destaining solution ( $20 \% \mathrm{v} / \mathrm{v}$ acetonitrile, $50 \mathrm{mM}$ sodium acetate, $\mathrm{pH} 4)$ for 45 minutes, washed 3 times in $\mathrm{ddH}_{2} \mathrm{O}$ for 10 minutes, and reimaged.

\subsubsection{Urea Treatments of GDH and Pulse Proteolysis}

Crayfish tail muscle tissue was homogenized as previously described, without the use of PMSF. To assess the possibility of structural/conformational changes in GDH 
between the normoxic and anoxic conditions, the susceptibility of GDH to denaturation by urea was evaluated. Aliquots of $20 \mu \mathrm{l}$ of crude muscle extracts were incubated with different concentrations of urea for 24 hours at $4^{\circ} \mathrm{C}$ in $100 \mu$ l of buffer A without the addition of PMSF. After incubation, GDH was subjected to pulse proteolysis as outlined by Park and Marqusee (2005) to cleave unfolded denatured enzyme. To do this, thermolysin $\left(0.40 \mathrm{mg} / \mathrm{ml}\right.$ in $50 \mathrm{mM}$ Tris, $\left.\mathrm{pH} 8.0,2.5 \mathrm{M} \mathrm{NaCl}, 10 \mathrm{mM} \mathrm{CaCl}_{2}\right)$ was added to initiate proteolysis. Various incubation times with thermolysin to discover the optimum amount of time required, resulting in the use of a 10 minute incubation optimum. Following a 10 minute pulse reaction time at $4^{\circ} \mathrm{C}$, the reaction was quenched by adding $18 \mu \mathrm{l} 50 \mathrm{mM}$ EDTA, pH 8.0. Western blotting was then performed as above and GDH band intensities were quantified to reveal the amount of folded native GDH remaining. From this, $\mathrm{C}_{50}$ values were calculated, representing the amount of urea that reduced the amount of folded protein by one-half.

\subsection{Results}

\subsubsection{Optimization of experimental conditions}

The various components in the homogenization buffers and assay conditions were evaluated prior to determining kinetic parameters of GDH from crayfish tail muscle. It was determined that the inclusion of EGTA and EDTA to the homogenization buffer did not alter the recoverable activity of GDH in the tail muscle of crayfish in either the control or anoxic conditions. The inclusion of the phosphatase inhibitor, $\beta$ glycerophosphate, gave a better recoverable activity as compared to $\mathrm{NaF}$ which reduced 
recoverable activity. Therefore, $\beta$-glycerophosphate, EGTA and EDTA were included in the standard homogenizing buffer. The $\mathrm{pH}$ optimum for GDH was determined to be $\mathrm{pH}$ 8.5 in the L-glutamate using direction; however, the activity remained fairly high over a large $\mathrm{pH}$ range (7.0-9.5). In the $\alpha$-ketoglutarate using direction the $\mathrm{pH}$ optimum was determined to be 7.0 .

\subsubsection{GDH Purification}

Partial purifications of GDH from the tail muscle of control and anoxic crayfish were done using a simple GTP-agarose affinity column with elution using a $\mathrm{KCl}$ gradient to remove background activity which interfered with the analysis of kinetic parameters. Background was tested by running a "blank" assay without the inclusion of the necessary substrate glutamate or $\alpha$-ketoglutarate. Since no activity was present in those assays run in the absence of glutamate or $\alpha$-ketoglutarate after partial purification of GDH, the background was deemed no longer present. Purified GDH was stable for 36 hours at $4{ }^{\circ} \mathrm{C}$ but after 48 hours the activity had decreased by approximately $50 \%$ of its initial value (Figure 2.1).

\subsubsection{GDH Kinetics}

Kinetic parameters of tail muscle GDH, semi-purified on a GTP column, were assessed to determine the differences between control and anoxic forms. GDH was also assayed in both directions to determine any possible changes in the directionality of the 
enzyme between control and anoxic states. Several kinetic parameters changed significantly in the L-glutamate using direction during anoxia in comparison to control conditions $(\mathrm{p}<0.05)\left(\right.$ Table 2.1). The $\mathrm{K}_{\mathrm{m}}$ for L-glutamate of the anoxic form of GDH increased by $18 \%$ as compared to GDH from aerobic control crayfish and the $\mathrm{K}_{\mathrm{m}}$ value for $\mathrm{NAD}^{+}$also increased by $20 \%$ under anoxia. However, there was no significant change in the $\mathrm{V}_{\max }$ value for GDH between the control and anoxic forms. Similar to the kinetics for the L-glutamate using direction, some kinetic parameters for $\alpha$-ketoglutarate utilizing direction showed statistically significant changes in the anoxic state as compared to the control condition (Table 2.1). The $\mathrm{K}_{\mathrm{m}}$ for $\alpha$-ketoglutarate increased by $31 \%$ under anoxia as compared to controls by the $\mathrm{K}_{\mathrm{m}}$ value for $\mathrm{NH}_{4}{ }^{+}$did not change. There was a significant decrease in the $\mathrm{V}_{\max }$ value for the anoxic form of GDH from tail muscle, a 57\% reduction in comparison to control GDH.

\subsubsection{Effect of Cellular Metabolites on GDH Activity}

The effects of common cellular metabolites involved in energy metabolism on the activity of crayfish muscle GDH were evaluated (Table 2.1). In the L-glutamate using direction the effects of ATP, GTP and ADP were explored, whereas ADP effects were evaluated in the $\alpha$-ketoglutarate using direction. $\mathrm{K}_{\mathrm{a}}$ and $\mathrm{I}_{50}$ values were determined using the Kinetics program (Brooks, 1994). In the L-glutamate using direction, ATP had no effect on GDH kinetic parameters whereas GTP greatly inhibited GDH; $\mathrm{I}_{50}$ values were 5 $\mu \mathrm{M}$ for control GDH and decreased significantly by $30 \%$ under anoxia. ADP activated GDH but was a less effective activator in anoxic muscle. Thus, compared to control 
conditions, the $\mathrm{K}_{\mathrm{a}}$ for ADP was $45 \%$ higher for anoxic GDH and the fold activation by ADP was $31 \%$ less during anoxia.

In the $\alpha$-ketoglutarate using direction, ADP also activated GDH. However, in this direction, the $\mathrm{K}_{\mathrm{a}}$ ADP was $29 \%$ lower for the anoxic form of GDH (ie. activator effects were stronger) as compared to the control form (Table 2.1).

\subsubsection{GDH protein levels}

Western blotting was used to evaluate the relative amount of GDH protein in tail muscle from control versus anoxic crayfish. Antibodies detecting mammalian GDH showed one strong band corresponding to GDH at the correct molecular weight of $\sim 42$ $\mathrm{kDa}$ (Kawakami et al., 2007) but found no significant difference in GDH protein levels between control versus anoxic conditions (Figure 2.3).

\subsubsection{Phosphorylation State of GDH}

Changes in enzyme kinetic parameters between two different physiological or cellular states are often the result of posttranslational modification of the enzyme, quite commonly by reversible protein phosphorylation carried out by protein kinases or protein phosphatases. Enzymes from the many pathways central to ATP production and usage are of the source of great interest as they may be controlled by phosphorylation related mechanisms in response to rapidly occurring stressors. To test whether or not reversible phosphorylation was the mechanism by which GDH kinetic parameters had changed 
under anoxia, purified extracts from both control and anoxic crayfish tail muscle were run on an SDS-PAGE gel and stained with ProQ Diamond phosphoprotein stain. GDH was easily identified since the enzyme was previously purified, and a strong staining band was found at $\sim 42 \mathrm{kDa}$ which coincides with the known molecular weight of a GDH monomer (Kawakami et al., 2007). Staining revealed a $42 \%$ increase in the relative band intensity $(\mathrm{p}<0.05)$ for purified anoxic GDH as compared with the control condition (Figure 2.4).

\subsubsection{In vitro Incubation to Stimulate Protein Kinases and Phosphatases}

To investigate the possibility of phosphorylation as a regulatory mechanism for GDH in crayfish tail muscle, purified extracts from both control and anoxic animals were incubated under conditions that stimulated endogenous protein kinases and phosphatases. Incubations denoted as STOP contained inhibitors of both protein kinases and phosphatases to keep the protein in its native state, to as a representation of the in vivo state of the enzyme. These STOP conditions provide the baseline values to which all other incubations are compared. The parameter being measured is fold activation by ADP and its significant difference $(\mathrm{p}<0.05)$ between control and anoxic conditions (see also Table 2.1). Incubations investigating phosphatase activity on the kinetics of GDH included; commercial phosphatase (alkaline phosphatase), and three treatments that stimulated the activities of different endogenous protein phosphatases (stimulating PP1+PP2A, PP2B, and PP2C). All treatments by phosphatases led to significant increases in the fold activation by ADP of GDH from both control and anoxic conditions (Figure 
2.5). By contrast, stimulation of the activities of endogenous protein kinases generally had the opposite effect. Treatments that stimulated AMPK, PKA or CaMK (but not PKC or PKG) significantly reduced the ADP fold activation in the incubations using enzyme from control animals (Figure 2.5) However, these kinase treatments had no effect on the enzyme from anoxic muscle.

\subsubsection{Structural Stability of Crayfish Tail Muscle GDH}

The structural stability of GDH was evaluated by testing the enzyme sensitivity to urea denaturation by using pulse proteolysis with thermolysin to quickly digest protein that was unfolded/denatured protein by urea while leaving folded protein intact. The amount of native protein remaining was then assessed by Western blotting. The calculated $\mathrm{C}_{50}$ value (concentration of urea that results in $50 \%$ loss of folded GDH) was 3.67 $\mathrm{M}$ for GDH from anoxic tail muscle, which showed no significant difference from the value of 3.88 M for GDH in control tail muscle (Table 2.1; Figure 2.6). 
Table 2.1 Comparison of kinetic parameters of partially purified GDH from tail muscle of anoxic and control crayfish. GDH was assayed in the glutamate-utilizing direction using $\mathrm{NAD}^{+}$as the cofactor as well as the $\alpha$-ketoglutarate-using direction using NADH as the cofactor. Data are means $\pm \mathrm{SEM}, \mathrm{n}=4$ (each $\mathrm{n}$ came from a unique crayfish tail muscle extract).

* - Significantly different from the corresponding control value using the Student's t-test, $\mathrm{P}<0.05$.

\begin{tabular}{|c|c|c|c|}
\hline Direction & Kinetic Parameter & Control & Anoxic \\
\hline \multirow{7}{*}{ 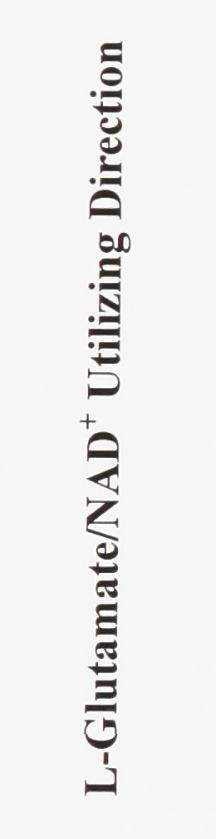 } & $\mathrm{K}_{\mathrm{m}}$ Glutamate $(\mathrm{mM})$ & $3.19 \pm 0.28$ & $3.89 \pm 0.13^{*}$ \\
\hline & $\mathrm{K}_{\mathrm{m}} \mathrm{NAD}^{+}(\mathrm{mM})$ & $0.37 \pm 0.02$ & $0.46 \pm 0.02 *$ \\
\hline & $\mathrm{V}_{\max }(\mathrm{U} / \mathrm{g})$ & $54.1 \pm 0.006$ & $53.6 \pm 0.006$ \\
\hline & $\begin{array}{c}\mathrm{K}_{\mathrm{a}} \text { ADP }(\mathrm{mM}) \\
\text { ADP Fold Activation }\end{array}$ & $\begin{array}{c}0.11 \pm 0.003 \\
2.28 \pm 0.04\end{array}$ & $\begin{array}{c}0.20 \pm 0.004^{*} \\
1.57 \pm 0.01^{*}\end{array}$ \\
\hline & $\mathrm{I}_{50} \mathrm{GTP}(\mu \mathrm{M})$ & $5.0 \pm 0.0004$ & $3.5 \pm 0.0005^{*}$ \\
\hline & $\mathrm{I}_{50} \mathrm{ATP}(\mathrm{mM})$ & No Effect & No Effect \\
\hline & $\mathrm{C}_{50} \operatorname{Urea}(\mathrm{M})$ & $3.88 \pm 0.23$ & $3.67 \pm 0.18$ \\
\hline Ð & $\begin{array}{c}\mathrm{K}_{\mathrm{m}} \alpha \text {-Ketoglutarate } \\
(\mathrm{mM})\end{array}$ & $0.24 \pm 0.02$ & $0.35 \pm 0.02 *$ \\
\hline 昰 & $\mathrm{K}_{\mathrm{m}} \mathrm{NH}_{4}^{+}(\mathrm{mM})$ & $61.8 \pm 3.17$ & $61.8 \pm 3.18$ \\
\hline$e_{0}^{0} \frac{\pi}{2}$ & $\mathrm{~K}_{\mathrm{a}} \operatorname{ADP}(\mathrm{mM})$ & $0.048 \pm 0.005$ & $0.034 \pm 0.002 *$ \\
\hline & $\mathrm{V}_{\max }(\mathrm{U} / \mathrm{g})$ & $54.0 \pm 0.93$ & $25.1 \pm 0.96^{*}$ \\
\hline
\end{tabular}


Figure 2.1 GTP-agarose elution profiles for tail muscle GDH from control and anoxic crayfish. GDH was eluted with a $0-1 \mathrm{M} \mathrm{KCl}$ gradient at $\mathrm{pH}$ 8. The peak fractions were collected for subsequent experiments (peaks 33 for both control and anoxic conditions). 
Figure 2.1

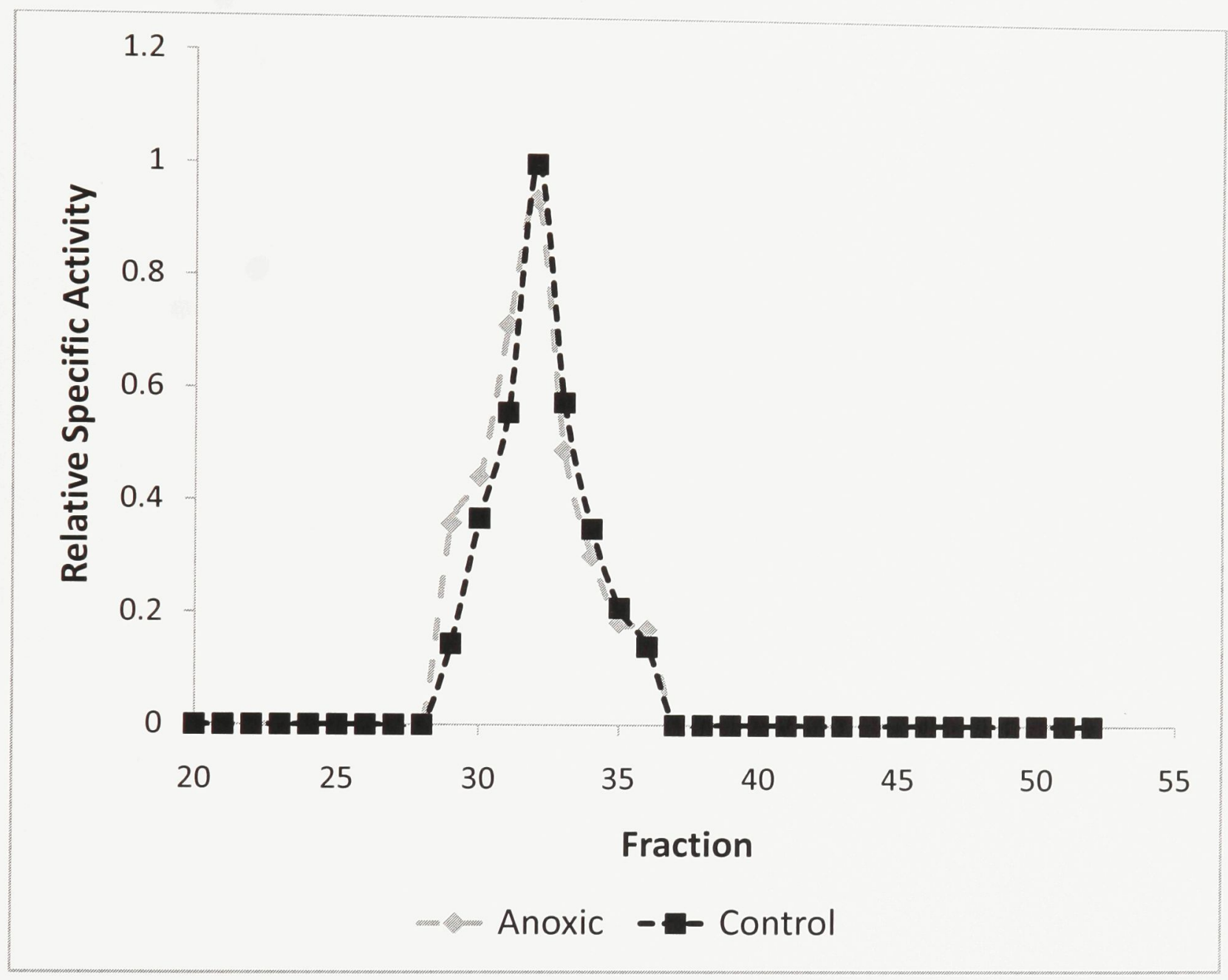


Figure 2.2 A flow chart showing the overview of the incubation protocol. 
Figure 2.2

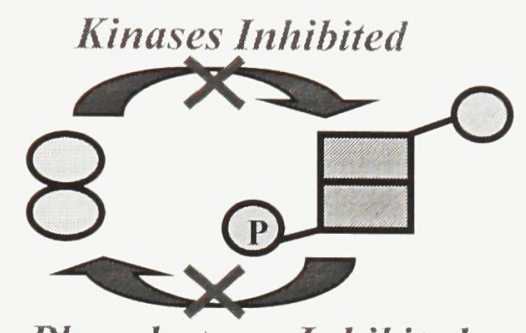

Phosphatases Inhibited

"Crude Homogenate"

$1 / 3$ of sample collected for incubation with:

$$
\begin{aligned}
& 1 / 3 \text { of sample } \\
& \text { collected for } \\
& \text { incubation with: }
\end{aligned}
$$

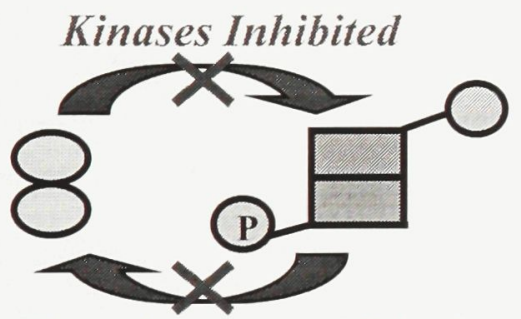

Phosphatases Inhibited

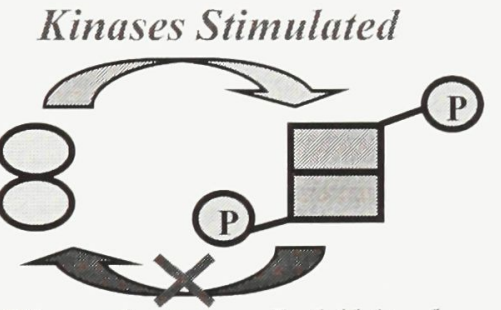

Phosphatases Inhibited
$1 / 3$ of sample

collected for

incubation with:

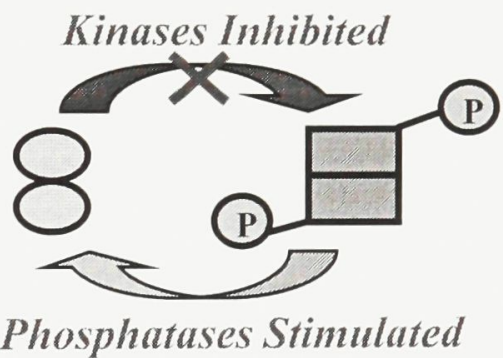


Figure 2.3 Western blotting analysis of the amount of GDH protein in the tail muscle of O. virilis showing no significant difference between control and anoxic conditions. Data are means \pm SEM, $n=3$. Coomassie blue staining was used to standardize the amount of protein in each band. 
Figure 2.3

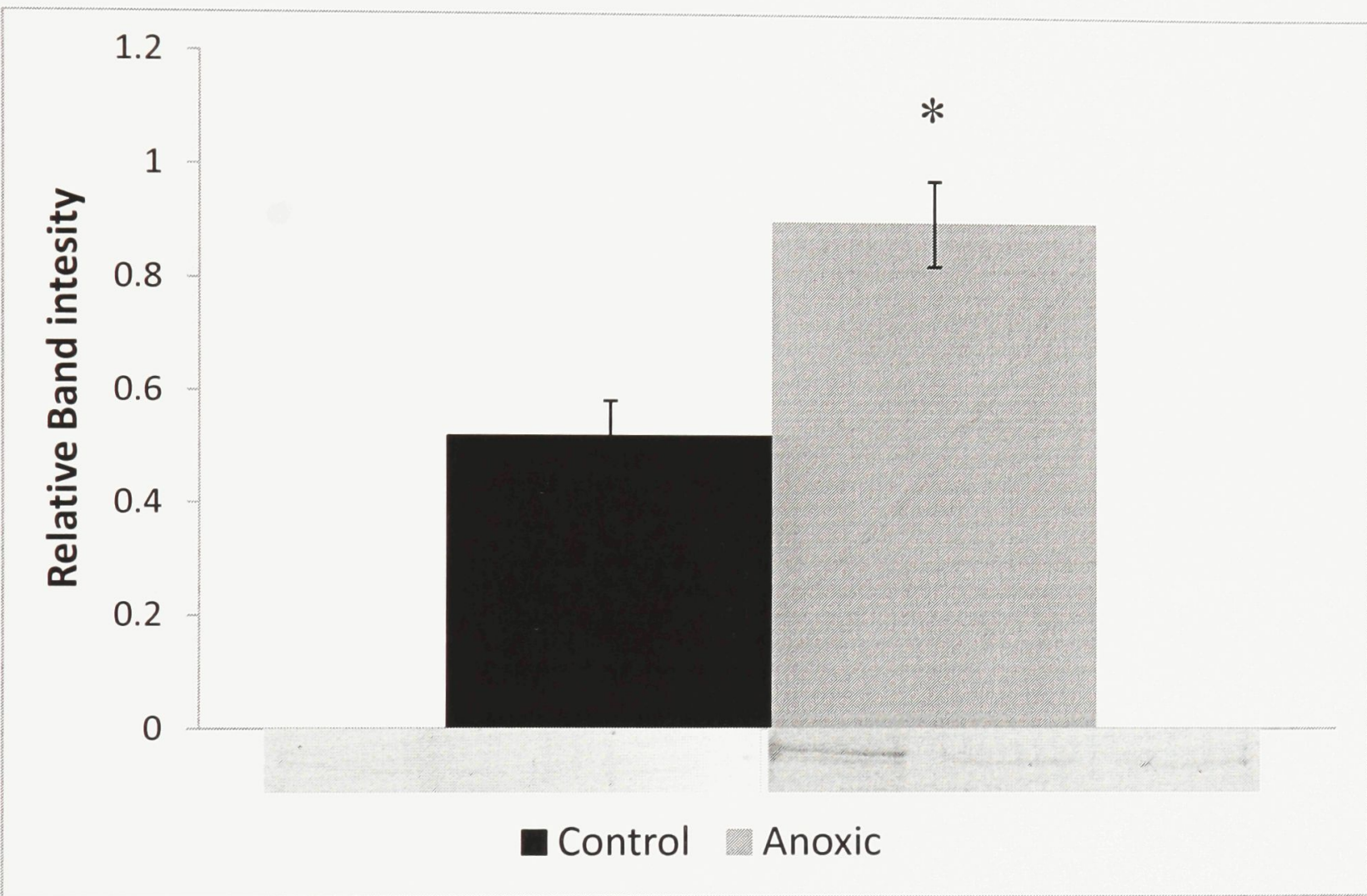


Figure 2.4 A comparison of the relative phosphorylation level of control and anoxic GDH from the tail muscle of $O$. virilis using Pro-Q diamond phospho-staining. Data are means \pm SEM, $n=3$. Coomassie blue staining was used to standardize the amount of protein in each band.

* - Significantly different from the corresponding control value via the Student's t-test, $\mathrm{p}<0.05$. 
Figure 2.4

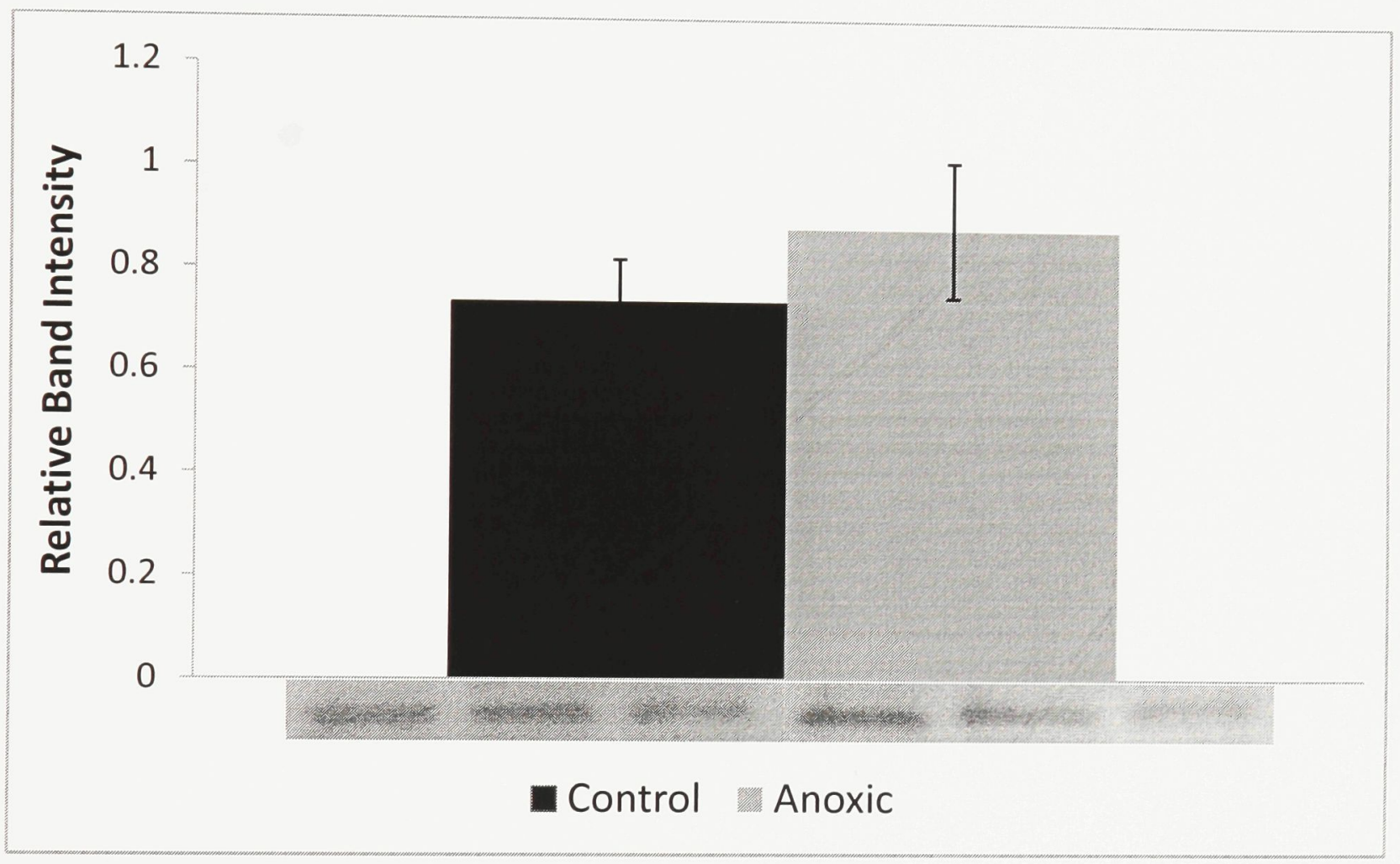


Figure 2.5 Effects of in vitro incubations which were used to stimulate the activities of endogenous protein kinases or phosphatases, and their effects on the fold activation of GDH by ADP in $O$. virilis tail muscle extracts. Crude extracts were incubated for $24 \mathrm{~h}$ at $\sim 4^{\circ} \mathrm{C}$ before assay. Data are means \pm SEM, $n=3$. Stop conditions are control or anoxic samples that were allowed to incubate in a buffer containing inhibitors of both protein kinases and phosphatases. Other incubations (described in the Methods) stimulated the activities of endogenous phosphatases including total serine/threonine phosphatases (Tot Ser/Thr) or individual phosphatase types 1 and $2 \mathrm{~A}, 2 \mathrm{~B}$ and $2 \mathrm{C}$; another incubation contained exogenous added calf intestine alkaline phosphatase (Alk PPase). Other incubations stimulated protein kinases A, C or G, the AMP-dependent protein kinase (AMPK), or Ca-calmodulin protein kinase (CaMK).

a -Significantly different from corresponding 'STOP' condition using the Student's t-test, $\mathrm{p}<0.05$.

b - Control and anoxic values for this condition are significantly different from each other using the Student's t-test, $\mathrm{p}<0.05$. 
Figure 2.5

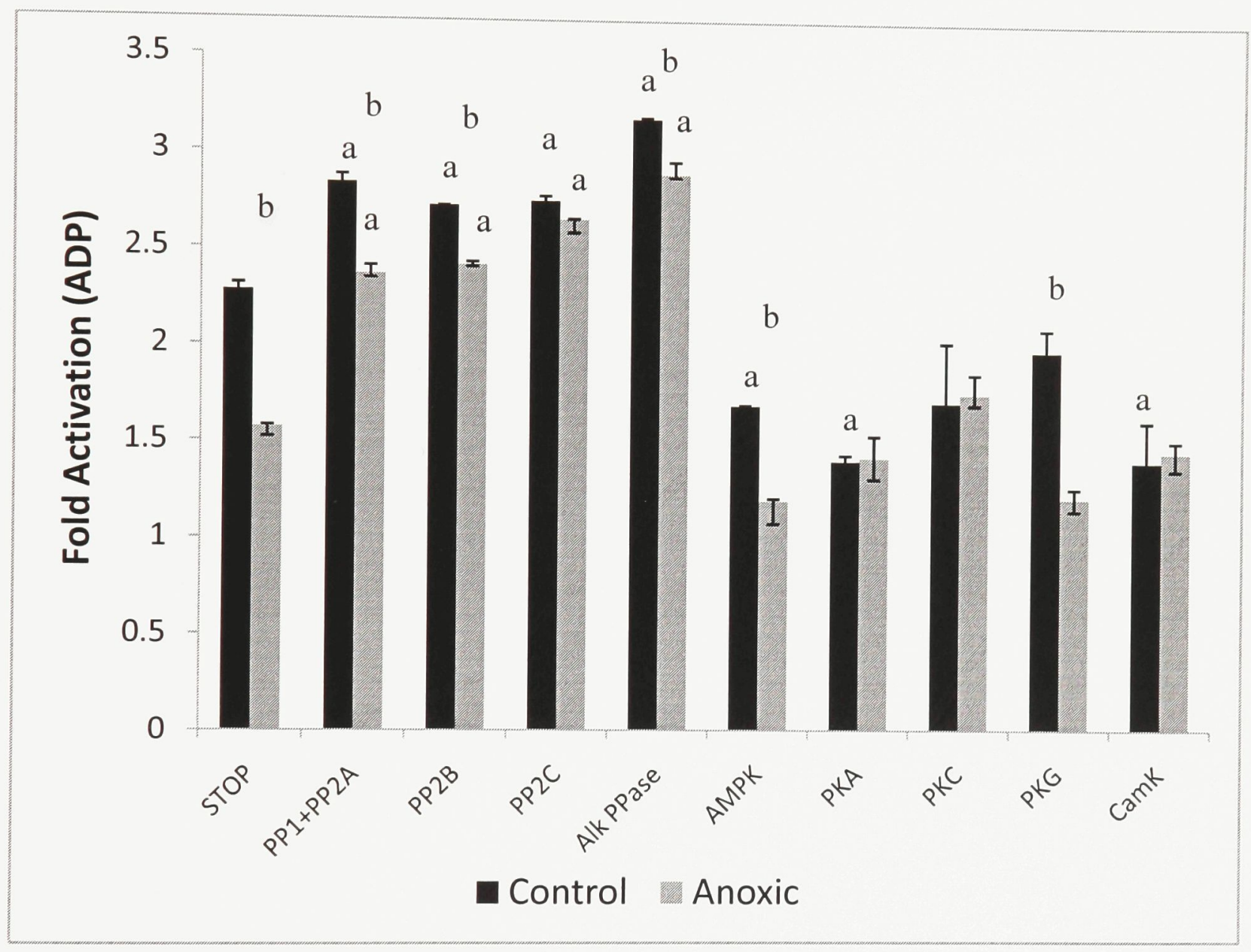


Figure 2.6 Stability of GDH from crude extracts of tail muscle. Samples were incubated for $24 \mathrm{~h}$ at $4{ }^{\circ} \mathrm{C}$ with different concentrations of urea and then treated with pulse proteolysis (10 min incubation with thermolysin) to digest denatured GDH. Western blotting was then used to measure the amount of remaining folded GDH. Figure shows a representative run from a total of 3 independent experiments. 
Figure 2.6
Urea
$\mathbf{0} 1$
2
345
$\begin{array}{ll}6 & 7\end{array}$
8 M

A

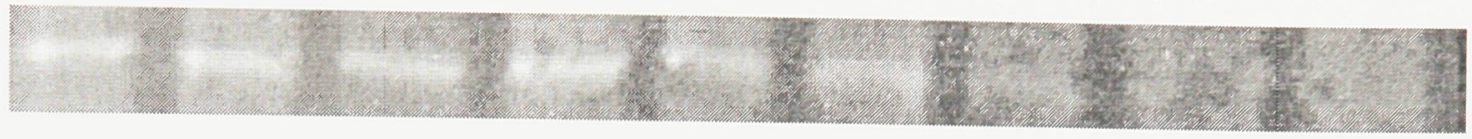

$\begin{array}{lllllllllll}\text { Urea } & 0 & 1 & 2 & 3 & 4 & 5 & 6 & 7 & 8 & \text { M }\end{array}$

B
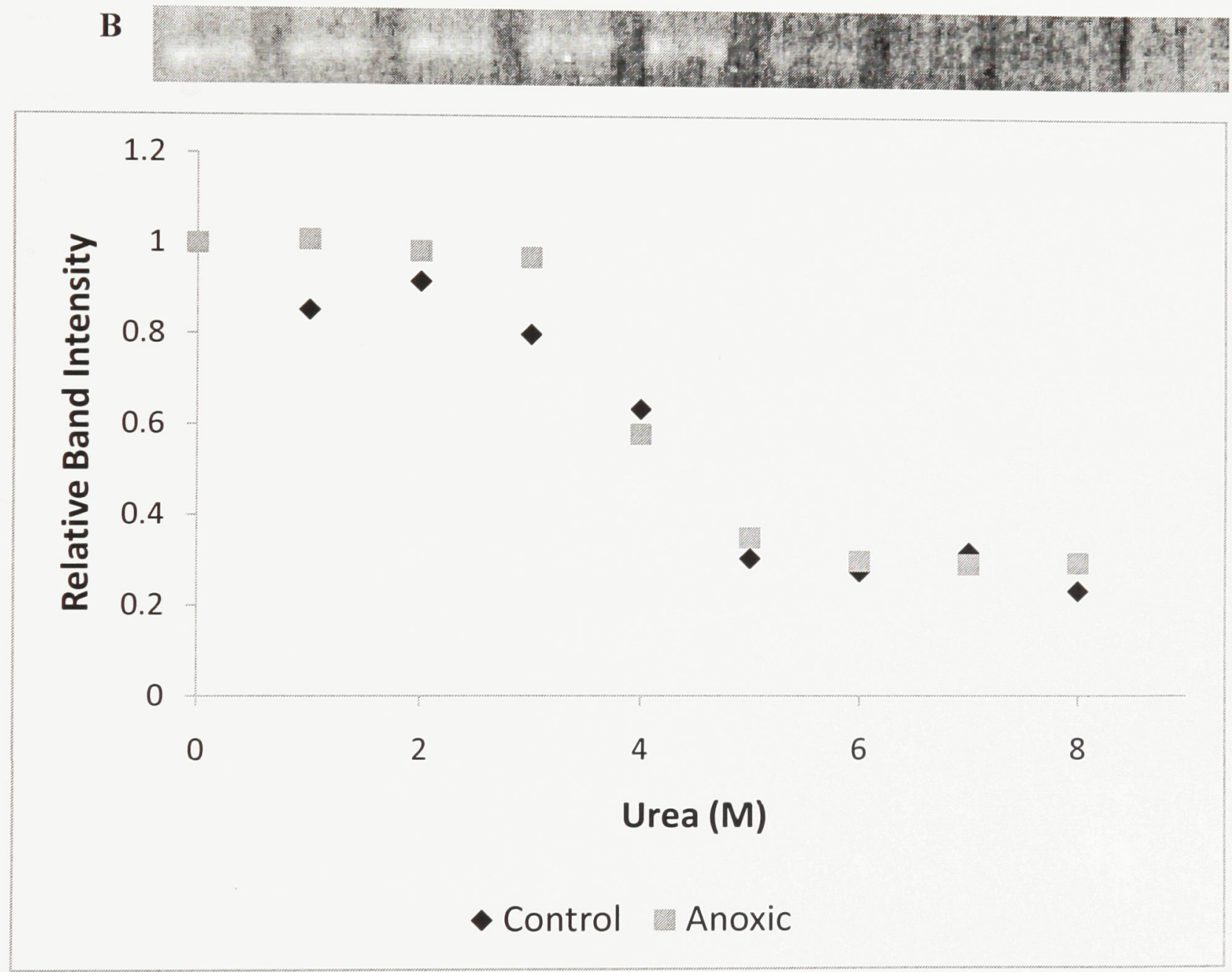


\subsection{Discussion}

Glutamate dehydrogenase from the tail muscle of the freshwater crayfish, $O$. virilis, seems to be subject to reversible phosphorylation and the data presented in the chapter demonstrates that this mechanism may be responsible for the changes in kinetic parameters associated with anoxia exposures experienced by the organism. Partially purified GDH from the tail muscle of aerobic control versus $20 \mathrm{~h}$ anoxic crayfish showed significantly different kinetic parameters and responses to cellular metabolites. This is one of the first studies to not only identify reversible phosphorylation as a possible control mechanism for the kinetic manipulation of GDH, but it is also one of the first to identify the potential kinases and phosphatases responsible for covalent modification of GDH.

GDH was purified from the tail muscle of both control and anoxic crayfish using a GTP-agarose affinity column. GTP is a known allosteric inhibitor of GDH at very low concentrations (Iwatsubo and Pantaloni, 1967; Koberstein and Sund, 1973), Hence, the GDH protein has a high affinity binding site for GTP which makes the GTP-agarose affinity column a highly suitable candidate for the purification of GDH. GDH was purified using the GTP-agarose affinity column, yielding an enzyme preparation that was free from background activity. This enzyme was then used for kinetic analysis.

Partially purified GDH from control and anoxic muscle showed significant differences in their kinetic parameters consistent with a stable modification of this enzyme during exposure to anoxia. Kinetic parameters were all collected in the presence of an allosteric activator of GDH, ADP, since the purified enzyme showed very little 
activity $(<10 \%)$ in the absence of ADP. ADP activated both the anoxic and control forms of GDH, and activated the enzyme in both the L-glutamate using direction as well as the $\alpha$-ketoglutarate using direction. This suggests that ADP is a global activator of GDH, and provides insight into a potential control mechanism using allosteric activation and inhibiton for the activity of GDH in both anoxic and control conditions. In a broad summary of the kinetic parameters investigated, the anoxic form of GDH is less active than its control counterpart in regards to the studied kinetic parameters.

The $\mathrm{K}_{\mathrm{m}}$ values for L-glutamate and $\mathrm{NAD}^{+}$and the $\mathrm{K}_{\mathrm{a}} \mathrm{ADP}$ all increased significantly during anoxia (Table 2.1). However, there were no differences in the maximal activities of purified GDH in the L-glutamate using direction under the two physiological conditions. Therefore, it would seem that the $\mathrm{K}_{\mathrm{m}}$ values are indicative of a requirement for increased concentrations of cellular metabolites to drive the same reaction in anoxia as compared to the control conditions. The levels of these metabolites in crayfish after exposure to anoxia show no significant difference in ADP levels (Fujimori and Abe, 2002) and a reduction in L-glutamate levels (Nilsson, 1990), suggesting that the decreased affinity for the necessary metabolites of anoxic GDH would be sufficient to reduce the catalytic capacity of GDH during anoxia in the L-glutamate using direction.

In the $\alpha$-ketoglutarate using direction, there was a significant decrease in the $V_{\max }$ of purified GDH from anoxic tail muscle, as well as an increase in the $\mathrm{K}_{\mathrm{m}}$ for $\alpha$ ketoglutarate, $\mathrm{NADH}$, and the $\mathrm{K}_{\mathrm{a}}$ for ADP (Table 2.1). These increases in $\mathrm{K}_{\mathrm{m}}$ values demonstrate again the reduced affinity of anoxic GDH for the necessary metabolites. The $\mathrm{V}_{\max }$ for the anoxic form of GDH in the L-glutamate using direction was found to be $29 \%$ 
greater than the $\mathrm{V}_{\max }$ for the $\alpha$-ketoglutarate using direction, possibly suggesting that the directionality of the anoxic form of GDH favors the L-glutamate using direction during anoxia.

A less active state of GDH during anoxia seems to agree with the changes in metabolism that occur during anoxia in the freshwater crayfish. During periods of anoxia, ATP generation is drastically reduced (Storey and Storey, 2004) as the primary role of oxygen is as the terminal electron acceptor in the electron transport chain, the major source of ATP production in the cell. The oxidative deamination of L-glutamate to $\alpha$ ketoglutarate to be fed into the TCA cycle, and ultimately the production of ATP via the ETC, would not be favourable during anoxia in crayfish since the oxygen required to drive ATP production is not present. Furthermore, crayfish are able to buffer the accumulation of protons, as a result of lactic acid via anaerobic metabolism, by the release of carbonate ions from the carapace (Jackson et al., 2001). Therefore, suppression of GDH during anoxia coincides with the lack of oxygen and apparent need to reduce the activity of the TCA cycle in $O$. virilis in light of this low oxygen environment.

Crayfish, like many other water-dwelling organisms, can easily secrete ammonia via their gills and antennal glands (Wheatly and Toop, 1989). During anoxia, changes in the activity and kinetic properties of GDH seem to indicate that the oxidative deamination of L-glutamate would be favoured over the synthesis of glutamate. A nearly complete reduction in the synthesis of proteins has been shown to occur during anoxia (Hochachka et al., 1996; Fraser et al., 2001). With decreased protein synthesis coupled with the ability of the crayfish to easily secrete ammonia, it is reasonable to infer that GDH in anoxic crayfish muscle could favor the oxidative deamination of L-glutamate. 
This is not necessarily to enhance activity of the TCA cycle, rather it would reduce the production of glutamate for ATP-expensive protein and amino acid synthesis.

Many enzymes are controlled via a delicate balance of cellular metabolites including ratios such as ATP:ADP, GTP:GDP, or NAD:NADH. It seems that GDH is no exception. GDH from animals (Frieden, 1965) is known to be regulated by several endogenous metabolites. GTP (Dieter et al., 1981; Iwatsubo and Pantaloni, 1967; Koberstein and Sund, 1973), and to a much lesser extent ( $\sim 100$ fold less) ATP (Frieden, 1965), are inhibitors that act by increasing the binding affinity of products by GDH. In contrast, ADP acts as an allosteric activator of GDH by facilitating product release (Frieden, 1965; Dieter et al., 1981; Baily et al., 1982; Iwatsubo and Pantaloni, 1967; Koberstein and Sund, 1973; Markau et al., 1972). Crayfish GDH is allosterically activated (2.28 and 1.57 during control and anoxia respectively) by ADP in both directions (Table 2.1), and inhibited by GTP in the oxidative deamination direction (Table 2.1). Allosteric regulation of GDH by these ligands changed significantly during anoxia, that is to say, the anoxic form of GDH was $~ 32 \%$ less activated by ADP, and more inhibited by GTP as compared to the control form of GDH. This discovery leads one to believe that although GDH is clearly under the influence of allosteric regulation, via common metabolites such as ADP or GTP, there must be some underlying form of regulation to alter the effect of these activators and inhibitors.

There are several forms of regulation possible that could account for these anoxia responsive changes in GDH activity and kinetic parameters, post-translational modification being the most common mechanism. Post-translational regulation in the form of reversible protein phosphorylation in the freshwater crayfish has already been 
demonstrated in the case of the enzymes pyruvate kinase and phosphofructokinase (K.

Cowan and K.B. Storey, unpublished data) as well as significant changes to the activities of protein kinases and protein phosphatases (PKA, PP1, PP2A, and PP2C) (Cowan and Storey, 2001). Therefore, I decided to investigate the phosphorylation state of the control and anoxic forms of GDH in O. virilis. Purified fractions of GDH were stained with ProQ Diamond phosphoprotein stain to reveal any changes in phosphorylation state between the anoxic and control conditions. Figure 2.3 shows that the less active anoxic form of GDH had $42 \%$ more phosphor-staining associated with it than the control form of GDH. Further analysis of reversible phosphorylation as an underlying control mechanism for GDH during anoxia was undertaken by analyzing the effects of endogenous kinases and phosphatases as well as a commercial phosphatase on the activation of GDH by ADP. Figure 2.5 shows a strong correlation between the putative phosphorylation state of GDH and the corresponding activation of GDH by ADP. Incubations that promoted the action of protein phosphatases PP1 + PP2A, PP2B, PP2C as well as the commercial phosphatase Alk PPase all resulted in significant increases in the activation of GDH by ADP in both the control and anoxic forms. For anoxic GDH this increased the fold activation by ADP to levels that not only returned to control values but surpassed them. The consistent action of phosphatases on GDH indicates that the anoxic enzyme contains a high content of phosphate whereas the aerobic control enzyme has a low content (that can be further reduced by phosphatase treatment). Incubations under conditions that stimulated the activities of protein kinases (AMPK, PKA and CaMK) all resulted in significant decreases in the ADP activation of GDH under control conditions. However, kinase incubations did not significantly affect the anoxia enzyme indicating that this enzyme 
form was already highly or fully phosphorylated (Figure 2.5). This suggests that phosphorylation results in a change in the activation of GDH by the allosteric activator ADP. In a study performed by Cowan and Storey (2001) activities of PP1, PP2A and PP2C were all shown to decrease significantly during the first 2 hours of anoxia exposure in $O$. virilis, whereas the activity of PKA increased significantly. This would suggest that PKA may one of the main regulatory kinases involved in the phosphorylation of GDH during the entry into anoxia, ultimately suppressing the activity state of GDH during anaerobic life. The decrease in phosphatase activities provides further evidence for reversible phosphorylation as a control mechanism for GDH during anoxia. A significant reduction in $\mathrm{PP} 1, \mathrm{PP} 2 \mathrm{~A}$ and $\mathrm{PP} 2 \mathrm{C}$ was seen in $O$. virilis, all of which were shown to significantly increase the activity of GDH (Cowan and Storey, 2001).

Western blot analysis of GDH in the tail muscle of $O$. virilis did not show any significant changes in total protein expression levels of the enzyme between aerobic and anoxic states (Figure 2.4). This would suggest that GDH is not subject to transcriptional or translational controls under anoxia, as well as indicating that GDH protein levels remain stable during anoxia.

Both control and anoxic forms of GDH displayed a similar pattern of denaturation and degradation by thermolysin proteolysis, and showed $\mathrm{C}_{50}$ values that were not significantly different. This suggests that there are no major structural differences affecting the stability of GDH between the control and anoxic states (Figure 2.6).

In summary, the data presented in this chapter provide strong evidence that GDH from tail muscle of aerobic versus anoxic crayfish demonstrates changes in kinetic 
properties, and that the anoxic form of GDH is less active in both directions. Through the use of both phosphoprotein staining, and incubations stimulating the action of endogenous protein phosphatases and kinases, it would appear that GDH is phosphorylated when animals are exposed to anoxia, resulting in a reduced activity state of the enzyme. Based on known changes in protein kinase and phosphatase activities in muscle under anoxia (Cowan and Storey (2001), these changes in GDH phosphorylation state may be under the control of protein kinase A and facilitated by a reduction in the activities of various protein phosphatases under anoxic conditions. Therefore, crayfish muscle GDH seems to allosterically regulated by a delicate balance between GTP and ADP levels, and is further controlled by reversible phosphorylation during anoxia resulting in a low activity state of GDH in accordance with overall metabolic rate depression in the anoxic state. 


\section{CHAPTER 3}

Regulation of tail muscle arginine kinase in the anoxia-tolerant freshwater crayfish, Orconectes virilis 


\subsection{Introduction}

Arginine Kinase (AK)(E.C. 2.7.3.3) is a crucial enzyme involved in energy metabolism in muscle. It is associated with the myofibrils and also present in the intermembrane space of the mitochondria and the cytosol (Newsholme et al. 1978). AK catalyses the following reaction;

$$
\text { ATP }+ \text { L-Arginine } \leftrightarrow \text { ADP }+ \text { Phospho-L-Arginine }
$$

$\mathrm{AK}$ is the invertebrate phosphagen kinase, the equivalent of creatine kinase (CK) in vertebrates. In this role, $\mathrm{AK}$ works in one direction to synthesize the phosphagen when ATP supply is plentiful, and in the opposite direction to mediate the rapid breakdown of phosphagen to regenerate ATP during burst muscle work (Newsholme et al. 1978; Ellington, 1989). Like CK, both cytosolic and mitochondrial forms of AK occur, the octameric mitochondrial form representing only a very small percentage of the total. The cytoplasmic form acts like a buffer for intracellular ATP:ADP ratios particularly during burst muscle work when ATP is consumed much faster than it can be replenished by glycolytic or mitochondrial ATP production (McLeish and Kenyon, 2005; Abnous and Storey, 2007). The mitochondrial form is present in the intermembrane space, where it produces phospho-arginine from mitochondrially-generated ATP and imported arginine from the cytosol, and thereby together with the cytoplasmic form, acts as a shuttle to move high energy phosphate from the mitochondria to the muscle fibrils (Newsholme et al. 1978; McLeish and Kenyon, 2005).

AK is a very abundant protein, comprising approximately $10-20 \%$ of the total protein from lobster muscle (Blethen and Kaplan, 1967). Cytoplasmic AK exists as a 
monomer or a dimer with a molecular weight of approximately $40 \mathrm{kDa}$ for the monomer (Blethen and Kaplan, 1967; Guo et al. 2004). The structure of AK from Limulus has been determined (Zou et al. 1998). The protein contains two domains, an $\mathrm{N}$-terminal domain where the binding site for arginine or arginine phosphate is located, and a C-terminal domain where ATP or ADP is bound (Zou et al. 1998). The catalytic centre, where the transfer of the phosphate group is achieved, is also located in the C-terminal domain (Zou et al. 1998).

AK is widely distributed amongst invertebrate organisms (Watts, 1971; Watts, 1975). It has been postulated that $\mathrm{AK}$ is the most primitive member of the phosphagen kinase family, and that $\mathrm{CK}$ along with other known phosphagen kinases including glycocyamine kinase (GK), lombricine kinase (LK), taurocyamine kinase (TK), hypotaurocyamine kinase (HTK) and opheline kinase (OK), arose from tandem gene duplication and other divergences (Muhlebach et al. 1994; Susuki et al. 1997; Watts, 1971). Therefore, AK shows much homology with CK, and the two enzymes are often lumped together when discussing trends.

Where CK has been widely studied and characterized, much less is known about its ancestral analogue, AK. This chapter presents the first studies to investigate the potential regulation of AK by post-translational modification, and is the first to investigate a possible control mechanism for the enzyme during an anoxic state.

As previously stated, there is evidence to support reversible phosphorylation as a potential control mechanism for altering metabolic responses in $O$. virilis in response to anoxia. This includes changes in kinetic parameters of protein kinases and phosphatases 
(PKA, PP1, PP2A, and PP2C) during anoxia (Cowan and Storey, 2001) as well as anoxia-stimulated changes in the properties and phosphate content of the glycolytic enzymes, phosphofructokinase and pyruvate kinase (Cowan and Storey, unpublished). This present chapter investigates the regulation of $\mathrm{AK}$ in the tail muscle of $O$. virilis comparing aerobic and anoxic states. I propose that AK is differentially regulated during anoxia, and that reversible phosphorylation is the mechanism responsible.

\subsection{Materials and Methods}

\subsubsection{Animals and Preparation of Tissue Extracts}

Experimental treatment of $O$. virilis and preparation of crayfish tail muscle extracts were performed as described in Chapter 2.

\subsubsection{Sephadex G-50 filtration of Crude Extracts}

Low molecular weight metabolites and ions were found to interfere with both the purification and kinetic assay of $\mathrm{AK}$, thus, it was necessary to remove these prior to further studies. To remove low molecular weight metabolites and ions, Sephadex G-50 gel filtration was used. A $5 \mathrm{~cm}$ column of Sephadex G-50 in a syringe barrel was equilibrated in homogenization buffer and centrifuged at $500 \mathrm{~g}$ in a bench-top centrifuge for 2 minutes to remove excess buffer. Then a $500 \mu \mathrm{L}$ aliquot of tail muscle extract was applied to the column and centrifuged again. The resulting eluant was collected. 


\subsubsection{Purification of AK}

Muscle extracts were prepared 1:5 w:v in homogenization buffer A (refer to chapter 2). A $750 \mu \mathrm{L}$ aliquot of crude extract was applied to a DEAE Sephadex G50 column $(1.5 \mathrm{~cm}$ x $5 \mathrm{~cm})$ equilibrated in $12.5 \mathrm{mM}$ Tris-HCl buffer $\mathrm{pH} 9.0,12.5 \mathrm{mM} \beta$ glycerophosphate, $2.5 \mathrm{mM}$ EGTA, $2.5 \mathrm{mM}$ EDTA and $10 \mathrm{mM} \beta$-mercaptoethanol and then eluted with a linear $\mathrm{KCl}$ gradient $(0-500 \mathrm{mM})$ in the same buffer. The peak fractions from the DEAE Sephadex G50 column were pooled and then applied to a Cibacron Blue $3 \mathrm{GA}$ column $(1.5 \mathrm{~cm} \times 5 \mathrm{~cm})$ and eluted under the same conditions as the DEAE column. Between each purification step, the aforementioned spun column protocol was used to remove excess salt. Peak fractions were pooled. The purity of AK at each step was checked by running samples on SDS-PAGE (as described for Western blotting) with Coomassie blue staining.

\subsubsection{AK Assay}

AK activity was measured as the rate of ADP production coupled to an assay system with pyruvate kinase (PK) and lactate dehydrogenase (LDH). Optimal assay conditions for AK were determined to be $50 \mathrm{mM}$ Tris buffer $\mathrm{pH} 8.0,5 \mathrm{mM} \mathrm{Mg}$.ATP, $10 \mathrm{mM} \mathrm{L}$-arginine, 20 $\mathrm{mM} \mathrm{MgCl} 2,100 \mathrm{mM} \mathrm{KCl}, 4 \mathrm{mM}$ PEP, $0.5 \mathrm{mM} \mathrm{NADH}$, and 1 U/assay each of LDH and PK in a total volume of $200 \mu \mathrm{L}$ with $5 \mu \mathrm{L}$ of purified enzyme extract (diluted 20 fold) per assay. Enzyme activity was assayed with a Thermo Labsystems Multiskan spectrophotometer at an absorbance of $340 \mathrm{~nm}$. Data were analyzed using the Kinetics v.3.5.1 program (Brooks, 1994). Significance was determined using a students t-test 
$(\mathrm{p}<0.05)$. Data was represented using Microsoft EXCEL graphing and spreadsheet program. If changes in kinetics were more than 1 fold, then fold increase was used to represent the changes discovered, whereas, if the changes in kinetics were less than 1 fold, \% change was used to represent the kinetic differences.

Protein concentrations of the tail muscle extracts were determined using the Coomassie blue dye-binding method with the BioRad prepared reagent. Bovine serum albumin was used as a standard.

\subsubsection{In vitro Incubation to Stimulate Protein Kinases and Phosphatases}

Samples of homogenates, prepared as previously described, were filtered through a G50 spun column equilibrated in buffer A. Aliquots of the filtered supernatants were incubated for 12 hours at $\sim 4^{\circ} \mathrm{C}$ with specific inhibitors and stimulators of protein kinases and phosphatases, as described in Macdonald and Storey (1999). Each aliquot was mixed 1:2 v:v with the appropriate solutions to stimulate either protein kinases or phosphatases. Each solution was prepared in a incubation buffer (50 mM Tris, $10 \% \mathrm{v}: \mathrm{v}$ glycerol, 30 $\mathrm{mM} \beta$-mercaptoethanol, $\mathrm{pH}$ 8.0) and the following three incubation conditions were used:

(I) STOP conditions: $2.5 \mathrm{mM}$ EGTA, $2.5 \mathrm{mM}$ EDTA and $30 \mathrm{mM} \beta-$ glycerophosphate.

(II) Commercial PKA: $5 \mathrm{mM}$ Mg-ATP, $30 \mathrm{mM} \beta$-glycerophosphate and the commercial catalytic subunit PKA from rabbit muscle.

(III) Commercial Alkaline Phosphatase: $10 \mathrm{mM} \mathrm{MgCl}_{2}, 5 \mathrm{mM}$ EDTA and $1 \mathrm{U}$ of calf intestine alkaline phosphatase (Alk PPase) 
After incubation, low molecular weight metabolites and ions were removed from the extracts by centrifugation for $2 \mathrm{~min}$ at $2000 \mathrm{rpm}$ through small spun columns of Sephadex G50 equilibrated in buffer A.

\subsubsection{Western blotting analysis of AK}

Blotting was performed as described in Chapter 2 with the following changes. Incubation was with primary antibody recognizing creatine kinase (a related phosphagen kinase) (creatine kinase c-19, anti-goat; Santa Cruz Biotechnology, Santa Cruz, CA, USA) in $10 \mathrm{ml}$ of TBST overnight at $4^{\circ} \mathrm{C}$. Bound antibody was detected with anti-goat IgG secondary antibody (1:3000 dilution) (Santa Cruz Biotechnology).

\subsubsection{ProQ Diamond Phosphoprotein Staining}

Semi purified tail muscle AK from control and anoxic crayfish were assessed using ProQ Diamond phosphoprotein staining as described in Chapter 2.

\subsubsection{Urea Treatments of AK and Pulse Proteolysis}

Crayfish tail muscle tissue was homogenized as previously described, and the possibility of structural changes in tail muscle AK between the normoxic and anoxic conditions was evaluated. Enzyme denaturation by urea was evaluated and pulse proteolysis was performed as outlined in Chapter 2. 


\subsection{Results}

\subsubsection{Optimization of experimental conditions}

Various components of the homogenization buffers and assay conditions were evaluated prior to kinetic analysis of AK from crayfish tail muscle. The inclusion of EGTA and EDTA in the homogenization buffer did not reduce the recoverable activity of AK under either control or anoxic conditions. However, the inclusion of the protein phosphatase inhibitor, $\mathrm{NaF}$, significantly decreased the recoverable activity in comparison to $\beta$-glycerophosphate which had negligible effect on activity. Therefore, $\beta$ glycerophosphate, EGTA and EDTA were included in the standard homogenizing buffer. The $\mathrm{pH}$ optimum for $\mathrm{AK}$ in the arginine utilizing direction was determined to be $\mathrm{pH} 8.5$ and activity remained fairly stable over a large range from $\mathrm{pH}$ 7.5-9.5.

\subsubsection{AK Purification}

The purification scheme used for crayfish tail muscle AK is shown in Table 3.1. The procedure used ion exchange chromatography on DEAE Sephadex followed by affinity chromatography on Cibacron Blue. Tail muscle AK was purified 21.8 fold with an overall yield of activity of $43.2 \%$. The final specific activity of enzyme was $26.2 \mathrm{U} / \mathrm{mg}$ protein. The success of each purification step was assessed using SDS-PAGE gel stained with Coomassie blue staining (Figure 3.1). This showed that the enzyme was purified to near homogeneity as there was one very strong band corresponding to correct molecular weight of $\sim 40 \mathrm{kDa}$ for AK (Suzuki et al., 2000) with only one additional faint band at a 
higher molecular weight. The same purification protocol was use to purify AK from tail muscle of anoxic crayfish.

\subsubsection{AK Kinetics}

Kinetic parameters of purified tail muscle AK were assessed to determine the differences between control and anoxic forms. Kinetic parameters changed in the Larginine-using direction during anoxia in comparison to the control enzyme $(\mathrm{p}<0.05)$ (Table 3.2). There was a $59 \%$ increase in the $\mathrm{K}_{\mathrm{m}}$ for $\mathrm{L}$-arginine for the anoxic form of AK as compared to the control enzyme. However, $\mathrm{K}_{\mathrm{m}}$ for ATP did not change significantly nor did $\mathrm{V}_{\max }$ values.

\subsubsection{AK protein levels}

Western blotting was used to evaluate the relative amount of AK protein in tail muscle from control versus anoxic crayfish. Since AK antibodies are not available, the analysis was done using antibodies detecting mammalian CK. The CK antibodies crossreacted with one strong band corresponding to the known AK molecular weight of $\sim 40 \mathrm{kDa}$ (Suzuki et al., 2000). No significant difference was detected between the protein levels in tail muscle of control versus anoxic crayfish (Figure 3.2). 


\subsubsection{Phosphorylation State of AK}

High and low phosphate forms of enzymes can also be resolved using ion exchange chromatography. This separation of high and low phosphate forms is a result of the change in net charge of an enzyme due to the addition of negatively charged phosphate groups that are covalently bound to the enzyme. Figure 3.3 shows elution patterns for control and anoxic forms of AK after chromatography on a DEAE-Sephadex column with elution using a $0-500 \mathrm{mM} \mathrm{KCl}$ gradient. Control AK eluted in one large peak with a bit of a lagging tail or smaller peak; the vast majority of activity was in the first large peak. Anoxic AK eluted in the opposite manner, showing a small amount of activity in the region where the control peak was. Interestingly, when the two peaks were superimposed, the large peak region of the control AK elution profile fitted over the tail region of the anoxic AK elution profile, and visa versa. These results indicate that $\mathrm{AK}$ is interconverted between two forms which dominate in aerobic versus anoxic states.

To test whether or not reversible phosphorylation was the mechanism by which AK kinetic parameters had changed during anoxia, the top 3 fractions from the DEAE elution profiles for each of control and anoxic AK were combined and run on an SDSPAGE gel, and stained with ProQ Diamond phosphoprotein stain. AK was easily identified as a strong band found at $\sim 40 \mathrm{kDa}$. When band densities were quantified, they showed a mean $64 \%$ higher band intensity $(\mathrm{p}<0.05)$ for anoxic AK when compared to the control bands (Figure 3.4). 


\subsubsection{In vitro Incubation with Commercial Protein Kinases and Phosphatases}

To further investigate the possibility of phosphorylation as a regulatory mechanism for AK in crayfish tail muscle, DEAE Sephadex purified extracts from both control and anoxic conditions were incubated under conditions that stimulated commercial protein kinases or protein phosphatases (Figure 3.5). Incubations denoted STOP included inhibitors of both protein kinases and phosphatases and revealed the status of the enzyme under aerobic control versus anoxic conditions. These showed a significant difference $(\mathrm{p}<0.05)$ in the $\mathrm{K}_{\mathrm{m}}$ of $\mathrm{L}$-arginine between control and anoxic conditions, as also reported in Table 3.2. Incubations that stimulated the commercial protein phosphatases alkaline phosphatase produced a significant decrease in the $\mathrm{K}_{\mathrm{m}}$ of L-arginine of the anoxic enzyme. By contrast, incubation with commercial catalytic subunit PKAc from rabbit muscle showed the opposite effect, with a significant ( 72\%) increase in the $\mathrm{K}_{\mathrm{m}}$ of L-arginine of the control enzyme to a value similar to that see for the anoxic enzyme form (Figure 3.5).

\subsubsection{Structural Stability of Crayfish Tail Muscle AK}

The structural stability of AK was evaluated by testing enzyme sensitivity to urea denaturation followed by proteolysis with thermolysin to digest unfolded denatured protein. The amount of native protein remaining was then assessed by Western blotting. The effect of urea denaturation on AK activity was evaluated by incubating extracts from both control and anoxic crayfish tail muscle for 24 hours a $\sim 4^{\circ} \mathrm{C}$ in the presence of different concentrations of urea ranging from 0-2 $\mathrm{M}$ and then assaying the different 
incubations for enzyme activity. The $\mathrm{C}_{50}$ values for loss of $\mathrm{AK}$ activity for both control and anoxic forms were calculated and a $24 \%$ decrease in $\mathrm{C}_{50}$ was discovered for the anoxic form as compared to control AK (Table 3.2; Figure 3.6). The calculated $\mathrm{C}_{50}$ value (concentration of urea that results in a 50\% loss of folded enzyme) was $4.01 \mathrm{M}$ for AK from anoxic tail muscle extracts, which was not significantly different than the value of 4.17 $\mathrm{M}$ for $\mathrm{AK}$ in control tail muscle extracts (Table 3.2; Figure 3.6). 
Table 3.1 Purification of AK from tail muscle of control crayfish.

\begin{tabular}{|c|c|c|c|c|c|}
\hline Purification Step & $\begin{array}{c}\text { Total } \\
\text { Protein } \\
(\mathrm{g})\end{array}$ & $\begin{array}{c}\text { Total } \\
\text { Activity } \\
(\mathrm{U})\end{array}$ & $\begin{array}{c}\text { Specific } \\
\text { Activity } \\
(\mathrm{U} / \mathrm{mg})\end{array}$ & $\begin{array}{c}\text { Fold } \\
\text { purification }\end{array}$ & $\begin{array}{c}\text { Yield } \\
(\%)\end{array}$ \\
\hline Crude extract & 1.925 & 231 & 1.2 & - & 100 \\
\hline DEAE ${ }^{+}$Sephadex & 0.546 & 177 & 3.24 & 2.7 & 76.6 \\
\hline Cibacron Blue & 0.038 & 100 & 26.17 & 21.8 & 43.2 \\
\hline
\end{tabular}


Table 3.2 Comparison of kinetic parameters of purified AK from tail muscle of anoxic and control crayfish. AK was assayed in the L-arginine utilizing direction. Data are means \pm SEM, $\mathrm{n}=4$ determinations on separate preparations of enzyme.

* - Significantly different from the corresponding control value using Student's t-test, $\mathrm{P}<0.05$.

\begin{tabular}{|c|c|c|}
\hline Kinetic Parameter & Control & Anoxic \\
\hline $\mathrm{K}_{\mathrm{m}}$ L-Arginine $(\mathrm{mM})$ & $0.46 \pm 0.02$ & $0.73 \pm 0.03^{*}$ \\
\hline $\mathrm{K}_{\mathrm{m}}$ ATP $(\mathrm{mM})$ & $0.48 \pm 0.03$ & $0.51 \pm 0.05$ \\
\hline $\mathrm{V}_{\max }(\mathrm{U} / \mathrm{g}$ wet weight) & $333 \pm 11.7$ & $318 \pm 27.0$ \\
\hline $\mathrm{I}_{50}$ Urea $(\mathrm{M})$ & $3.98 \pm 0.21$ & $3.01 \pm 0.27^{*}$ \\
\hline $\mathrm{C}_{50}$ Urea $(\mathrm{M})$ & $4.17 \pm 0.31$ & $4.01 \pm 0.28$ \\
\hline
\end{tabular}


Figure 3.1 SDS-PAGE with Coomassie blue staining of samples taken at every step in the purification of AK from the tail muscle of control O.virilis. Lanes represent: (1) Crude Tail extract, (2) pooled AK fractions after elution from a DEAE Sephadex column, (3) pooled AK from a Cibacron Blue agarose column, and (4) Fermentas PageRuler Prestained Protein Ladder molecular weight standards ( $3 \mu \mathrm{L})$. 
Figure 3.1

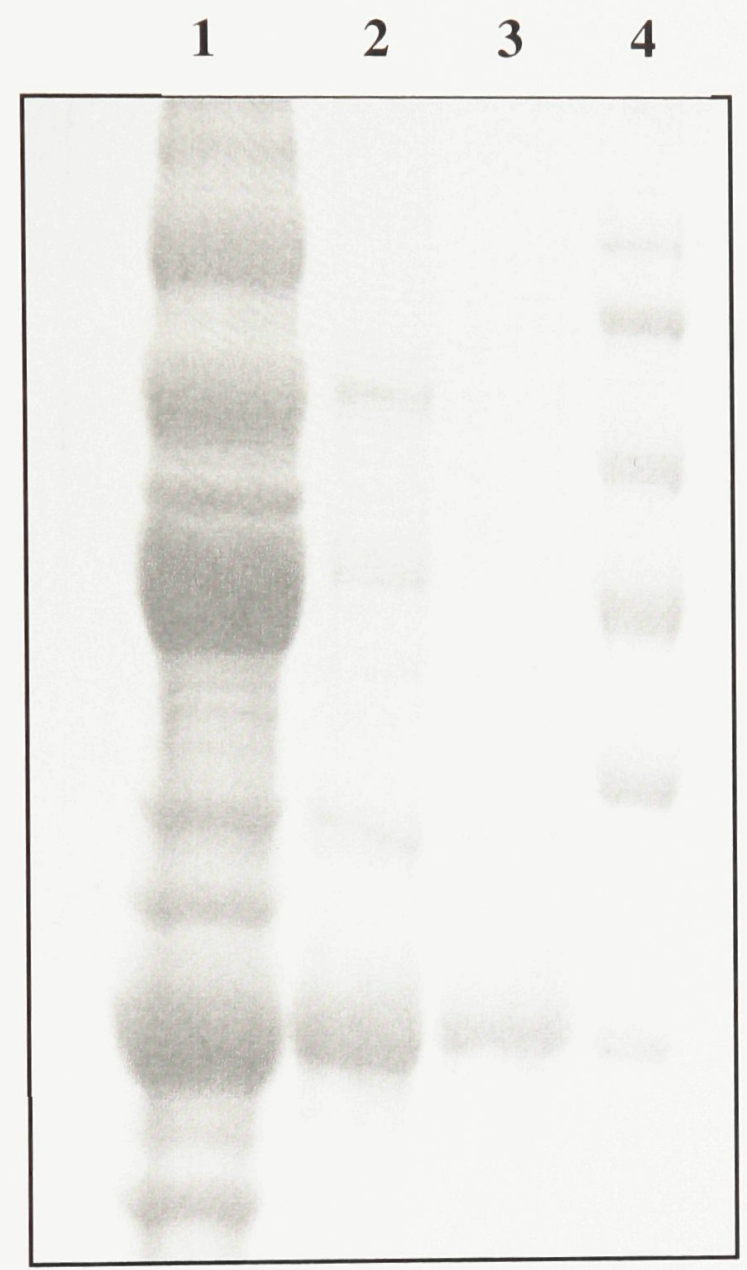


Figure 3.2. Western blotting analysis of the amount of AK protein in the tail muscle of O. virilis showing no significant difference between control and anoxic conditions. Data are means \pm SEM, $n=3$. Coomassie blue staining was used to standardize the amount of protein in each band. 
Figure 3.2

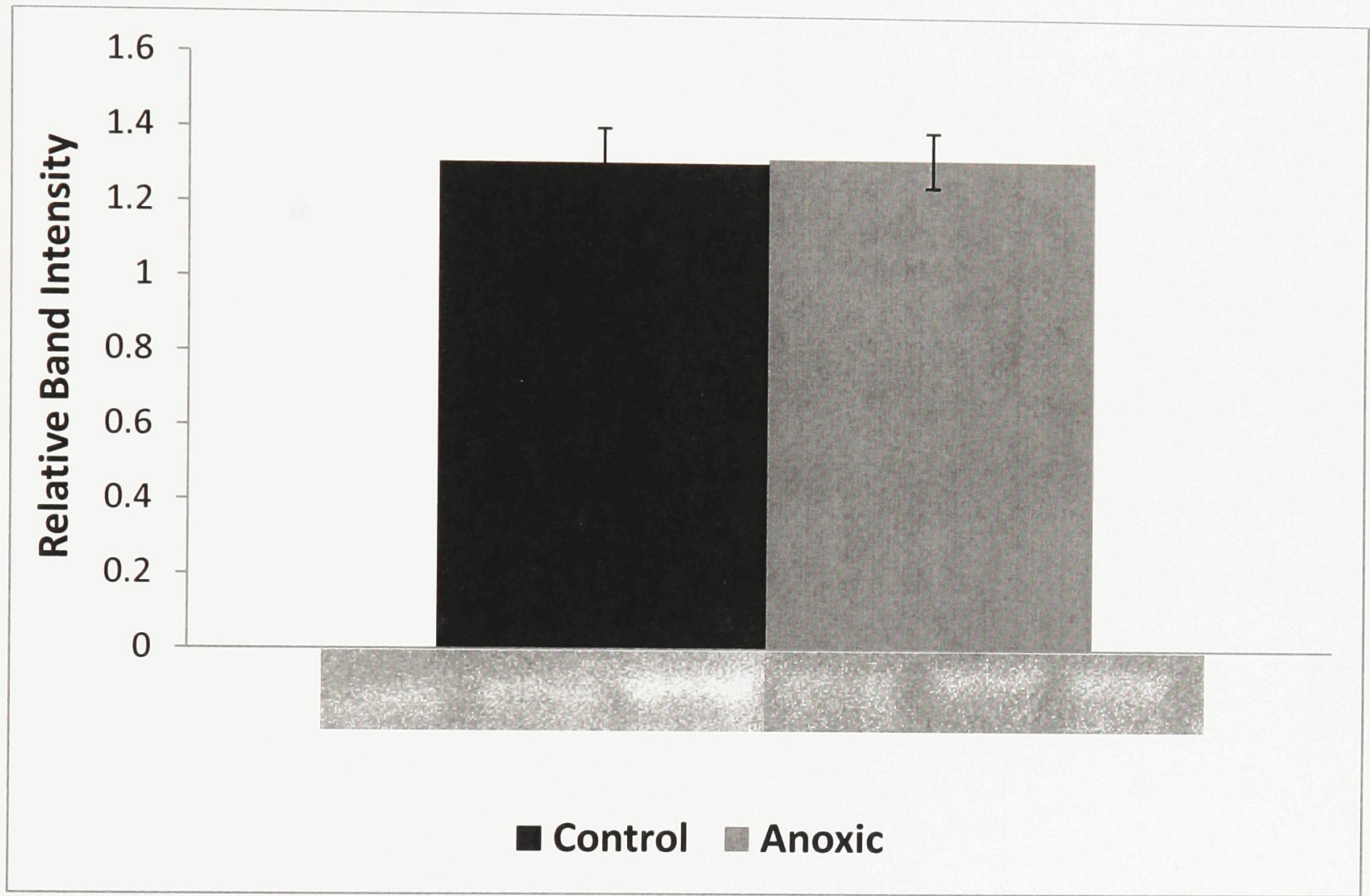


Figure 3.3. $\mathrm{DEAE}^{+}$Sephadex elution profiles for $\mathrm{AK}$ activity from tail muscle tissue from normoxic and anoxic crayfish. AK was eluted using a 0-500 $\mathrm{mM} \mathrm{KCl}$ gradient in column buffer at $\mathrm{pH} 9.0$. 
Figure 3.3

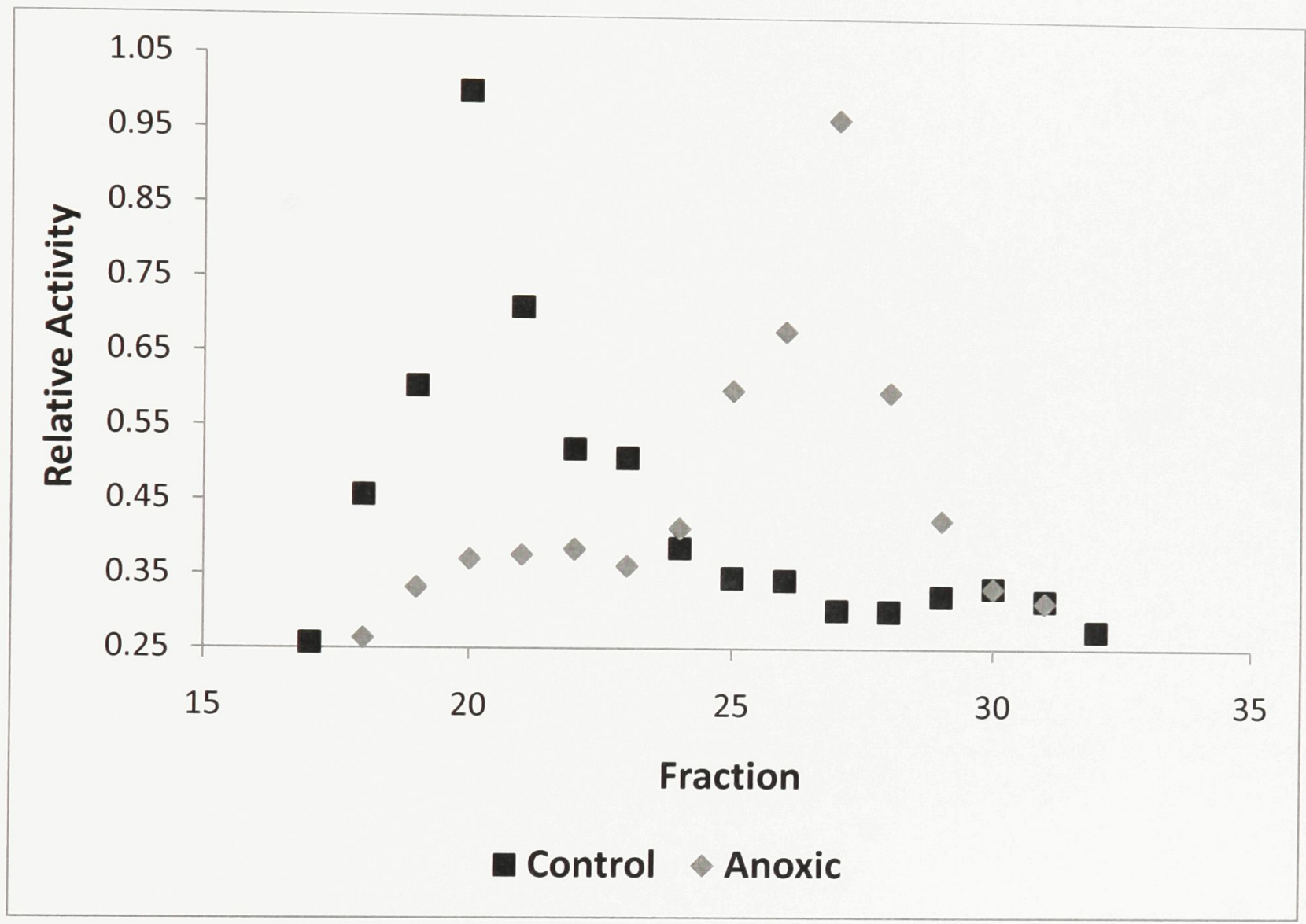


Figure 3.4. A comparison of the relative phosphorylation level of control and anoxic AK from the tail muscle of $O$. virilis using Pro-Q diamond phospho-staining. Data are means + SEM, $n=3$. * - Significantly different from the corresponding control value via the Student's t-test, $\mathrm{p}<0.05$. Coomassie blue staining was used to standardize the amount of protein in each band. 
Figure 3.4

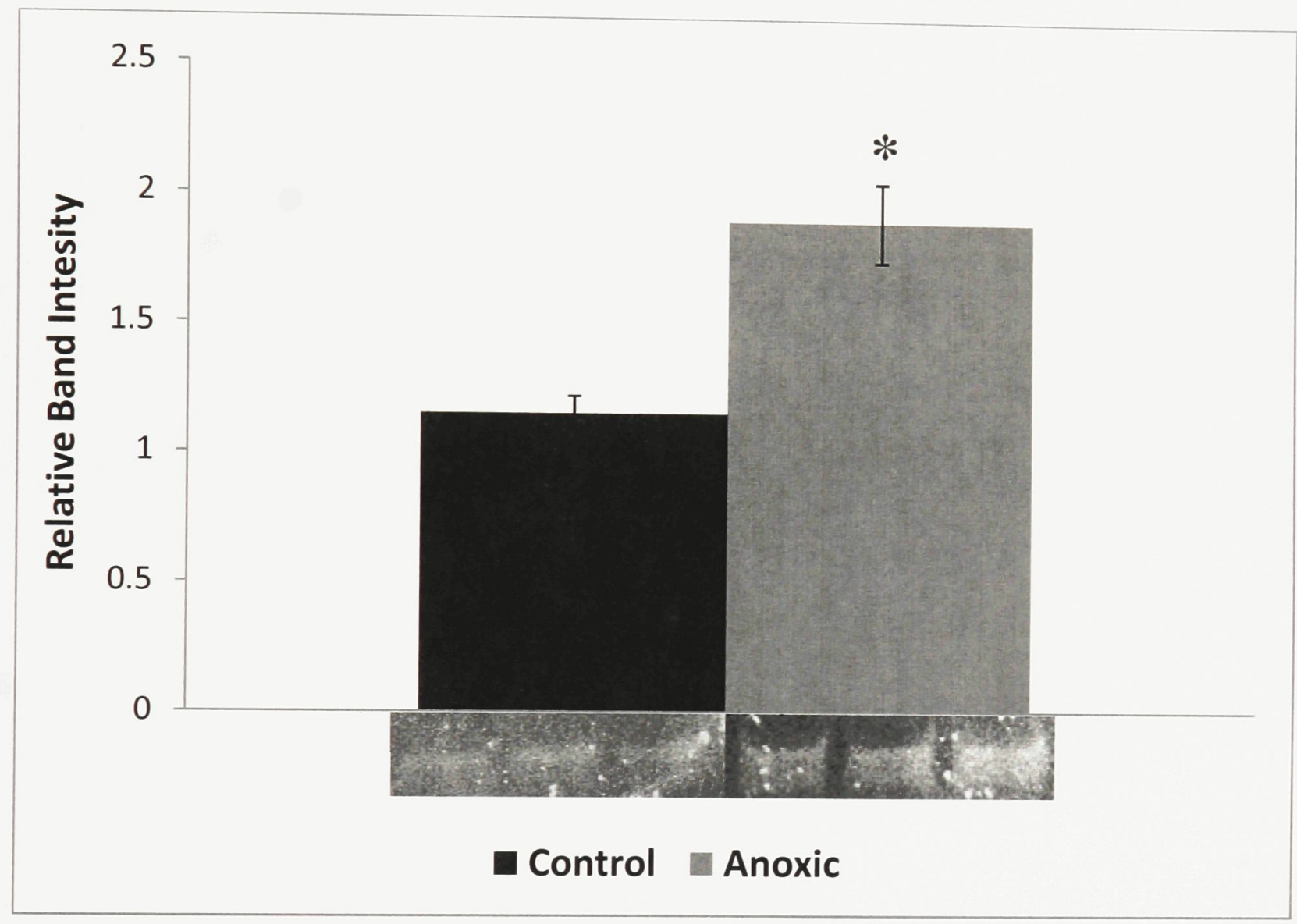


Figure 3.5. Effects of in vitro incubations to stimulate the activities of endogenous protein kinases or phosphatases on the $\mathrm{K}_{\mathrm{m}}$ of L-arginine for $\mathrm{AK}$ in $O$. virilis tail muscle extracts. Crude extracts were incubated for $24 \mathrm{~h}$ before assay at $\sim 4^{\circ} \mathrm{C}$. Data are means + SEM, $n=3$. Stop conditions are control or anoxic samples allowed to incubate in a buffer inhibiting the effect of all protein kinases and phosphatases. Incubations stimulated total serine/threonine phosphatases (PPASE) or the commercial catalytic subunit protein kinase A from rabbit muscle (PKA).

a - Control and anoxic values for this condition are significantly different from each other using the Student's t-test, $\mathrm{p}<0.05$. b -Significantly different from corresponding 'STOP' condition, $\mathrm{p}<0.05$. 
Figure 3.5

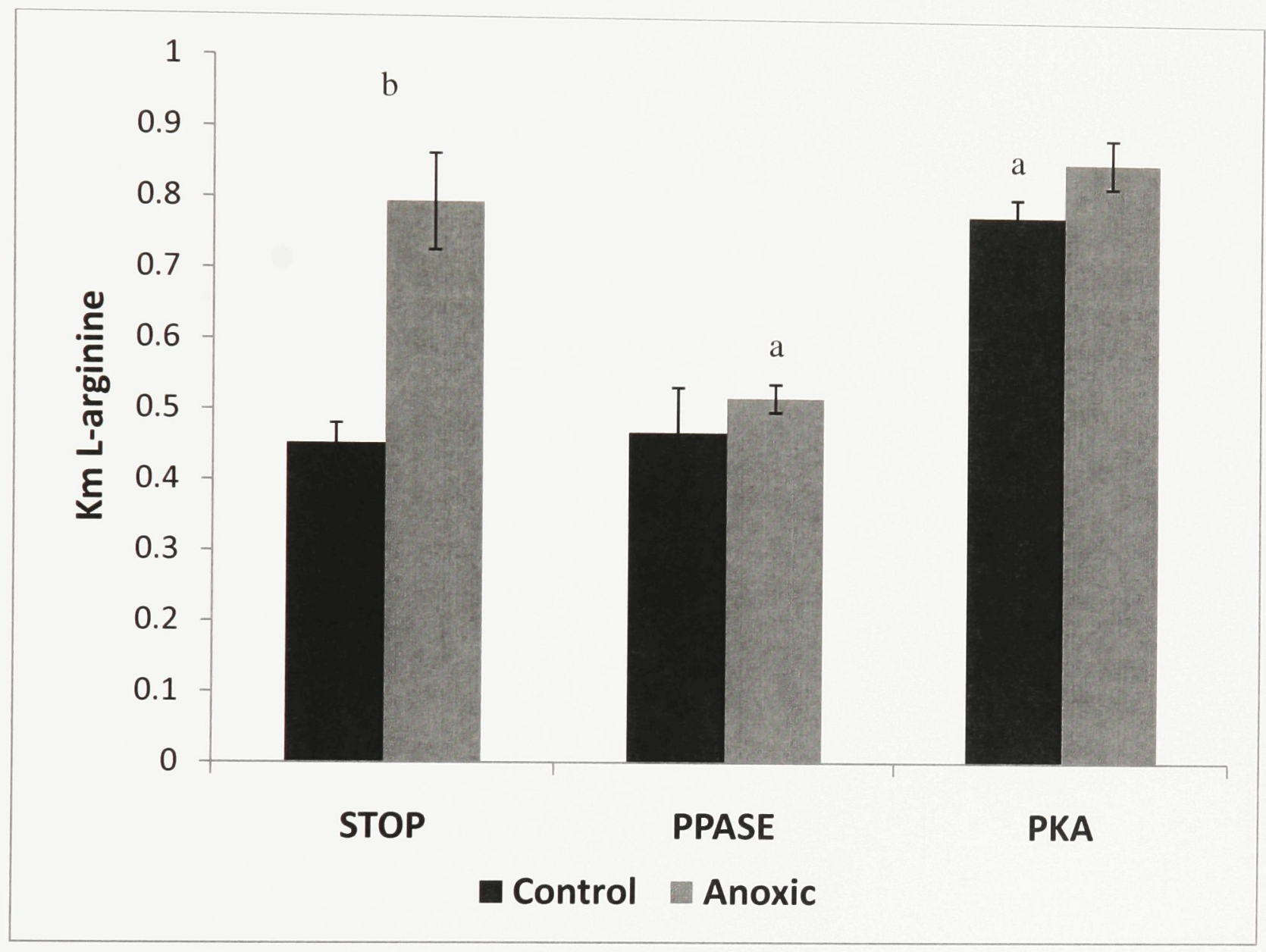


Figure 3.6 (A) Stability of AK from crude extracts of tail muscle. Samples were incubated for $24 \mathrm{~h}$ at $4^{\circ} \mathrm{C}$ with different concentrations of urea and then treated with pulse proteolysis (10 min incubation with thermolysin) to digest denatured AK. Western blotting was then used to measure the amount of remaining folded AK. Figure shows representative results from a total of 3 independent experiments. (B) Effect of $24 \mathrm{~h}$ incubation with different concentrations of urea on the recoverable activity of crude AK. 
Figure 3.6

$\begin{array}{lllllllllll}\text { Urea } & 0 & 1 & 2 & 3 & 4 & 5 & 6 & 7 & 8 \text { M }\end{array}$ Anoxic

$\begin{array}{llllllllll}\text { Urea } & 0 & 1 & 2 & 3 & 4 & 5 & 6 & 7 & 8 \text { M }\end{array}$

Control

A

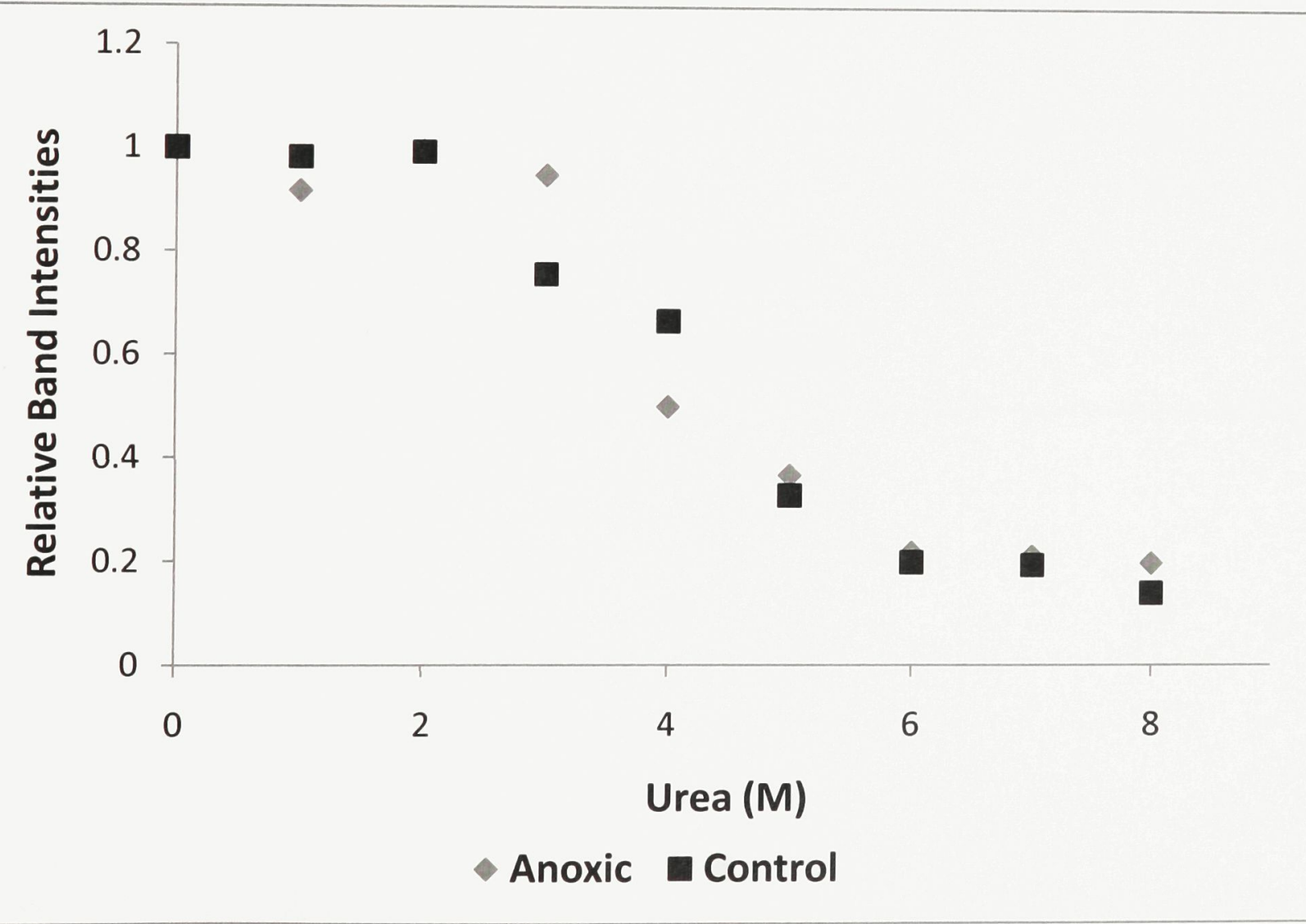




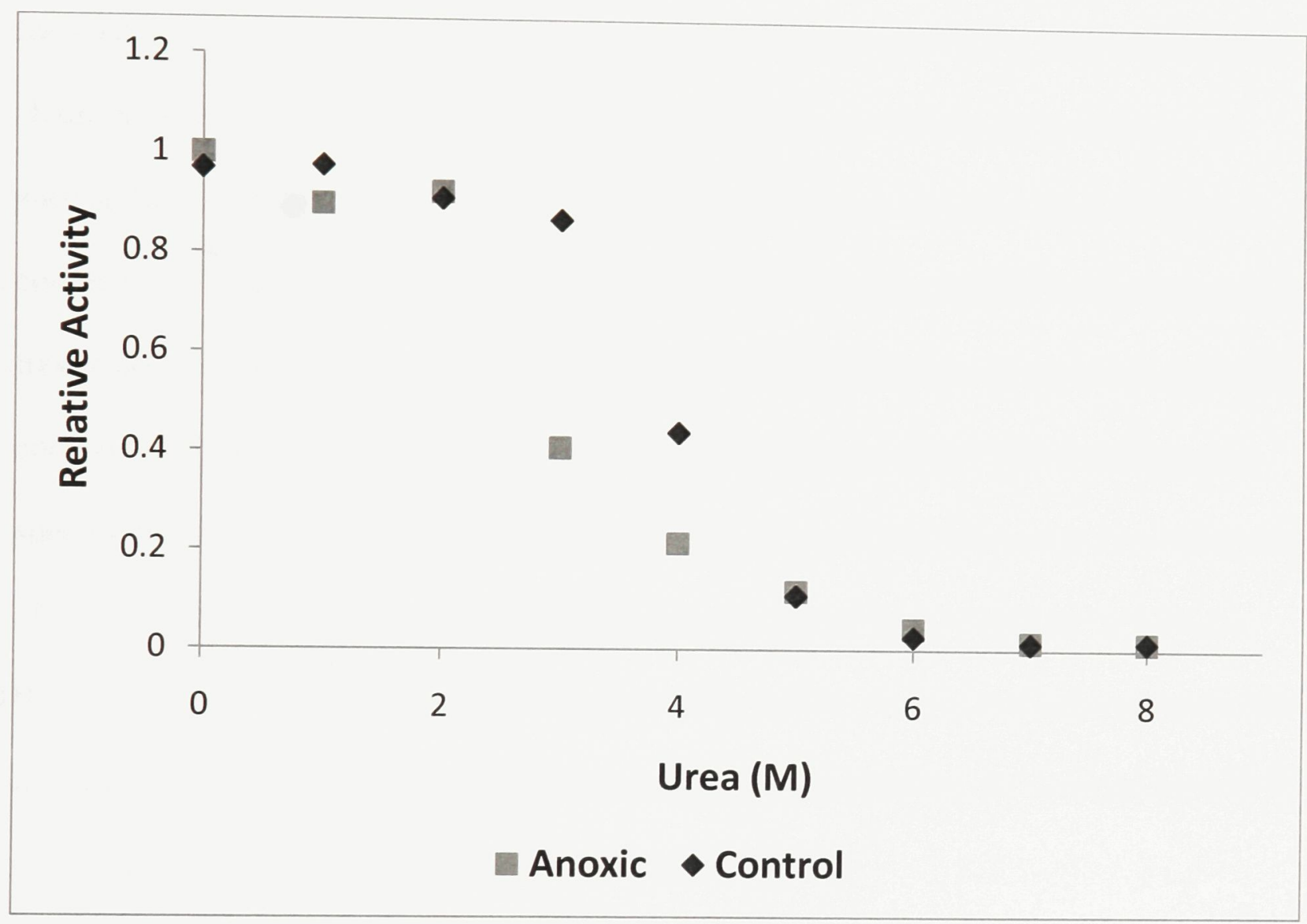




\subsection{Discussion}

Management of muscle energy requirements is essential during periods of stress, as ATP levels can be depleted quickly unless kept in check. During periods of anoxia, ATP generation is drastically reduced (Storey and Storey, 2004) since the cell's major source of ATP production, oxidative phosphorylation by mitochondria, cannot go forward without oxygen which is the terminal electron acceptor of the electron transport chain. Muscle ATP levels in crayfish have been shown to vary greatly in response to anoxia; the crayfish Procambarus clarkii showed significant decreases in ATP levels coupled with large increases in AMP levels (Fujimori and Abe, 2002). Others such as the freshwater crayfish Orconectes Iimosus are able to keep their muscle energy levels fairly constant even in the face of long exposures to anoxia (Gäde, 1984). The latter crayfish species also showed decreases in total phospho-arginine levels and increases in the levels of arginine during exposure to anoxia (Gäde, 1984). In the same study, upon recovery from anoxia, there was a significant increase in the total percentage of arginine phosphate in comparison to the sum of total arginine and arginine phosphate; an increase from 33\% to $59 \%$ of arginine phosphate was observed (Gäde, 1984).

This study shows that there are two distinct forms of $\mathrm{AK}$ in crayfish $(O$. virilis) tail muscle, one that dominates under aerobic control conditions and one that occurs under anoxic conditions. These show different kinetics, and are differentially phosphorylated. The two AK forms showed differences in the binding of arginine. Anoxic AK had a 59\% higher $\mathrm{K}_{\mathrm{m}}$ for $\mathrm{L}$-arginine in comparison to the control conditions (Table 2.1). This suggests that anoxic AK has a lower affinity for L-arginine, meaning that AK in its anoxic form does not facilitate the transfer of ATP to L-arginine as easily 
as its control counterpart. The exact in vivo concentrations of metabolites are not known in $O$. virils, therefore the physiological significance cannot be inferred. Although, the changes discussed in this chapter show the potential for in vivo changes. Once the levels of metabolites are known, we can then infer the physiological significance. Therefore, if these results are found to be significant in a physiological sense, they seem to coincide well with the expected role of AK in an anoxic situation in which the enzyme should be poised to consume arginine phosphate to help support ATP levels under anoxic conditions. The opposite direction, which would "waste" ATP to produce arginine phosphate would be detrimental to the survival of the crayfish in anoxia.

AK catalyses the reversible phosphorylation of L-arginine to phospho-arginine resulting in the consumption or regeneration of ATP. A $59 \%$ increase in the $\mathrm{K}_{\mathrm{m}}$ for Larginine may be indicative of more than a simple reduction in the efficacy of AK to produce phospho-arginine. As L-arginine is the product of the dephosphorylation of phospho-arginine by $\mathrm{AK}$, this may suggest an increase in the rate of product release of AK for L-arginine as a product in the formation of ATP. Therefore, by decreasing the affinity of AK for L-arginine during anoxia, the overall directionality of the reversible reaction catalyzed by AK may be altered during anoxia to favor the production of ATP and L-arginine. As previously discussed, ATP levels typically decrease during anoxia (Fujimori and Abe, 2002; Storey and Storey, 2004), and L-arginine levels increase (Gade, 1984), therefore, these data suggest that AK seems to favor the dephosphorylation of phospho-arginine to generate muscle ATP levels during anoxia.

Past studies haves shown that $\mathrm{CK}$ is subject to reversible phosphorylation in a number of different organisms (Ingwall, 2002; Chida, 1990; Chida et al., 1990; 
Kuzhikandathil and Molloy, 1994; Hemmer et al., 1993). Previous studies have also shown differential phosphorylation during periods of stress. For example, CK from frog (Rana sylvatica) and ground squirrel Spermophilus richardsonii skeletal muscle both appear to exist in high and low phosphate forms (Abnous and Storey, 2007; Dieni and Storey, 2009). The data presented in this chapter also seem to indicate that crayfish tail muscle $\mathrm{AK}$ is a phosphoprotein, and that its phosphorylation state changes between anoxic and control conditions. This suggests that reversible phosphorylation is a form of regulation of AK during anoxia.

Changes in kinetic parameters between two different enzymatic states are often the result of posttranslational modification, quite commonly, reversible phosphorylation. Using ion exchange chromatography, two forms of crayfish muscle AK were resolved (Figures 3.4). The enzyme from aerobic control muscle eluted from DEAE Sephadex at a much lower ionic strength than did the anoxic form of AK. Since phosphorylation increases the negative charge on an enzyme, leading to stronger binding to DEAE and later elution on a salt gradient, these results are consistent with control AK being primarily in the low phosphate enzyme form and anoxic AK being mostly the high phosphate form. To further confirm this designation, extracts from control and anoxic muscle were combined and run together on the ion exchange column; this resulted in two distinct peaks of similar activity. These data, when taken together, suggest that there are two stable forms of $\mathrm{AK}$, a low phosphate form in aerobic control muscle that elutes before the higher phosphate form found in anoxic muscle (Figure 3.4).

Further evidence to support the idea that phosphorylation was the reason for the shift in elution patterns observed between the control and anoxic conditions was obtained 
using ProQ diamond phosphoprotein staining. Purified samples of both anoxic and control AK were separated on SDS-PAGE and then tested using ProQ diamond phosphoprotein staining. Figure 3.3 shows a $64 \%$ greater level of phosphorylation of anoxic AK as compared with the control condition.

Further exploration of reversible phosphorylation as a control mechanism for AK in the tail muscle of $O$. virils came from in vitro incubations that stimulated the activities of alkaline phosphatase. This resulted in a significant decrease in the $\mathrm{K}_{\mathrm{m}}$ arginine of anoxic AK, to a level similar to the value for aerobic control AK incubated under STOP control conditions (Figure 3.5). This suggests that not only is AK more phosphorylated under anoxic conditions, but that it can be dephosphorylated by stimulating endogenous phosphatases. CK from both frog muscle and squirrel muscle also showed kinetic properties that can be altered via the action of endogenous phosphatases on the enzyme (Dieni and Storey, 2009; Abnous and Storey, 2007). Conversely, incubations of the aerobic control enzyme with commercial catalytic subunit PKAc resulted in an increase in the $\mathrm{K}_{\mathrm{m}} \mathrm{L}$-arginine to a value similar to that of anoxic AK under STOP conditions (Figure 3.5). These data provide us not only with information demonstrating that control AK can be phosphorylated, resulting in similar kinetic parameters to the more phosphorylated anoxic form, but suggest also that AK may be phosphorylated at a serine or threonine residue and/or PKA may be the kinase responsible for this phosphorylation in vivo. This is interesting since PKA has been shown to be differentially expressed during anoxia exposure in crayfish; a strong increase in catalytically active PKA occurred during the first 2 hours of anoxia exposure, followed by a reduction in active PKA under prolonged exposure to anoxia (Cowan and Storey, 2001). 
Summed together, the demonstrated responses of AK from control and anoxic conditions to the in vitro incubations, coupled with the elution profiles of control and anoxic AK on DEAE Sephadex, as well as the results from ProQ phosphoprotein staining are all consistent with AK from control conditions being the low phosphate form, whereas AK from anoxic muscle is the high phosphate form.

Western blot analysis of AK in the tail muscle of $O$. virilis did not show any significant changes in total protein expression levels of the enzyme between aerobic and anoxic states. This would suggest that AK is not subject to transcriptional or translational controls after 20 hours of anoxia, as well as indicating that $\mathrm{AK}$ protein levels seem to remain stable (close to control conditions) after 20 hours of anoxia (Figure 3.2).

AK stability may also be affected under anoxic conditions as a consequence of accompanying factors such as temperature changes or $\mathrm{pH}$ fluctuation (cytoplasmic $\mathrm{pH}$ typically drops under anoxia) or as a consequence of differential stability of the phosphorylated versus dephosphorylated forms of AK. Previous studies on isolated AK showed that changes in temperature affect enzyme stability and function (Wu et al., 2009). However, in a study performed by Fan et al., 1992 it was discovered that AK in vivo did not display any changes in kinetic rate constants with varying temperature. Therefore, structural and functional analysis of AK by urea denaturation and pulse proteolysis was explored. Results showed that AK from anoxic muscle was more susceptible to loss of activity due to treatment by urea $\left(\mathrm{I}_{50}\right.$ values were $\sim 3 \mathrm{M}$ urea for anoxic AK compared to $4 \mathrm{M}$ for control AK). However, thermolysin proteolysis revealed no significant changes in band intensities of the enzyme after treatment by urea between the control and anoxic states $\left(\mathrm{C}_{50}\right.$ values were $\sim 4 \mathrm{M}$ urea for both states) (Figure 
3.6). The data produced by this method shows us relative decrease in band intensities of $\mathrm{AK}$, and gives insight into changes of the structural integrity of AK between control and anoxic conditions. The anoxic form of AK had a loss of enzymatic activity at a much lower concentration of urea than in the control condition. The loss of enzymatic activity occurred at a faster rate than the apparent loss of structural integrity as shown by digestion using the pulse proteolysis technique; this suggests first that the active site of the anoxic form of AK is much more susceptible to loss of conformation than overall 3D structure, and secondly that $\mathrm{AK}$ from anoxic conditions is more susceptible to loss of conformation at it's active site than AK from control conditions.

In summary, given that the in vivo levels of ATP are not known for $O$. virils, these changes demonstrate potential for AK to play a role in the maintenance of ATP levels during anoxia. Through the use of reversible phosphorylation, the affinity of anoxic AK for L-arginine is reduced, which suggests that arginine kinase is not involved primarily with the transfer of phosphate from ATP to produce arginine phosphate. Further evidence of a change in conformation of the active site of AK during anoxia is provided by the greater sensitivity of activity to urea denaturation in the anoxic form of AK at a urea concentration lower than that for digestion via thermolysin proteolysis. Therefore, phosphorylation of AK during anoxia may result in a conformational change in the active site for binding L-arginine, facilitating product release and driving the reaction to favor the production of ATP to keep the balance of precious adenylates during this period of low oxygen stress. 


\section{CHAPTER 4}

Regulation of tail muscle hexokinase in the anoxia-tolerant freshwater crayfish, Orconectes

virilis 


\subsection{Introduction}

Hexokinase (HK)(E.C.2.7.1.1) is the enzyme responsible for catalyzing the first step of glucose metabolism, the phosphorylation of glucose to glucose-6-phosphate (G6P):

$$
\text { D-Glucose }+ \text { ATP } \rightarrow \text { D-Glucose-6-phosphate }+ \text { ADP }+\mathrm{H}^{+}
$$

Glucose is a key source of energy for living organisms and is delivered by the blood to all organs of the body. Once transported into cells, glucose is rapidly phosphorylated by HK to form G6P and this allows the sugar to be directed into many different pathways such as; glycolysis to produce ATP, the pentose phosphate pathway to form NADPH and various sugar phosphates, or glycogen as a fuel storage (Wilson, 2003). There have been 4 isozymes reported in mammals, HK I-IV, which are found in different tissues and locations within the cell (Gonzalez et al., 1964; Katzen and Schimke, 1965). HK IV, otherwise known as glucokinase, is liver-specific and is primarily responsible for storing excess sugar into glycogen reserves; it has a high $\mathrm{K}_{\mathrm{m}}$ for glucose.

HK I-III all share a similar molecular weight $(\sim 100 \mathrm{kDa})$ and much lower $\mathrm{K}_{\mathrm{m}}$ values for glucose $(<1 \mathrm{mM})$. HK I-III have been separated by ion exchange chromatography and isoelectric focusing (Gonzalez et al. 1964; Katzen and Schimke, 1965). HK isozymes I-III can bind to the outer membrane of mitochondria via an association with the porin that is located on the outer surface of the mitochondria (Polakis and Wilson, 1985). The isozymes exhibit different kinetic parameters such as their substrate affinities for ATP and glucose, as well as their susceptibility to product inhibition by G6P (Wilson, 2003). 
Crayfish have a significant capacity for long term survival under anoxic conditions by switching to anaerobic glycolysis as their primary ATP-generating pathway and buffering lactate accumulation by $\mathrm{Ca}^{2+}$ release from their carapace (Jackson et al., 2001). Past studies on the regulation of glycolytic enzymes have demonstrated that, in cancer, a delicate interaction between the transcription factors MYC and HIF cause a differential expression of HK II (Dang et al., 2008). As MYC levels decrease and HIF expression increase under low oxygen conditions, HK is upregulated. In addition to altered amounts of HK protein under low oxygen conditions, HK could also be regulated by posttranslational or allosteric mechanisms to alter its activity and/or function under high versus low oxygen conditions. Given the well-developed anaerobic capacity of crayfish, this model would be a good one in which to assess the effects of anoxia on HK regulation, particularly in light of the results from the previous two chapters showing anoxia-responsive regulation of other key enzymes in crayfish muscle.

Previous studies in our lab have shown that one of the mechanisms of HK regulation in response to stress is reversible protein phosphorylation. HKI and II from the skeletal muscle of hibernating ground squirrels (Abnous and Storey, 2008) and HK from the skeletal muscle of freeze-tolerant frogs (Dieni, 2008) was shown to be regulated by reversible phosphorylation.

Given the role of HK in gating glucose entry into glycolysis and the particular importance of HK to energy metabolism under anoxic conditions, as well as the evidence from previous studies of differential regulation of HK in response to stress, the current chapter investigates the regulation of HK during anoxia in the tail muscle of $O$. virilis. I 
hypothesized that HK is differentially regulated during anoxia, and that reversible phosphorylation is the mechanism responsible.

\subsection{Materials and Methods}

\subsubsection{Animals}

Experimental treatment of $O$. virilis was as previously described in Chapter 2.

\subsubsection{Preparation of Tissue Extracts}

Preparation of crayfish trail muscle extracts was performed as previously in Chapter 2, with the following except that in buffer A, $50 \mathrm{mM} \mathrm{NaF}$ was used instead of 30 $\mathrm{mM} \beta$-glycerophosphate at $\mathrm{pH} 7.5$.

To assess the kinetic properties of membrane bound HK, pellets from crude extracts were resuspended in homogenization buffer, recentrifuged, and the supernatant was removed. This was repeated three times to ensure that there was no contaminating cytosolic HK. The resulting pellet was then resuspended in $1 \mathrm{~mL}$ of homogenization buffer and HK was assayed in the pellet fraction.

\subsubsection{Sephadex G-50 filtration of crude extracts}

Low molecular weight metabolites, sugars and ions, were found to interfere with both the purification and kinetic assays of $\mathrm{HK}$, thus, it was necessary to remove these prior to experimental studies. To remove these, Sephadex G-50 gel filtration via spun columns was used as described in Chapter 3. Spun columns were incubated with buffer A 
as per homogenization protocol for kinetic assays, while spun columns were incubated with the same buffer as described in the purification protocol during purification procedures.

\subsubsection{DEAE ion exchange chromatography}

Ion exchange chromatography was used to purify both control and anoxic forms of HK. Muscle extracts were prepared 1:5 w:v in $12.5 \mathrm{mM}$ Tris- $\mathrm{HCl}$ buffer $\mathrm{pH}$ 9.0, 25 mM NaF, 2.5 mM EGTA, $2.5 \mathrm{mM}$ EDTA and $10 \mathrm{mM} \beta$-mercaptoethanol. A $500 \mu \mathrm{L}$ aliquot of crude extract was applied to a DEAE Sephadex G50 column $(1.5 \mathrm{~cm}$ x $5 \mathrm{~cm})$ equilibrated in the buffer mentioned above. The column was washed with this same buffer and then eluted with a linear $\mathrm{KCl}$ gradient $(0-1 \mathrm{M})$ in the same buffer and peak fractions were pooled.

\subsubsection{Purification of HK}

The peak fractions from the DEAE Sephadex G50 column were pooled and applied to a Cibacron Blue 3GA column $(1.5 \mathrm{~cm} \times 5 \mathrm{~cm})$ and eluted under the same conditions as the DEAE column. After both the DEAE and Cibacron Blue steps, the aforementioned spun column protocol was used to remove excess salt from the preparation before assay or application of the enzyme to the next column. Peak fractions were pooled. The purity of HK at each step was checked by running samples on SDSPAGE (as described for Western blotting) with Coomassie blue staining. 


\subsubsection{HK assay}

HK activity was measured as the rate of ADP production coupled to an assay system with glucose-6-phosphate dehydrogenase. Optimal assay conditions for HK were found to be $50 \mathrm{mM}$ Tris buffer $\mathrm{pH}$ 7.5, $10 \mathrm{mM} \mathrm{Mg.ATP,} 10 \mathrm{mM}$ glucose, $10 \mathrm{mM} \mathrm{MgCl}_{2}$, $1.5 \mathrm{mM}$ NADP and 1 unit G6PDH. Enzyme activity was assayed with a Thermo Labsystems Multiskan spectrophotometer at an absorbance of $340 \mathrm{~nm}$. Data was analyzed using Kinetics v.3.5.1 program (Brooks, 1994). One unit of HK activity is defined as the amount that utilizes $1 \mu \mathrm{mol}$ of glucose per minute at $23^{\circ} \mathrm{C}$.

Protein concentrations in tail muscle extracts were determined using the Coomassie blue dye-binding method with the BioRad prepared reagent and bovine serum albumin as a standard.

\subsubsection{In vitro Incubation to Stimulate Protein Kinases and Phosphatases}

Samples of tissue extracts, prepared as previously described, were filtered through a G50 spun column equilibrated in buffer A. Aliquots of the filtered supernatants were incubated for 12 hours at $4^{\circ} \mathrm{C}$ with specific inhibitors and stimulators of protein kinases and phosphatases, as described in Macdonald and Storey (1999). Each aliquot was mixed 1:2 v:v with the appropriate solutions to stimulate either protein kinases or phosphatases. Each solution was prepared in a incubation buffer (50 mM Tris, $10 \%$ v:v glycerol, 30 $\mathrm{mM} \beta$-mercaptoethanol, $\mathrm{pH} 7.5$ ) and the following three incubation conditions were used:

(a) STOP conditions: $2.5 \mathrm{mM}$ EGTA, $2.5 \mathrm{mM}$ EDTA and $30 \mathrm{mM} \beta$ glycerophosphate. 
(b) Stimulation of endogenous kinases: $5 \mathrm{mM} \mathrm{Mg-ATP,} 30 \mathrm{mM} \beta$ glycerophosphate, $1 \mathrm{mM}$ cAMP (to stimulate PKA), $1 \mathrm{mM}$ cGMP (for PKG), $1.3 \mathrm{mM}$ $\mathrm{CaCl}_{2}+7 \mu \mathrm{g} / \mathrm{mL}$ PMA (for PKC), $1 \mathrm{mM}$ AMP (for AMPK), and $1 \mathrm{U}$ of calf intestine calmodulin $+1.3 \mathrm{mM} \mathrm{CaCl}_{2}$ (for $\mathrm{CaMK}$ )

(c) Stimulation of endogenous phosphatases: $5 \mathrm{mM} \mathrm{CaCl}_{2}$ and $5 \mathrm{mM} \mathrm{MgCl}_{2}$.

$\beta$-glycerophosphate was used instead of $\mathrm{NaF}$ during incubations, as $\mathrm{NaF}$ caused precipitation and ultimately failure of the incubation procedure. After incubation, low molecular weight metabolites and ions were removed from the extracts by centrifugation for $2 \mathrm{~min}$ at $2000 \mathrm{rpm}$ through small spun columns of Sephadex G50 equilibrated in buffer A.

\subsubsection{Western blotting of HK}

Western blotting was performed as described in Chapter 2 with the following changes. Incubation was with primary antibody (1:3000 dilution) against muscle HKII (HK goat polyclonal IgG) (Santa Cruz Biotechnology, Santa Cruz, CA, USA) in $10 \mathrm{ml}$ of TBST overnight at $4^{\circ} \mathrm{C}$. Bound antibody was detected with anti-goat IgG secondary antibody (1:3000 dilution) (Santa Cruz Biotechnology, Santa Cruz, CA, USA) and visualized on the ChemiGenius Bioimaging System (Syngene, Frederick, MD).

\subsubsection{ProQ Diamond Phosphoprotein Staining}

Purified tail muscle HK from control and anoxic crayfish were assessed by ProQ Diamond phosphoprotein staining (Invitrogen, Eugene, OR) as described in Chapter 2. 


\subsubsection{Pulse Proteolysis of HK}

Crayfish tail muscle was homogenized as previously described, and the possibility of structural changes of tail muscle HK between the normoxic and anoxic conditions was evaluated. Pulse proteolysis was performed as outlined in Chapter 2.

\subsection{Results}

\subsubsection{Optimization of experimental conditions}

The various components in the homogenization buffers, and assay conditions were evaluated prior to determining kinetic parameters of HK from crayfish tail muscle. It was determined that the inclusion of EGTA and EDTA to the homogenization buffer did not reduce the recoverable activity of $\mathrm{HK}$ in the tail muscle of crayfish in either the control or anoxic conditions. The inclusion of the protein phosphatase inhibitor, $\beta$ glycerolphosphate, significantly decreased the recoverable activity in comparison to $\mathrm{NaF}$ which showed negligible changes in activity. Therefore, NaF, EGTA and EDTA were included in the standard homogenizing buffer. The $\mathrm{pH}$ optimum for $\mathrm{HK}$ was determined to be $\mathrm{pH} 7.5$ and activity remained fairly stable over a large $\mathrm{pH}$ range (7.0-9.0).

\subsubsection{HK Purification}

The purification scheme for tail muscle HK from crayfish is shown in Table 4.1. Two affinity columns, $\mathrm{DEAE}^{+}$Sephadex and Cibacron Blue, were used. Tail muscle HK was purified 10.1 fold with an overall yield of $53.2 \%$. The final specific activity of enzyme was $1.45 \mathrm{U} / \mathrm{mg}$ protein. The success of each purification step was assessed by electrophoresis on an SDS-PAGE gel stained with Coomassie blue staining (Figure 4.1). 
The end result of the purification showed that the enzyme was purified to homogeneity as there is only one strong band corresponding to $\mathrm{HK}$ at the correct molecular weight of $\sim 100 \mathrm{kDa}$ (Gonzalez et al. 1964; Katzen and Schimke, 1965). The same purification protocol was use to purify HK from anoxic crayfish tail muscle.

\subsubsection{HK Kinetics}

Kinetic parameters of tail muscle HK were assessed to determine any differences between control and anoxic forms. Kinetic parameters changed significantly in response to anoxia. As compared to control conditions, the $\mathrm{HK} \mathrm{K}_{\mathrm{m}}$ for glucose increased by $36 \%$ in anoxic muscle and, although $\mathrm{K}_{\mathrm{m}}$ ATP did not change, ATP kinetics showed a shift from a sigmoidal velocity versus [ATP] relationship to Michaelis Menten kinetics ( $h=2.06$ for control, $h=1.33$ for anoxic) (Table 4.2). Furthermore, $H K V_{\max }$ increased by 2.74 fold under anoxia.

Muscle HK is known to bind to mitochondria and a as a result, some percentage of muscle HK will undoubtedly remain in the pellet after homogenization and centrifugation. A change in the amount of bound HK between control and anoxic states could potentially be the cause of the above-mentioned large increase in HK activity in soluble extracts under anoxic conditions. After removal of soluble HK in the supernatant after the first centrifugation, the pellet was resuspended, recentrifuged and washed three times (the washes were added to the soluble fraction) and then the pellet was resuspended a final time and activity of HK in the bound fraction and the soluble fraction was assessed. Fig. 4.2 shows that there was a significant decrease $(\mathrm{P}<0.05)$ in the amount of bound HK activity during anoxia (11.3\% of total ) as compared to control aerobic 
conditions ( $30.9 \%$ bound).

\subsubsection{HK protein levels}

Western blotting was used to evaluate the relative amount of HK protein in tail muscle from control versus anoxic crayfish. Antibodies detecting mammalian HK crossreacted with the crayfish protein and showed one strong band at the expected molecular weight of $\sim 100$ kDa for HK (Gonzalez et al. 1964; Katzen and Schimke, 1965). A comparison of control versus anoxic conditions showed a significant increase in HK protein content of $43 \%$ under anoxia (Figure 4.3).

\subsubsection{Phosphorylation State of HK}

High and low phosphate forms of enzymes can be resolved using ion exchange chromatography due to a change in net charge of an enzyme arising from the addition of negatively charged phosphate groups onto an enzyme when it is phosphorylated Figure 4.4 shows the elution patterns for both aerobic control and anoxic HK activity after chromatography on a DEAE-Sephadex column with elution using a 0-1 $\mathrm{M} \mathrm{KCl}$ gradient. HK from aerobic control crayfish muscle eluted in one large broad peak between the $45^{\text {th }}$ and $58^{\text {th }}$ fractions, whereas the anoxic form of HK eluted earlier on the salt gradient between the $35^{\text {th }}$ and $47^{\text {th }}$ fractions. This indicates a substantial change in the net charge state of the enzyme between control and anoxic conditions, probably due to a change in the amount of covalently bound phosphate on the protein.

To test whether or not reversible phosphorylation was the mechanism by which HK kinetic parameters had changed, the top 3 fractions from the control and anoxic peaks 
eluted off the above DEAE columns were pooled and aliquots containing equal amounts of soluble protein were loaded onto gels and subjected to SDS-PAGE, followed by staining with ProQ Diamond phosphoprotein stain. HK was easily identified since the extract was previously purified, and a strong band was seen $\sim 100 \mathrm{kDa}$. Phosphoprotein staining showed a strong $39 \%$ decrease in the relative band intensity for the purified anoxic HK when compared to the control condition $(\mathrm{p}<0.05)$ (Figure 4.5).

\subsubsection{In vitro Incubation to Stimulate Protein Kinases and Phosphatases}

To investigate the possibility of phosphorylation as a regulatory mechanism for HK in crayfish tail muscle, crude enzyme from both control and anoxic muscle were incubated under conditions that stimulated either endogenous protein kinases or protein phosphatases and compared with incubations where both kinases and phosphatases were inhibited (denoted STOP). Results for the STOP condition showed a significant difference $(\mathrm{p}<0.05)$ in the $\mathrm{K}_{\mathrm{m}}$ of glucose for HK between the control and anoxic conditions and these STOP conditions served as the basis for evaluating the effects of incubations that promoted the activities of total endogenous protein phosphatases (PP1+PP2A, PP2B, PP2C) and total endogenous protein kinases (AMPK, PKA, PKC, PKG, CaMK). However, neither total phosphatase nor total kinase stimulations significantly altered the $\mathrm{K}_{\mathrm{m}}$ for glucose of either control or anoxia $\mathrm{HK}$ as compared to the corresponding STOP conditions (Figure 4.6).

\subsubsection{Structural Stability of Crayfish Tail Muscle HK}

The structural stability of HK was evaluated by testing the enzyme sensitivity to 
urea denaturation followed by proteolysis with thermolysin to degrade unfolded denatured enzyme. The amount of native protein remaining was then assessed by Western blotting. The calculated $\mathrm{C}_{50}$ value (concentration of urea that results in $50 \%$ loss of folded GDH) was 5.97 M urea for HK from anoxic tail muscle, which was significantly higher in comparison to the mean value of $4.48 \mathrm{M}$ urea for HK from control tail muscle $(\mathrm{P}<0.05)$ (Table 4.2; Figure 4.7). 
Table 4.1 Purification of HK from tail muscle of control crayfish.

\begin{tabular}{|c|c|c|c|c|c|}
\hline Purification Step & $\begin{array}{c}\text { Total } \\
\text { Protein } \\
(\mathrm{mg})\end{array}$ & $\begin{array}{c}\text { Total } \\
\text { Activity } \\
(\mathrm{U})\end{array}$ & $\begin{array}{c}\text { Specific } \\
\text { Activity } \\
(\mathrm{U} / \mathrm{mg})\end{array}$ & $\begin{array}{c}\text { Fold } \\
\text { purification }\end{array}$ & $\begin{array}{c}\text { Yield } \\
(\%)\end{array}$ \\
\hline Crude Extract & 0.962 & 13.82 & 1.44 & - & 100 \\
\hline DEAE $^{+}$Sephadex & 0.554 & 10.03 & 1.81 & 1.26 & 72.6 \\
\hline Cibacron Blue & 0.051 & 7.36 & 14.46 & 10.06 & 53.2 \\
\hline
\end{tabular}


Table 4.2 Comparison of kinetic parameters of crude HK from tail muscle of control and anoxic crayfish assayed at $23^{\circ} \mathrm{C}$. Data are means $\pm \mathrm{SEM}, \mathrm{n}=4$.

* - Significantly different from the corresponding control value using the Student's t-test, $\mathrm{P}<0.05$.

\begin{tabular}{|c|c|c|}
\hline & Control & Anoxic \\
\hline $\mathrm{K}_{\mathrm{m}}$ Glucose $(\mathrm{mM})$ & $0.11 \pm 0.01$ & $0.15 \pm 0.01^{*}$ \\
\hline $\mathrm{K}_{\mathrm{m}}$ ATP $(\mathrm{mM})$ & $0.36 \pm 0.02$ & $0.32 \pm 0.01$ \\
Hill Coefficient & $\mathrm{h}=2.06 \pm 0.03$ & $\mathrm{~h}=1.33 \pm 0.07 *$ \\
\hline $\mathrm{V}_{\mathrm{max}}(\mathrm{U} / \mathrm{g}$ wet weight $)$ & $19.34 \pm 0.58$ & $52.95 \pm 1.53 *$ \\
\hline $\mathrm{C}_{50}$ Urea $(\mathrm{M})$ & $4.48 \pm 0.36$ & $5.97 \pm 0.51 *$ \\
\hline
\end{tabular}


Figure 4.I SDS-PAGE with Coomassie blue staining of samples taken at every step in the purification of HK from the tail muscle of control O. virilis. Lanes represent: (1) Crude tail extract, (2) pooled HK fractions after elution from a DEAE Sephadex column, (3) pooled HK from a Cibacron Blue agarose column, and (4) Fermentas PageRuler Prestained Protein Ladder molecular weight standards ( $3 \mu \mathrm{L})$. 
Figure 4.I

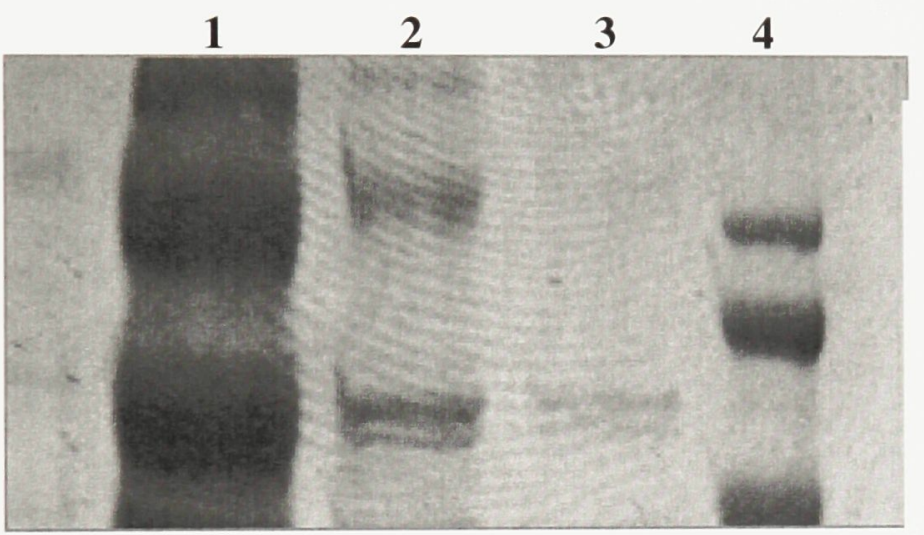

Da

Da

a 
Fig. 4.2 Distribution of HK between cytoplasmic and bound states in tail muscle extracts of control and anoxic crayfish. Total HK is cytoplasmic HK + bound HK. Data are expressed in milliunits per $\mathrm{mg}(\mathrm{mU} / \mathrm{mg})$ protein, means $\pm \mathrm{SEM}, \mathrm{n}=3$.

* - Significantly different from the corresponding control value, $\mathrm{P}<0.05$. 
Fig. 4.2

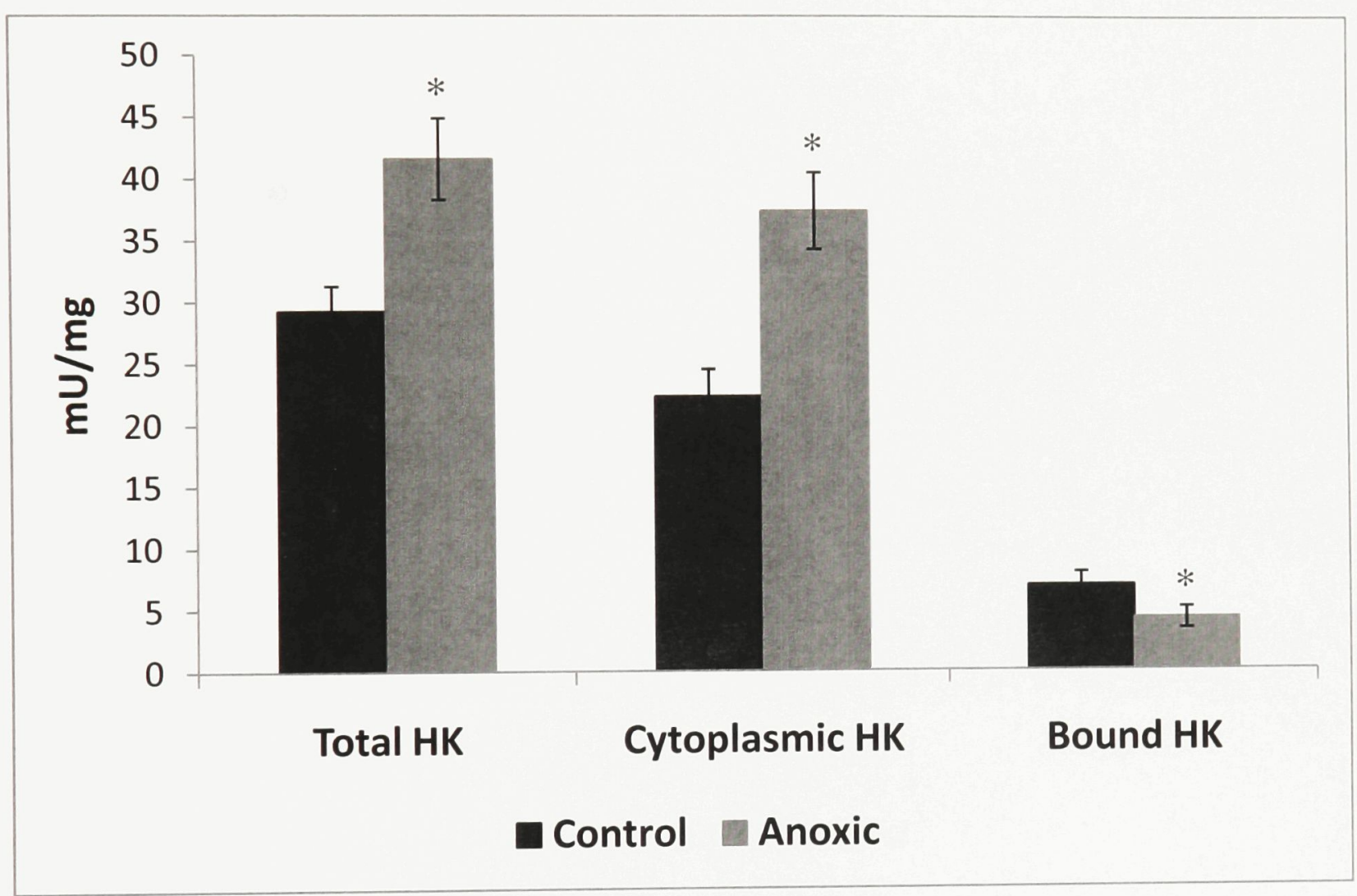


Figure 4.3 Western blotting analysis of the amount of HK protein in the tail muscle of O. virilis showing upregulation of protein amount from control to anoxic conditions. Data are means \pm SEM, $n=3$. Coomassie blue staining was used to standardize the amount of protein in each band.

* - Significantly different from the corresponding control value via the Student's t-test, $\mathrm{p}<0.05$. 
Figure 4.3

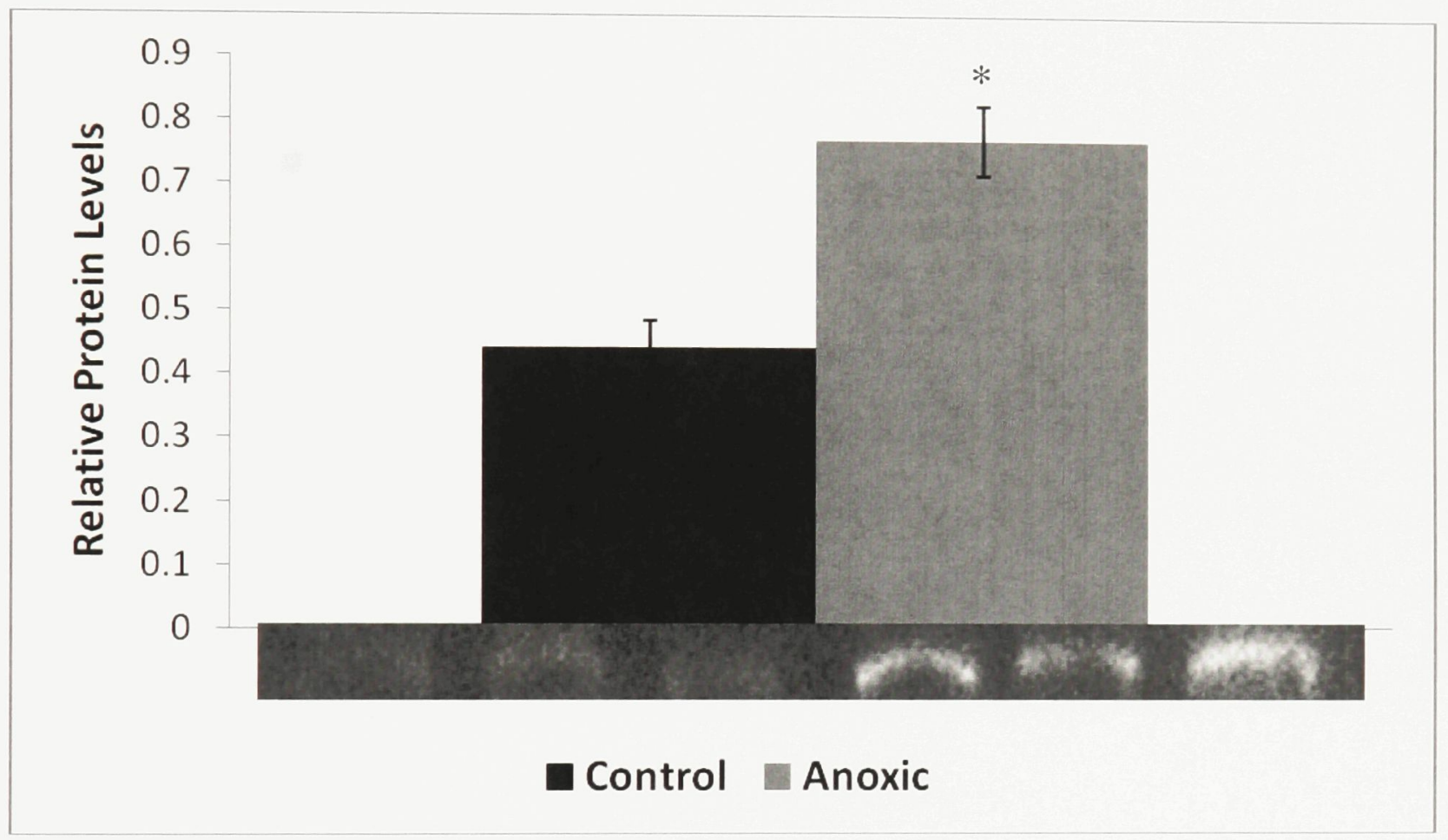


Figure 4.4 $\mathrm{DEAE}^{+}$Sephadex elution profiles for $\mathrm{HK}$ activity from tail muscle from normoxic and anoxic crayfish. $\mathrm{HK}$ was eluted using a 0-500 $\mathrm{mM} \mathrm{KCl}$ gradient in column buffer at $\mathrm{pH}$ 9.0. Activity profiles are expressed relative to activity in the peak tube. Control and anoxic extracts were run separately and then activity profiles were superimposed in one graph. The data are representative of $n=3$ trials on separate preparations of enzyme. 
Figure 4.4

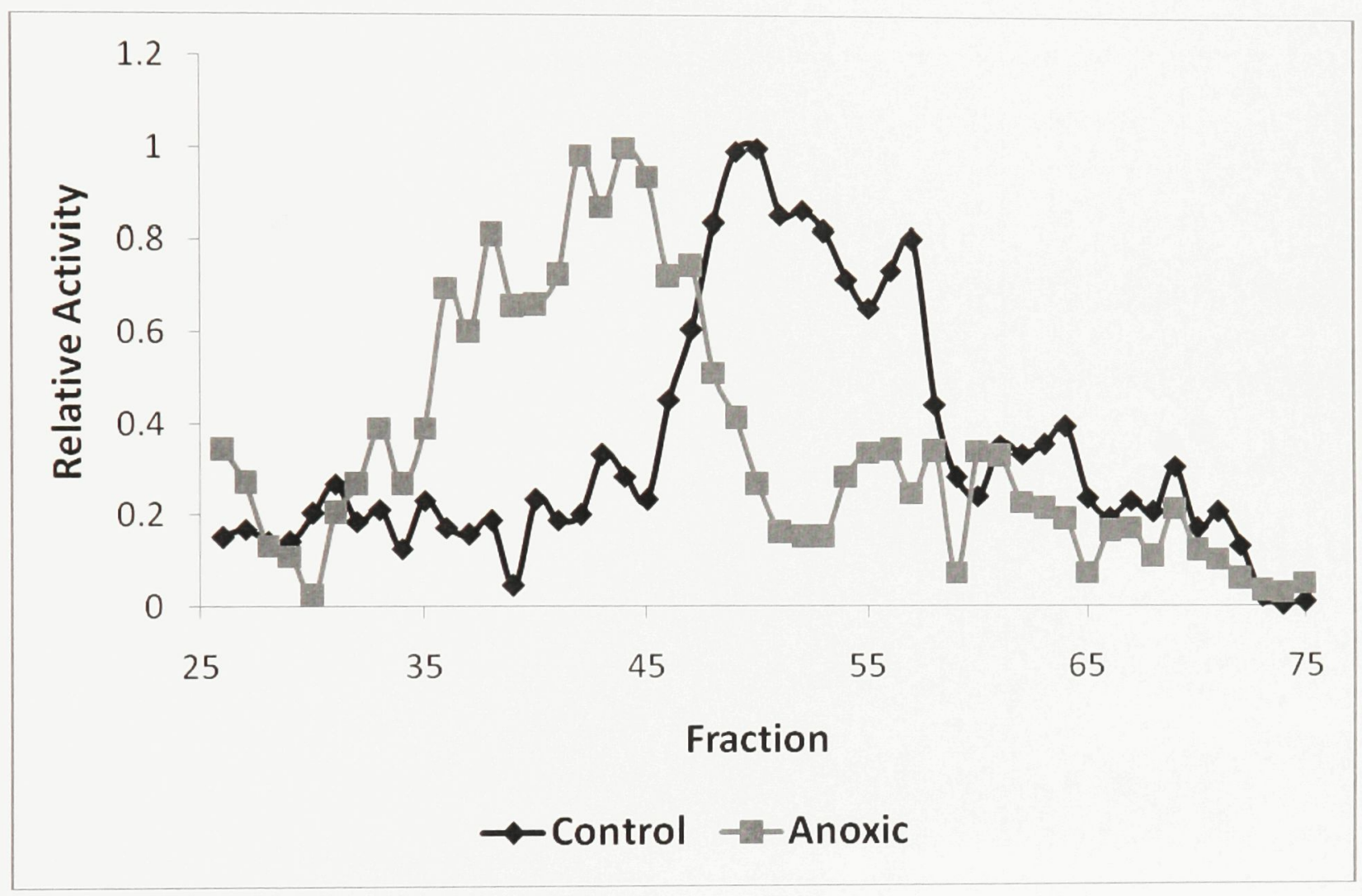


Figure 4.5 A comparison of the relative phosphorylation state of control and anoxic HK from the tail muscle of $O$. virilis using Pro-Q diamond phospho-staining. Data are means + SEM, $n=4$. Coomassie blue staining was used to standardize the amount of protein in each band.

* - Significantly different from the corresponding control value via the Student's t-test, $\mathrm{p}<0.05$. 
Figure 4.5

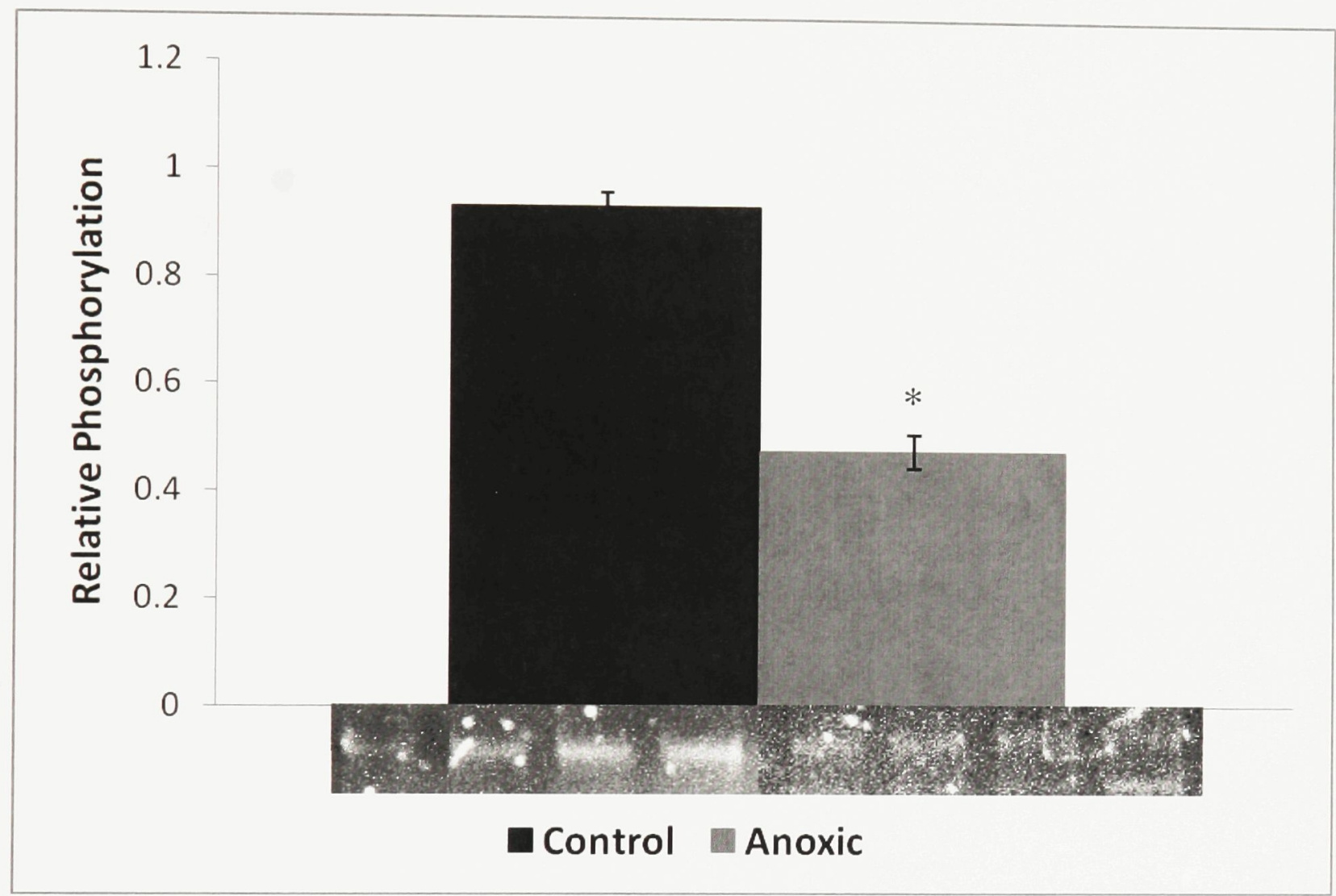


Figure 4.6 Effects of in vitro incubations that stimulated the activities of endogenous protein kinases or protein phosphatases on the $\mathrm{K}_{\mathrm{m}}$ of glucose of $\mathrm{HK}$ from $O$. virilis tail muscle extracts. Crude extracts were incubated at $4^{\circ} \mathrm{C}$ for $24 \mathrm{~h}$ before assay. Data are means \pm SEM, $n=3$. Stop conditions contained inhibitors of all protein kinases and phosphatases. Other incubations stimulated total phosphatases (TPP) or total kinases (TK).

* - Significantly different from the corresponding control value via the Student's t-test, $\mathrm{p}<0.05$. 
Figure 4.6

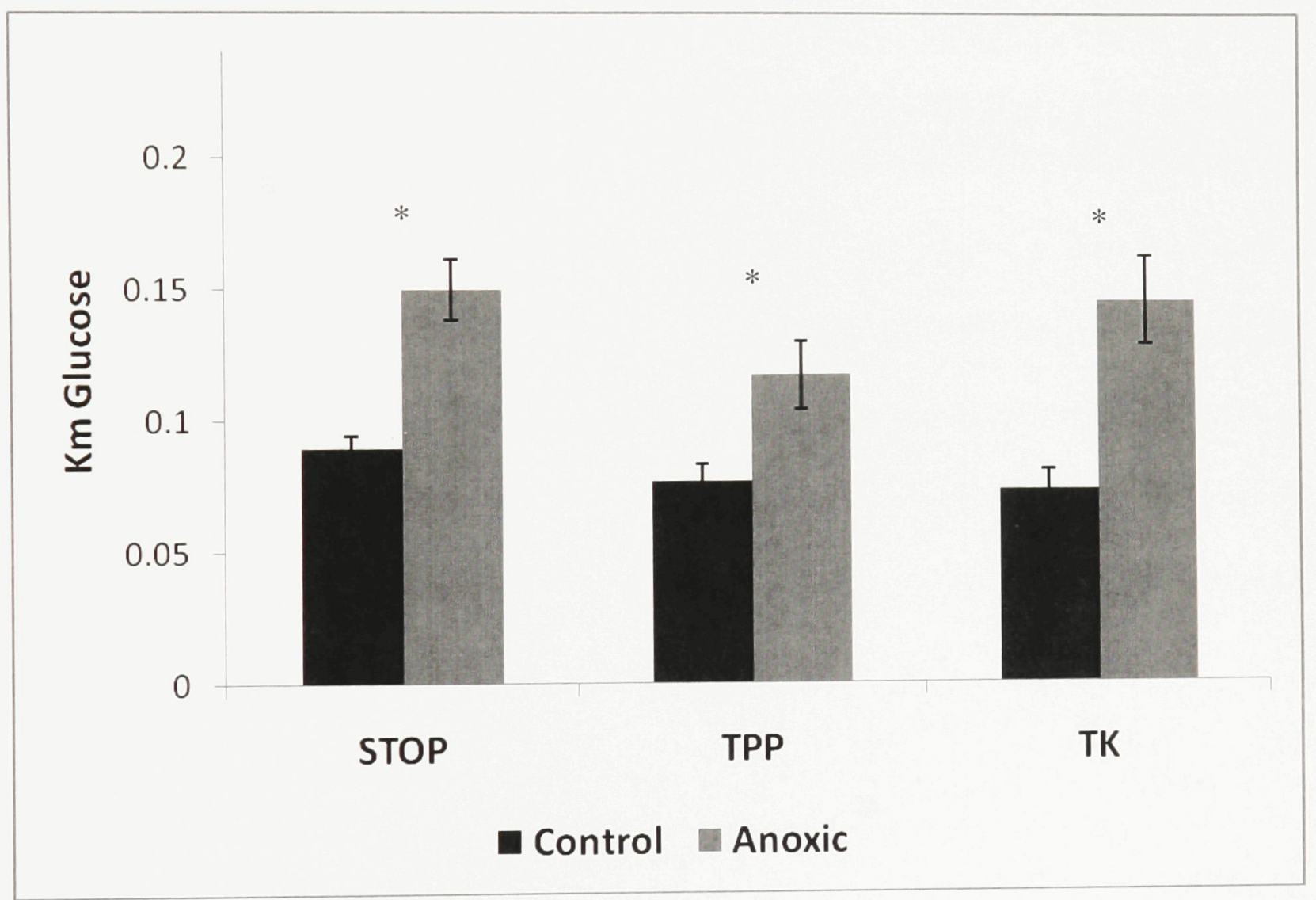


Figure 4.7 Stability of HK from crude extracts of tail muscle. Samples were incubated for $24 \mathrm{~h}$ at $4{ }^{\circ} \mathrm{C}$ with different concentrations of urea and then treated with pulse proteolysis (10 min incubation with thermolysin) to digest denatured HK. Western blotting was then used to measure the amount of remaining folded HK. Figure shows representative results from a total of 3 independent experiments. 
Figure 4.7

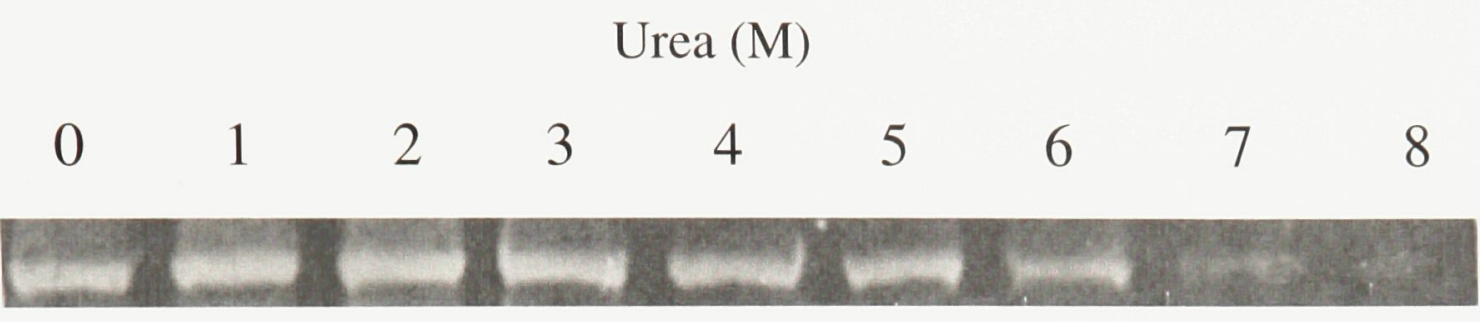

Anoxic

Control

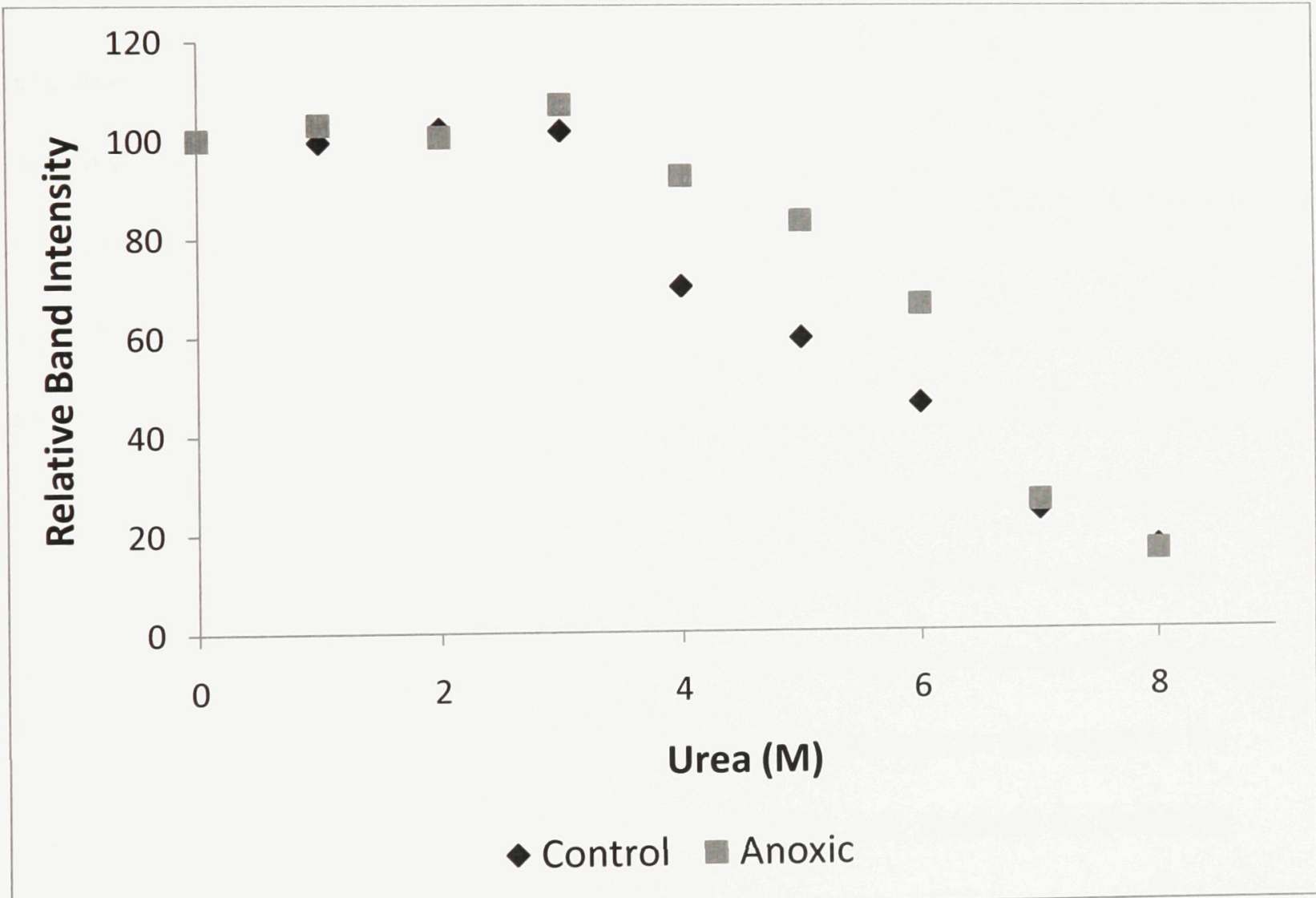




\subsection{Discussion}

During exposure to severe hypoxia or anoxic conditions, organisms that have evolved to tolerate such exposures, cope with oxygen limitation by entering a hypometabolic state where ATP demand and metabolic fuel use are greatly reduced. By doing so, they greatly extend the time that body fuel reserves can support survival and, in the case of oxygen deprivation, lower metabolic rate to a level that can be supported by the ATP output of anaerobic pathways (chiefly glucose or glycogen catabolism by glycolysis ending in lactate). Of particular interest is the regulation of those pathways responsible for fuel catabolism and ATP generation. Most anoxia tolerant species show a switch from aerobic metabolism that is probably primarily based on lipid catabolism to anaerobic metabolism that must be based primarily on carbohydrate fermentation. Many invertebrates have boosted their capacity for anaerobic ATP production by making use of additional fermentable substrates (some amino acids) and linking the output of glycolysis (pyruvate) into further reactions that yield extra ATP while producing end products including succinate, propionate and acetate (Storey and Storey, 2004 - see below). However, this is not true of crustaceans, so their survival relies on anaerobic glycolysis alone with lactate as the end product. Some enhancements improve the capacity for anaerobic ATP production (e.g. large stores of glycogen fuel, methods for buffering lactate production) and metabolic rate depression lowers the ATP demand. Muscle tissue is a prime candidate for requiring a basal level of metabolism under anoxia to maintain basal cell function, to sustain the transmembrane ion gradients that support contraction by tail muscle should the animal need to flee danger, and to remain prepared for recovery from the anoxic state. 
$\mathrm{HK}$ is the first enzyme involved in the breakdown and use of glucose as a fuel, therefore, the regulation of HK is vital to understanding carbohydrate metabolism during anoxia. At first glance, the kinetic parameters of HK in the tail muscle of the freshwater crayfish, $O$. virilis, seem to indicate that $\mathrm{HK}$ is less active during the anoxic state, since there is a significant $(\sim 36 \%)$ increase in the $\mathrm{K}_{\mathrm{m}}$ glucose in transitioning from the control to anoxic state (Table 4.2). However, a large 2.74-fold increase in the maximal activity of HK also occurs during anoxia. This dramatic increase in enzyme activity is indicative of a major change in the regulation of HK. Such a change in maximal activity could be based on allosteric regulation, transcriptional or translational regulation, posttranslational modifications, or changes in the distribution of HK between free and bound states. In previous studies, increased activity of HK has been observed during hypoxia or anoxia in many different species and tissues such as; anoxic rat heart muscle (Regen et al., 1964), hypoxic pancreatic or liver cancer cells (Natsuizaka et al., 2007; Yasuda et al., 2003), anoxic plant seedlings (Fox et al., 1998), as well as anoxic maize roots (Bouny and Saglio 1996).

Western blotting was implemented to determine if the large, 2.74 , increase in HK enzymatic activity during anoxia was due to a change in HK protein expression. The results showed a significant increase in the amount of HK protein in muscle under anoxic conditions in comparison to control conditions (Figure 4.3). An up-regulation of HK gene expression to produce more HK protein under low oxygen conditions is conducive to a potential enhancement of glycolytic potential (Dang et al. 2008), which agrees with the needs of an anoxic crayfish. In the same study, a cooperative activation of both HK2 and 
pyruvate dehydrogenase kinase 1 (PDK1) (which inhibits pyruvate dehydrogenase to shut down pyruvate use by mitochondria) were shown to occur in hypoxic cancer cells, ultimately resulting in an increase in the glycolytic conversion of glucose to lactate. These results are indicative of an increase in anaerobic metabolism during low oxygen events and this also seems to be the case for crayfish muscle.

Although there is strong evidence to support a translational regulation of HK in crayfish muscle in response to anoxia, this does not account for the changes in kinetic parameters discovered in the anoxic state. Therefore, further exploration into the regulation of $\mathrm{HK}$ is required. Kinetic parameters can often be manipulated via posttranslational modification of an enzyme, often by reversible phosphorylation. Through the use of ion exchange chromatography, two distinct elution profiles were seen for HK from anoxic and control muscle samples, suggesting that there are two forms of crayfish muscle HK that differ in their charge state (Figure 4.4). The enzyme from anoxic tail muscle eluted from DEAE Sephadex at a lower ionic strength than did the control form of AK. Since phosphorylation increases the negative charge on an enzyme, leading to stronger binding to DEAE and later elution on a salt gradient, these results suggest that anoxic HK is present primarily in a low phosphate form, whereas the control form is present mostly in a high phosphate form.

To determine if the ion exchange data above was truly the result of a change in phosphorylation state, ProQ diamond phosphoprotein staining was used. Samples of DEAE Sephadex purified AK from both anoxic and control conditions were separated on SDS-PAGE and then tested using ProQ diamond phosphoprotein staining. Figure 4.5 
shows a greater level of phosphorylation of control HK as compared with the anoxic condition. This confirms the ion exchange data and allows the conclusion that $\mathrm{HK}$ is subject to anoxia-responsive changes in its phosphorylation state with the anoxic versus control forms being the low versus high phosphate forms, respectively.

Further exploration of this change in phosphorylation state, and the impact on HK kinetic parameters was explored. Incubations which stimulated total phosphatase and total kinase activity were utilized to elucidate any potential changes in kinetic parameters, which mirror a change in the phosphorylation of the enzyme. Data obtained from incubations exploring the change in the $\mathrm{K}_{\mathrm{m}}$ for glucose in tail muscle $\mathrm{HK}$ showed no significant changes despite the use of incubations that stimulated either kinase or phosphatase activity (Figure 4.6). This suggests that the kinetic change in the affinity of HK for glucose noticed during anoxia is not a result of reversible phosphorylation.

Another parameter that was explored in both anoxic and normoxic states was the stability of HK. The ability of yeast HK to bind glucose is dependent on a conformational change in the enzyme (Bennet and Steitz, 1978). Therefore, changes in the stability of HK may arise due to post-translational modification such as reversible phosphorylation. Structural analysis of HK by urea denaturation and pulse proteolysis was explored. Results showed that HK from control muscle was more susceptible to conformational denaturation by urea as assessed by the subsequent destruction of denatured protein by thermolysin (Figure 4.7). This suggests that reversible phosphorylation may be affecting the structural configuration and susceptibility of HK to urea denaturation. Phosphorylation of an enzyme introduces a large negative charge, 
which may affect the structural arrangement of an enzyme, either making it more or less stable (Newton, 2003).

Crayfish muscle HK also showed a significant decrease in the percentage of bound HK versus soluble cytosolic HK during anoxia (Figure 4.2). Phosphorylation can often affect the subcelluar location of an enzyme (Edwards et al. 1999; Hsu et al. 1997; Saitoh and Schwartz, 1985). Studies have shown that bound HK (associated with mitochondrial porins) prefers to use ATP generated in the mitochondria rather than cytosolic ATP (Arora and Pederson, 1988). Since generation of ATP by mitochondria is essentially halted during anoxia, this source of ATP for HK would be wiped out. This would result in a need for HK to use ATP generated by glycolysis in the cytosol, probably requiring a release of $\mathrm{HK}$ from binding interactions and resulting in an increased amount of $\mathrm{HK}$ in the soluble cytoplasmic fraction.

In conclusion, the regulation of crayfish tail muscle HK during anoxia seems to be a complex chain of events. The activity and protein content of $\mathrm{HK}$ increases during anoxia, as does the amount of soluble HK (released from mitochondrial binding), the enzyme undergoes dephosphorylation and shows alters kinetic properties and an increase in the susceptibility to urea denaturation. All of these factors could readjust HK for a key role in optimizing glycolytic energy production under anoxic conditions. Changes in the phosphorylation state of tail muscle $\mathrm{HK}$ in anoxia may be responsible for a variety of the anoxia-induced effects on HK properties. Thus, the aerobic control enzyme is more phosphorylated, less stable, and has a higher percentage of bound enzyme, whereas the less phosphorylated anoxic form of HK is more stable, yet has less bound enzyme. 
CHAPTER 5

\section{General Discussion}




\section{General Discussion}

There are many organisms which inhabit environments where they experience varying degrees of oxygen availability and the survival of these organisms hinges upon their ability to adapt metabolically to endure these hypoxic or anoxic conditions. A capacity to withstand low oxygen conditions is a crucial factor in the life of many freshwater invertebrates. These animals may encounter variable oxygen in their environment for a number of different reasons including; high pollution, streams and ponds which dry out seasonally, or oxygen depletion arising from high summer temperatures that lower water oxygen content or due to oxygen consumption by animal/plant/bacterial respiration in ice-locked waters in winter. One such organism that can survive significant periods of environmentally induced anoxia is the freshwater crayfish, O. virilis (Cowan and Storey, 2001).

Many anoxia tolerant species use metabolic rate depression as a crucial component of their survival strategy. When oxygen drops below a critical point, a coordinated suppression of many cellular processes begins, ultimately reducing the rate of ATP turnover by $>90 \%$ in many cases. This reduction in ATP usage is achieved by coordinating and reprioritizing the rates of ATP-using versus ATP-producing pathways so that homeostasis is reestablished at a much lower global rate of ATP turnover. Past studies have shown that the major regulatory mechanism operating to achieve metabolic depression across phylogeny is reversible protein phosphorylation (Storey and Storey, 1990; Storey and Storey, 2007). During anoxia, carbohydrate catabolism by glycolysis is

often the sole source of ATP, and control over this pathway is vital for the survival of the organism. Key regulatory enzymes of the glycolytic pathway have been shown to be 
controlled via reversible phosphorylation in a variety of anoxia tolerant organisms such as marine mollusks and freshwater turtles, as well as in other stress conditions calling for metabolic suppression such as hibernation or estivation (Storey and Storey, 1990; Storey and Storey, 2007; Brooks and Storey, 1997). The research in the present thesis represents the first time that reversible phosphorylation has been shown to regulate key enzymes of intermediary energy metabolism in response to anoxia in a freshwater crayfish including enzymes of carbohydrate, amino acid and phosphagen pathways.

\section{Glutamate dehydrogenase regulation during anoxia}

GDH is a key enzyme involved in bridging carbohydrate and amino acid metabolism, and is vital to regulating the flow of nitrogen within an organism. GDH plays a pivotal role in both ammonia incorporation, and ammonia secretion by acting as both a nitrogen donor and acceptor. Many species also use amino acids as a sources of fuel for aerobic metabolism. Amino acids such as glutamine, proline are catabolized via glutamate during high speed aerobic muscle work. This is often the case with aquatic species as they can easily excrete ammonia into the surrounding water, and fat stores can cause problems with buoyancy. Salmon, for example, burn muscle protein as they move upriver, as do squids during mating frenzies (Mommsen, 2004). When proline or glutamate is used as a fuel source, it either becomes transaminated or is channeled through GDH. Some animals do catabolize glutamate and glutamine under hypoxia or anoxia to make alanine when pyruvate builds up, and the carbon skeleton is channeled into succinate/propionate synthesis which can be metabolized to make ATP in the absence of oxygen. From the data obtained in this present study, GDH showed a global 
suppression under anoxic conditions; enzyme activities in both directions were reduced. This suggests that amino acid metabolism is left largely separate from carbohydrate metabolism by reducing the activity of this enzymatic bridge. Therefore, during anoxia, the freshwater crayfish, O.virilis, seems to restrict the flow of nitrogen and carbon skeletons from amino acid catabolism by phosphorylating GDH, a major bridge point of carbohydrate metabolism and amino acid metabolism.

\section{Arginine kinase regulation during anoxia}

AK is the enzyme responsible for the reversible phosphorylation of L-arginine to phosphoarginine. Invertebrate muscles generally have large reservoirs of phosphoarginine which are draw upon to quickly regenerate ATP during burst muscle work. Arginine phosphate (or creatine phosphate in vertebrates) is the first instantaneous source of ATP when contraction starts and bridges the initial few seconds until ATP production by glycolysis is fired up (Storey and Storey, 2004). During hypoxic events, the crayfish could also draw upon this reservoir to create an influx of ATP to help keep muscle metabolism and cellular processes running under low oxygen conditions.

However, during long term bouts of hypoxia or anoxia, these reservoirs of phosphoarginine would surely become depleted. With a reduction in metabolic needs coupled with a reduction in muscle movement, both of which are anoxia survival strategies used by many anoxia-tolerant species (Storey and Storey, 2004), the levels of phosphoarginine stored in the muscle tissues can be drawn upon to greatly increase the

length of time that the organism can survive low oxygen exposure. AK was demonstrated to be inhibited in the phosphoarginine producing direction during anoxia, suggesting that 
this enzyme favors the regeneration of ATP from phosphoarginine when oxygen is low rather than the synthesis of phosphagen reserves.

\section{Hexokinase regulation during anoxia}

Glucose is rapidly phosphorylated by HK to form G6P and this allows the sugar to be directed into many different pathways such as; glycolysis to produce ATP, the pentose phosphate pathway to form NADPH and various sugar phosphates, or glycogen as a fuel storage (Wilson, 2003). HK was shown to have an increased level of activity, protein levels, a decrease in binding affinity for glucose, increased stability and an increase in the percentage of bound enzyme during anoxia in the tail muscle of $O$. virilis. This suggests that HK has many different levels of control, probably all of which interact and create a very complex system. Phosphorylation of both GDH and AK led to decreased binding affinity for their respective substrates and/or allosteric activators and inhibitors, and both showed a propensity to become phosphorylated by PKA. However, the kinetic properties of HK did not show changes in either control to anoxic like kinetic parameters, or visa versa, when serine/threonine phosphatases or total kinases (PKA,PKC,PKG, AMPK, CaMK) were stimulated, suggesting that either other kinases/phosphatases are involved in the apparent drop in binding affinity of HK for glucose during anoxia, or perhaps a completely different method of regulation. Therefore, HK during anoxia seems to be released from the mitochondrial membrane, stabilized, and protein expression increased all as part of the mechanism to increase sugar phosphorylation to feed anaerobic glycolysis, and support anaerobiosis. 


\section{Role of kinases and phosphatases during anoxia}

Reversible phosphorylation of proteins has been identified as a key control mechanism involved in the regulation of cellular metabolic pathways in many organisms. Many factors such as mitogens, hormones, nerve impulses and cytokines can signal a change in the phosphorylation state of a protein. A wide variety of pathways and cell functions including catabolism, anabolism, gene transcription, protein synthesis, cell division, transmembrane transport, etc., are controlled by the actions of numerous protein kinases and phosphatases. These kinases and phosphatases, along with their substrates, are part of signal transduction pathways which are usually very tightly regulated. Much research has been done on the actions of these signaling pathways, and the proteins involved, across a wide variety of conditions such as; disease states, normal cell functions, and multiple stress states.

A rapid adaptation to low oxygen is vital to the survival of $O$. virilis during anoxia. During anoxia, $O$. virilis, requires a rapid coordinated suppression of many metabolic pathways. It has been discovered recently that one of the key regulatory mechanism that helps coordinate often drastic metabolic depression across many difference organisms and stresses is reversible protein phosphorylation (Storey and Storey, 1990). Several enzymes have been demonstrated to show changes in activity during anoxia in $O$. virilis, which seem to suggest changes in metabolic rates of key pathways (Cowan and Storey 1998a). Both serine/threonine phosphatases and cAMPdependant protein kinase activities change during anoxia (Cowan and Storey 1998c), and it was shown that the less phosphorylated form of these regulatory enzymes dominated during anoxia in crayfish (Cowan and Storey 1998b). 
A general trend in the activities of protein kinases and phosphatases seems to arise during exposure to anoxia in $O$. virilis; protein kinases appear to act upon the entry or initial stages of anoxia exposure, whereas protein phosphatases act during the midst of anoxia exposure. In a study performed by Cowan and Storey (2001), there were changes discovered in the soluble and insoluble fraction of protein kinases and phosphatases demonstrating that total protein tyrosine kinase activity in tail muscle fell dramatically during anoxia, whereas total protein tyrosine phosphatase activity remained fairly stable (Cowan and Storey, 2001). In this thesis, both GDH and AK appeared to be more phosphorylated during anoxia, and each seemed to be phosphorylated by PKA, whereas HK seemed to be less phosphorylated (it remains unclear which kinases or phosphatases act upon HK). It may be that certain protein kinases act upon key enzymes, reducing their activity in preparation for anoxia, whereas certain protein phosphatases seem to act on other enzymes during anoxia to increase the activity of key enzymes, crucial for survival of prolonged anoxia exposure.

\section{Conclusion}

In conclusion, the study presented in this thesis demonstrates the importance of reversible phosphorylation as a control mechanism for regulating energy metabolism and mediating a general metabolic suppression during anoxia in the freshwater crayfish, $O$. virilis. Key enzymes involved in both carbohydrate metabolism and the maintenance of cellular energetics were shown to be regulated by reversible phosphorylation during anoxia in the tail muscle of $O$. virilis. Regulation of HK was consistent with an activation of the glycolytic pathway due to increased HK activity in support of muscle cell energetic 
needs during anoxia. The regulation of GDH by specific kinases and phosphatases seems to demonstrate a decrease in the need for the use of amino acids as a fuel source under anoxia, as well as an apparent separation of amino acid metabolism from carbohydrate metabolism. The data also indicate that a regeneration of adenylate ratios using phosphoarginine reserves during anoxia seems to be achieved via the regulation of AK by PKA, as well as regulation by phosphatases (as demonstrated by the use of calf intestine alkaline phosphatase). This not only illuminates reversible phosphorylation as a crucial method of regulation during anoxia, but provides us with valuable insights into the fine metabolic control of $O$. virilis muscle metabolism during anoxia. Furthermore, the metabolic changes observed here may be general principles of anoxia survival, applicable to other anoxia tolerant organisms.

\section{Future Directions}

The research herein establishes several key points of regulation of intermediary metabolism under anoxic conditions; however, many new directions for future research topics were discovered as a result. In Chapter 2, that data indicated that GDH seems to be globally suppressed during anoxia in muscle. However, GDH is a very complex enzyme, with multiple putative phosphor-sites (Bell, 2008). Therefore, it would be interesting to discover which kinases or phosphatases are involved in phosphorylating GDH under different conditions (burst muscle work, normoxic, hypoxia, anoxia, etc.). It would be interesting to elucidate the regulatory mechanisms behind the regulation of GDH from the hepatopancreas to provide a comparative study across two different tissues further insight into the complex control of this enzyme in the crayfish during anoxia. GDH from 
the hepatopancreas may respond differently to phosphorylation, and may be phosphorylated by different kinases.

In chapter 3, AK was shown to be less active in the direction favoring the phosphorylation of arginine to phosphoarginine, suggesting that this enzyme may favor the dephosphorylation of phosphoarginine to replenish ATP levels during anoxia exposure. Further exploration of AK kinetic parameters in the opposite direction would shed more light on this topic and give a much greater understanding of the directionality of the reaction catalyzed by this enzyme. A direct antagonist of the regeneration of ATP levels by AK are the ATPases which hydrolyze ATP to ADP and free Pi. By examining the relative activity of ATPases during anoxia, more can be understood of the ever important changes that occur in the ratio of adenylates. It might also be of interest to explore the levels of arginine and phosphoarginine across the entire anoxia response and recovery time. This would allow us to discover if the organism builds up reservoirs in anticipation of hypoxic or anoxic events, as well as how quickly the phosphoarginine levels are used during anoxia, and regenerated during recovery from anoxia. The specific kinases and phosphorylation sites could also be explored at multiple stresses, and time points to discover when they are phosphorylated, and which kinases are responsible. There are also other key enzymes central to adenylate metabolism such as adenylate kinase or AMP deaminase which could be explored under various stresses (AMP deaminase was shown to be differentially regulated by reversible phosphorylation in freezing frogs by Dieni, 2008).

The last data chapter shows that protein levels of HK are up-regulated during anoxia, and that reversible phosphorylation plays a role in structural stability and 
subcellular localization of the enzyme. By looking at the relative levels of membrane bound HK to free HK found in the cytoplasm at various time periods of anoxic exposure and recovery, much more could be elucidated about the propensity for reversible phosphorylation of HK to be the mechanism by which HK is bound or released from the membrane. Through the use of multiple time points, and comparing the relative phosphorylation of $\mathrm{HK}$ versus the relative amount of $\mathrm{HK}$ bound to the mitochondria, much could be ascertained about the role of phosphorylation and the subcellular localization of HK during anoxia. 


\section{REFERENCES}


Abnous K, Storey KB: Skeletal muscle hexokinase: regulation in mammalian hibernation. Mol Cell Biochem. 2008 319:41-50.

Arora KK, Pedersen PL: Functional significance of mitochondrial bound hexokinase in tumor cell metabolism. Evidence for preferential phosphorylation of glucose by intramitochondrially generated ATP. 1988 263:17422-17428.

Bailey JS, Bell ET, Bell JE: Regulation of bovine glutamate dehydrogenase. J Biol Chem 1982 257:5579-5583.

Bell, R: Regulation of glutamate dehydrogenase in hypometabolic states. M.Sc. Biology, Carleton University. 2008.

Bennett WS, Steitz TA: Glucose-induced conformational change in yeast hexokinase. Proc Natl. Acad Sci. 1978 75:4848-4852.

Blethen SL, Kaplan NO: Purification of arginine kinase from lobster and a study of some factors affecting its reactivation. Biochem. 1967 6:1413-1421.

Bouny JM, Saglio PH: Glycolytic flux and hexokinase activities in anoxic maize root tips acclimated by hypoxic pretreatment. Plant Physiol. 1996 111:187-194.Brenman JE, Temple BR: Alternative views of AMP-activated protein kinase. Cell Biochem Biophys. 2007 47:321-331.

Brewis JM, Bowler K: A study of the dynamics of population of the freshwater crayfish, Austropotamobius pallipes. 2006 13:443-452.

Brooks SPJ: A program for analyzing enzyme rate data obtained from a microplate reader. BioTechniques 1994 17:1155-1161.

Brooks SPJ, Storey KB: Glycolytic controls in estivation and anoxia: a comparison of metabolic arrest in land and marine molluscs. Comp Biochem Physiol A 1997, 118:1103-1114.

Celada JD, Carral JM, Gaudioso VR, Gonzalez J, Lopez-Baisson C, Fernandez R: Survival and growth of juvenile freshwater crayfish Pacifastacus leniusculus dana fed two raw diets and two commercial formulated feeds. J World Aquacul Soc. 2007 24:108-111.

Carlsson KH, Gade G: Metabolic adaption of the horseshoe crab, Limulus polyphemus, during aexercise and environmental hypoxia and subsequent recovery. Biol Bull 1986 171: 217235 .

Churchill T, Storey KB: Metabolic responses to freezing and anoxia by the periwinkle Littorina littorea. J Therm Biol. 1996 21:57-63.

Cowan KJ, Storey KB: Protein kinase and phosphatase response to anoxia in crayfish, Orconectes virilis: Purification and characterization of cAMP-dependent protein kinase. Comp Biochem Phys - B Biochem Molec Biol. 2001 130:565-577.

Cowan KJ, Storey KB: Effects of anoxia on enzyme metabolism in the anoxia-tolerant 
Orconectes virilis. Personal Communication. 1998a.

Cowan KJ, Storey KB: Covalent modification by reversible phosphorylation in the regulation of glycolytic enzymes in Orconectes virilis. Personal Communication. 1998b.

Cowan KJ, Storey KB: Purification and characterization of the cAMP-dependent protein kinase from the tail muscle of the crayfish, in Orconectes virilis. Personal Communication. $1998 c$.

Dang CV, Kim J, Gao P, Yustein J: The interplay between MYC and HIF in cancer. Nat Rev Canc. 2008 8:51-56.

Dieni, CA: Regulation of enzyme function in freeze tolerance. Ph.D. Chemistry, Carleton University. 2008.

Dieter H, Koberstein R, Sund H: Studies of glutamate dehydrogenase. The interaction of ADP, GTP, and NADPH in complexes with glutamate dehydrogenase. Eur J Biochem 1981 115:217-226.

Edwards AS, Faux MC, Scott JD, Newton AC: Carboxyl-terminal phosphorylation regulates the function and subcellular localization of protein kinase C. J Biol Chem. 1999 274:64616468.

Ellington WR: Phosphocreatine represents a thermodynamic and functional improvement over other muscle phosphagens. J Exp Biol. 1989 143:177-194.

Fan TWM, Higashi RM, Lane AN: Temperature dependence of arginine kinase reaction in the tail muscle of live Sycionia ingentis as measured in vivo by ${ }^{31} \mathrm{P}-\mathrm{NMR}$ driven saturation transfer. Mol Cell Res. 1992 1135:44-49.

Figler MH, Twum M, Finkelstein JE, Peeke HVS: Maternal aggression in red swamp crayfish (Procambarus clarkia, Girard): The relation between reproductive status and outcome of aggressive encounters with male and female conspecifics. Behaviour. 1995 132:107-125.

Fox TC, Green BJ, Kennedy RA, Rumpho ME: Changes in hexokinase activity in Echinochloa phyllopogon and Echinochloa crus-pavonis in response to abiotic stress. Plant Physiol. 1998 118:1403-1409.

Fraser KPP, Houlihan DF, Lutz PL, Leone-Kabler S, Manuel L, Brechin JG: Complete suppression of protein synthesis during anoxia with no post-anoxia protein synthesis debt in the red-eared slider turtle Trachemys scripta elegan. J Exp Biol 2001 204:4353-4360.

Frieden C: Glutamate dehydrogenase VI. Survey of purine nucleotides and other effects on the enzyme from various sources. J Biol Chem 1965 240:2028-2037.

Fujimori T, Abe H: Physiological roles of free D- and L-alanine in the crayfish Procambarus clarkii with special reference to osmotic and anoxic stress responses. Comp Biochem Physiol A 2002, 131:893-900. 
Gäde G: Effects of oxygen deprivation during anoxia and muscular work on the energy metabolism of the crayfish, Orconectes limosus. Comp Biochem Physiol A. 1984 77:495502.

Gajewski E, Steckler DK, Goldberg RN: Thermodynamics of the hydrolysis of adenosine 5'triphosphate to adenosine 5'-diphosphte. J Biol Chem. 1986 261:12733-12737.

González C, Ureta T, Sanchez R, Niemeyer H (1964) Multiple molecular forms of ATP: hexokinase 6-phosphotransferase from rat liver. Biochem Biophys Res Commun. 16:347352.

Guo Q, Zhao F, Guo Z, Wang X: Intermediates in the inactivation and unfolding of dimeric arginine kinase induced by GdnHCl. J Biochem. 2004 136:49-56.

Hemmings BA: Purification and properties of the phosphor and dephospho forms of yeast NADdependent glutamate dehydrogenase. J Biol Chem 1980 255:7925-7932.

Hsu YT, Wolter KG, Youle RJ: Cytosol-to-membrane redistribution of Bax and Bcl-XL during apoptosis. Proc Natl Acad Sci. 1997 94:3668-3672.

Iwatsubo M, Pantaloni D: Régulation de l'activité de la glutamate déshydrogènase par les effecteurs GTP et ADP: étude par "stopped flow". Bull Soc Chim Biol. 1967 49:15631572.

Jackson DC, Wang T, Koldkjaer P, Taylor EW: Lactate sequestration on the carapace of the crayfish Austropotambius pallipes during exposure in air. 2001 J. Exp. Biol. 204: 941946.

Johnson LK, Dillaman RM, Gay DM, Blum JE, Kinsey ST: Metabolic influences of fiber size in aerobic and anaerobic locomotor muscles of the blue crab, Callinectes sapidus. J Exp Biol. 2004 207:4045-4056.

Katzen HM, Schimke RT: Multiple forms of hexokinase in the rat: tissue distribution, age dependency, and properties. Proc Natl Acad Sci. 1965 54:1218-1225.

Koberstein R, Sund H: Studies of glutamate dehydrogenase. The influence of ADP, GTP, and Lglutamate on the binding of the reduced coenzyme to beef-liver glutamate dehydrogenase. Eur J Biochem 1973 36:545-552.

Lin HP, Reeves HC: In vivo phosphorylation of $\mathrm{NADP}^{+}$glutamate dehydrogenase in Escherichia coli. Curr. Microbiol. 1994 28:63.

MacDonald JA, Storey KB: Regulation of ground squirrel $\mathrm{Na}^{+} \mathrm{K}^{+}$-ATPase activity by reversible phosphorylation during hibernation. Biochem Biophys Res Commun. 1999 254:424-429.

Markau K, Schneider J, Sund H: Kinetic studies on the mechanism of the action of ADP on the glutamate dehydrogenase reaction. FEBS Lett. 1972 24:32-36.

Miflin BJ, Habash DZ: The role of glutamine synthetase and glutamate dehydrogenase in 
nitrogen assimilation and possibilities for improvement in the nitrogen utilization of crops. J Exp Bot 2002 53:979-987.

Mommsen, TP: Salmon spawning migration and muscle protein metabolism: the August Krogh principle at work. 2004 139:383-400.

Muhlebach SM, Gross M, Wirz T, Walliman T, Perriard JC, Wyss M: Sequence homology and structure predictions of the creatine kinase isoenzymes. Mol Cell Biochem. 1994 133/134:245-262.

Natsuizaka M, Ozasa M, Darmanin S, Miyamoto M, Kondo S, Kamada S, Shindoh M, Higashino F, Suhura W, Koide H, Aita K, Nakagawa K, Kondo T, Asaka M, Okada F, Kobayashi M: Synergistic up-regulation of Hexokinase-2, glucose transporters and angiogenic factors in pancreatic cancer cells by glucose deprivation and hypoxia. Exp Cell Res. 2007 313:3337-3348.

Newsholme EA, Beis I, Leech AR, Zammit VA: The role of creatine kinase and arginine kinase. Biochem J. 1978 172:533-537.

Newton AC: Regulation of the ABC kinases by phosphorylation: protein kinase $\mathrm{C}$ as a paradigm. Biochem J. 2003 370:361-371.

Nilsson GE: Long-term anoxia in crucian carp: changes in the levels of amino acid and monoamine neurotransmitters in the brain, catecholamines in chromaffin tissue and liver glycogen. J Exp Biol 150:295-320.

Park C, Marqusee S: Pulse proteolysis: a simple method for quantitative determination of protein stability and ligand binding. Nature Methods 2005 2:207-212.

Pradet A, Raymond P: Adenine nucleotide ratios and adenylate energy charge in metabolism. Ann Rev Plant Physiol. 1983 34:199-224.

Regen DI, Davis WW, Iorgan HE, and Park CR: The regulation of hexokinase and phosphofructokinase activity in heart muscle: Effects of alloxan diabetes, growth hormone, cortisol, and anoxia. J Biol Chem. 1964 239:43.

Röckl KS, Witczak CA, Goodyear LJ: Signaling mechanisms in skeletal muscle: acute responses and chronic adaptations to exercise. IUBMB Life 2008 60:145-153.

Ryushi K, Haruhiko S, Toshihisa O: Gene cloning and characterization of the very large NADdependant L-glutamate dehydrogenase from the psychrophile Janthinobacterium lividum, isolated from cold soil. J Bacteriol 2007, 189:5626-5633.

Saitoh T, Schwartz JH: Phosphorylation-dependent subcellular translocation of a $\mathrm{Ca} 2+/$ calmodulin-dependent protein kinase produces an autonomous enzyme in Aplysia neurons. J Cell Biol. 1985 100:835-842.

Skijoldal HR, and Bakke T: Anaerobic metabolism of the scavenging isopod Cirolana borealis Lillijeborg. Adenine nucleotides. Physiology and Behaviour of Marine Organisms, 
Pergamon Press, Oxford. 1978 67-74.

Smith TJ, Stanley CA: Untangling the glutamate dehydrogenase allosteric nightmare. Trends Biochem Sci. 2008 33:557-564.

Storey KB, Storey JM: Facultative metabolic rate depression: molecular regulation and biochemical adaptation in anaerobiosis, hibernation, and estivation. Quart Rev Biol 1990, 65:145-174.

Storey KB: Metabolic adaptations supporting anoxia tolerance in reptiles: recent advances. Comp Biochem Physiol B. 1996 113:23-35.

Storey KB: Life in the slow lane: molecular mechanisms of estivation. Comp Biochem Physiol A. 2002 133:733-754.

Storey KB, Storey JM: Oxygen limitation and metabolic rate depression. Functional Metabolism - Regulation and Adaptation. Wiley-Liss, Inc., Hoboken, New Jersey. 2004 415-442.

Storey KB, Storey JM: Putting life on 'pause' - molecular regulation of hypometabolism. J Exp Biol 2007, 210:1700-1714.

Suzuki T, Kawasaki Y, Furukohri T: Evolution of phosphagen kinase. Isolation, characterization and cDNA-derived amino acid sequence of two-domain arginine kinase from the sea anemone Anthopleura japonicus. Biochem J. 1997 328, 301-306.

Suzuki T, Yamamoto Y, Umekawa M: Stichopus japonicus arginine kinase: gene structure and unique substrate recognition system. Biochem J. 2000 351:579-585.

Watts DC: Evolution of phosphagen kinases. Biochemical Evolution and the Origin of Life Schoffeniels, E., ed. 1971 150-173.

Watts DC: Evolution of phosphagens along the chordate line. Symp Zool Soc Lond. 1975 36:105127.

Wheatly MG, Toop T: Physiological responses of the crayfish Pacifastacus leniusculus to environmental hyperoxia II. Role of the antennal gland in acid-base and ion regulation. $J$ Exp Biol 1989 143:53-70.

Wilson JE: Isozymes of mammalian hexokinase: structure, subcellular localization and metabolic function. J Exp Biol. 2003 206:2049-2057.

Yasuda S, Arii S, Mori A, Isobe N, Yang W, Oe H, Fujimoto A, Yonenaga Y, Sakashita H, Imamura M: Hexokinase II and VEGF expression in liver tumors: correlation with hypoxia-inducible factor- $1 \alpha$ and its significance. J Hepatol. 2003 40:117-123.

Zhou G, Somasundaram T, Blanc E, Parthasarathy G, Ellington WR, Chapman M: Transition state structure of arginine kinase: implications for catalysis of bimolecular reactions. Proc Natl Acad Sci. 1998 95:8449-8454. 
Wu XQ, Zhu WJ, Lu ZR, Xia Y, Yang JM, Zou F, Wang XY: The effect of rutin on arginine kinase: Inhibition kinetics and thermodynamics merging with docking simulation. Int $J$ Biol Marcromolec. 2009 44:149-155. 